\title{
Radionuclide Partitioning in an Underground Nuclear Test Cavity
}

\section{T.P. Rose, Q. Hu, P. Zhao,}

C.L. Conrado, R. Dickerson, G.F. Eaton, A.B. Kersting, J.E. Moran, G. Nimz, B.A. Powell, E.C. Ramon, F.J. Ryerson, R.W. Williams, P.T. Wooddy, and M. Zavarin

February 18, 2011 
LLNL-TR-409817

\title{
Radionuclide Partitioning in an Underground Nuclear Test Cavity
}

\author{
T.P. Rose ${ }^{1}$, Q. $H u^{1}$, P. Zhao ${ }^{1}$ \\ C.L. Conrado ${ }^{1}$, R. Dickerson ${ }^{2}$, G.F. Eaton ${ }^{1}$, A.B. Kersting ${ }^{1}$, \\ J.E. Moran ${ }^{1}$, G. Nimz' ${ }^{1}$, B.A. Powell', E.C. Ramon ${ }^{1}$, F.J. Ryerson ${ }^{1}$, \\ R.W. Williams ${ }^{1}$, P.T. Wooddy ${ }^{1}$, and M. Zavarin ${ }^{1}$ \\ ${ }^{1}$ Lawrence Livermore National Laboratory, Livermore, CA \\ ${ }^{2}$ Stoller-Navarro Joint Venture, Las Vegas, NV
}

February 18, 2011

Prepared for the U.S. Department of Energy, National Nuclear Security Administration Nevada Site Office 


\section{DISCLAIMER}

This document was prepared as an account of work sponsored by an agency of the United States government. Neither the United States government nor Lawrence Livermore National Security, LLC, nor any of their employees makes any warranty, expressed or implied, or assumes any legal liability or responsibility for the accuracy, completeness, or usefulness of any information, apparatus, product, or process disclosed, or represents that its use would not infringe privately owned rights. Reference herein to any specific commercial product, process, or service by trade name, trademark, manufacturer, or otherwise does not necessarily constitute or imply its endorsement, recommendation, or favoring by the United States government or Lawrence Livermore National Security, LLC. The views and opinions of authors expressed herein do not necessarily state or reflect those of the United States government or Lawrence Livermore National Security, LLC, and shall not be used for advertising or product endorsement purposes.

Funding for this project was provided by the Underground Test Area Project of the U.S. Department of Energy, National Nuclear Security Administration, Nevada Site Office. This work performed under the auspices of the U.S. Department of Energy by Lawrence Livermore National Laboratory under Contract DE-AC52-07NA27344.

This report is available for a processing fee to the U.S. Department of Energy and its contractors, in paper, from:

U.S. Department of Energy

Office of Scientific and Technical Information

P.O. Box 62, Oak Ridge, TN 37831-0062

Phone: 8655768401

Fax: 8655765728

Email: reports@adonis.osti.gov

http://www.doe.gov.bridge

Available for sale to the public from:

U.S. Department of Commerce

National Technical Information Service

5285 Port Royal Road

Springfield, VA 22161

Phone: 8005536847

Fax: 7036056900

Email: orders@ntis.fedworld.gov

http://www.ntis.gov/ordering.htm

OR

Lawrence Livermore National Laboratory

Technical Information Department, Digital Library

http://www.Ilnl.gov/tid/library.html 


\section{TABLE OF CONTENTS}

Executive Summary...............................................1

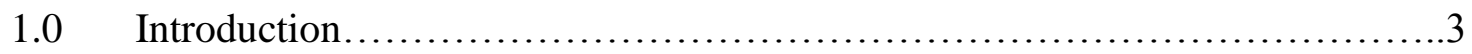

2.0 Geochemical and Radiochemical Characterization of U-19ad PS1A

Groundwater Samples........................................... 14

3.0 Physical and Chemical Characterization of Test Debris Samples..............20

4.0 Gamma Spectroscopy Analysis of Test Debris Samples.......................29

5.0 Uranium and Plutonium Analysis of Test Debris Samples....................41

6.0 Distribution of Long-Lived Soluble Fission Products.......................47

$7.0 \quad$ Conclusions.....................................................61

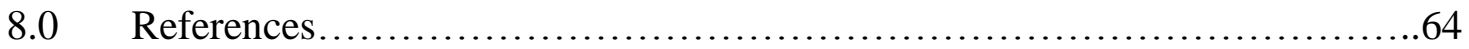

Appendix A. Lithologic Descriptions of U-19ad PS1A Sidewall Core................72

Appendix B. Analytical Methods for Uranium and Plutonium..................... 77

Appendix C. Analytical Methods for Technetium and Iodine.........................80 


\section{Executive Summary}

In 2004, a borehole was drilled into the 1983 Chancellor underground nuclear test cavity to investigate the distribution of radionuclides within the cavity. Sidewall core samples were collected from a range of depths within the re-entry hole and two sidetrack holes. Upon completion of drilling, casing was installed and a submersible pump was used to collect groundwater samples. Test debris and groundwater samples were analyzed for a variety of radionuclides including the fission products ${ }^{99} \mathrm{Tc},{ }^{125} \mathrm{Sb},{ }^{129} \mathrm{I},{ }^{137} \mathrm{Cs}$, and ${ }^{155} \mathrm{Eu}$, the activation products ${ }^{60} \mathrm{Co},{ }^{152} \mathrm{Eu}$, and ${ }^{154} \mathrm{Eu}$, and the actinides $\mathrm{U}, \mathrm{Pu}$, and Am. In addition, the physical and bulk chemical properties of the test debris were characterized using Scanning Electron Microscopy (SEM) and Electron Microprobe measurements.

Analytical results were used to evaluate the partitioning of radionuclides between the melt glass, rubble, and groundwater phases in the Chancellor test cavity. Three comparative approaches were used to calculate partitioning values, though each method could not be applied to every nuclide. These approaches are based on: (1) the average Area 19 inventory from Bowen et al. (2001); (2) melt glass, rubble, and groundwater mass estimates from Zhao et al. (2008); and (3) fission product mass yield data from England and Rider (1994). The U and Pu analyses of the test debris are classified and partitioning estimates for these elements were calculated directly from the classified Miller et al. (2002) inventory for the Chancellor test.

The partitioning results from this study were compared to partitioning data that were previously published by the IAEA (1998). Predictions of radionuclide distributions from the two studies are in agreement for a majority of the nuclides under consideration. Substantial differences were noted in the partitioning values for ${ }^{99} \mathrm{Tc},{ }^{125} \mathrm{Sb},{ }^{129} \mathrm{I}$, and uranium. These differences are attributable to two factors: chemical volatility effects that occur during the initial plasma condensation, and groundwater remobilization that occurs over a much longer time frame.

Fission product partitioning is very sensitive to the early cooling history of the test cavity because the decay of short-lived $\left(\mathrm{t}_{1 / 2}<1\right.$ hour) fission-chain precursors occurs on the same time scale as melt glass condensation. Fission product chains that include both volatile and refractory elements, like the mass 99, 125, and 129 chains, can show large variations in partitioning behavior depending on the cooling history of the cavity. Uranium exhibits similar behavior, though the chemical processes are poorly understood.

The water temperature within the Chancellor cavity remains elevated $\left(75^{\circ} \mathrm{C}\right)$ more than two decades after the test. Under hydrothermal conditions, high solubility chemical species such as ${ }^{125} \mathrm{Sb}$ and ${ }^{129} \mathrm{I}$ are readily dissolved and transported in solution. SEM analyses of melt glass samples show clear evidence of glass dissolution and secondary hydrothermal mineral deposition. Remobilization of ${ }^{99} \mathrm{Tc}$ is also expected during hydrothermal activity, but moderately reducing conditions within the Chancellor cavity appear to limit the transport of ${ }^{99} \mathrm{Tc}$. It is recommended that the results from this study 
should be used together with the IAEA data to update the range in partitioning values for contaminant transport models at the Nevada National Security Site (formerly known as the Nevada Test Site). 


\subsection{Introduction}

Timothy P. Rose, Qinhong Hu, Pihong Zhao, Mavrik Zavarin, and Annie B. Kersting

Chemical Sciences Division, Lawrence Livermore National Laboratory

This report describes a field and laboratory investigation of the radionuclide distribution in an underground nuclear test cavity at the Nevada National Security Site (NNSS) (formerly known as the Nevada Test Site). This study was motivated by the need to develop predictive models to describe the release and transport behavior of radionuclides in groundwater. Funding for this work was provided by the National Nuclear Security Administration, Nevada Site Office (NNSA/NSO) through the Environmental Restoration Division's Underground Test Area (UGTA) Project. The UGTA project is tasked with developing an integrated set of groundwater flow and contaminant transport models that will forecast the extent of radionuclide migration at the NNSS over a 1,000 year timeframe. The results of the present study are intended to extend the knowledge base that is needed to build these models.

Underground nuclear detonations produce a diverse suite of radionuclides that includes tritium, fission products, activation products, and residual actinide fuel (Bowen et al., 2001). The initial distribution of these species within the test cavity and chimney is determined by the temperature and pressure history immediately following the explosion, and by the chemical properties of the radionuclides themselves (Borg et al., 1976; Moody, 2003). Radionuclides that condense at high temperatures ('refractory' elements) tend to be partitioned into the 'melt glass' that is formed by vaporization and melting of the rock surrounding the nuclear device. In contrast, nuclides that condense at lower temperatures ('volatile' elements) are more widely dispersed on rock surfaces throughout the entire volume of material disturbed by the detonation (the 'rubble' and surrounding geologic media). A few nuclides, including tritium, never condense as solid phases and occur only as gaseous or aqueous species.

The initial partitioning of radionuclides between the melt glass and rubble plays an important role in determining the subsequent transfer of radioactivity to circulating groundwater. Radionuclides that are deposited on free surfaces are more susceptible to dissolution in groundwater through ion exchange, desorption, and surface-layer alteration processes. Refractory species that are largely partitioned into the melt glass are less accessible to groundwater, and their release is dependent on the rate of melt glass dissolution. Glass dissolution rates tend to be very slow due to the low permeability of the melt glass zone and the slow rate of water-glass reaction under silica-saturated conditions (Pawloski et al., 2001; Zavarin et al., 2004a).

In the 1990s, the International Atomic Energy Agency (IAEA) evaluated the partitioning of radionuclides between glass, rubble, water, and gas phases based on experience gained from the French underground test program (IAEA, 1998). Distribution data for some of the nuclides considered during the IAEA study are listed in Table 1.1. For the highly refractory elements $\mathrm{Eu}$ and $\mathrm{Pu}, 95 \%$ and $98 \%$ of the source term is inferred to be present 
in the melt glass, respectively. In comparison, only $90 \%$ of the uranium occurs in the melt glass due to its slightly higher volatility. A smaller fraction of the source term is contained in the melt glass for the fission products ${ }^{90} \mathrm{Sr},{ }^{99} \mathrm{Tc},{ }^{129} \mathrm{I}$, and ${ }^{137} \mathrm{Cs}$, in accordance with the higher volatilities of these species and/or their short-lived precursors. Two values are reported for ${ }^{137} \mathrm{Cs}$ in Table 1.1, reflecting differences in the partitioning behavior of this nuclide at the two French underground test locations (Mururoa and Fangataufa atolls).

Table 1.1 Distribution of selected radionuclides associated with French underground nuclear tests (IAEA, 1998).

\begin{tabular}{|l|cccc|}
\hline \multirow{2}{*}{ Radionuclide } & \multicolumn{4}{|c|}{ Distribution (\%) } \\
\hline${ }^{3} \mathrm{H}$ (tritium) & Glass & Rubble & Gas & Water \\
${ }^{90} \mathrm{Sr}$ & 0 & 0 & 2 & 98 \\
${ }^{99} \mathrm{Tc}$ & 40 & 60 & 0 & 0 \\
${ }^{129} \mathrm{I}$ & 80 & 20 & 0 & 0 \\
${ }^{137} \mathrm{Cs}$ & 50 & 40 & 0 & 10 \\
${ }^{152} \mathrm{Eu},{ }^{154} \mathrm{Eu},{ }^{155} \mathrm{Eu}$ & $25 / 40$ & $75 / 60$ & 0 & 0 \\
${ }^{234} \mathrm{U},{ }^{235} \mathrm{U},{ }^{236} \mathrm{U},{ }^{238} \mathrm{U}$ & 95 & 5 & 0 & 0 \\
${ }^{239} \mathrm{Pu},{ }^{240} \mathrm{Pu},{ }^{241} \mathrm{Pu},{ }^{241} \mathrm{Am}$ & 90 & 10 & 0 & 0 \\
\hline
\end{tabular}

While all underground nuclear detonations show similar phenomenology (Section 1.4), it is the early cooling history - especially the first few minutes after detonation - that is most critical to radionuclide partitioning. The lag time between the detonation and the collapse of the overlying geologic material (chimney formation) helps determine how quickly the cavity is 'quenched' by the influx of colder materials. Fission product partitioning is especially sensitive to this timing, because the decay of short-lived $\left(t_{1 / 2}<1\right.$ hour) fission products often occurs on the same time scale as melt glass condensation. For example, consider the mass-90 fission product chain:

$$
{ }^{90} \mathrm{Br} \rightarrow{ }^{1.9} \mathrm{~s} \mathrm{Kr} \rightarrow{ }^{32} \mathrm{Rb} \longrightarrow{ }^{90} \mathrm{Sr} \rightarrow{ }^{90} \mathrm{Y} \stackrel{2.7 \mathrm{~d}}{\rightarrow}{ }^{90} \mathrm{Zr} \text { (stable). }
$$

Although ${ }^{90} \mathrm{Sr}$ is the longest-lived radioactive species in this chain, less than one percent of the chain is 'born' as ${ }^{90} \mathrm{Sr}$ (England and Rider, 1994). Most of the chain is created as shorter-lived precursors $\left({ }^{90} \mathrm{Br},{ }^{90} \mathrm{Kr}\right.$ and $\left.{ }^{90} \mathrm{Rb}\right)$, all of which are volatile chemical elements that tend to be excluded from the melt glass. Conversely, strontium behaves as a refractory element, and tends to be incorporated in the melt glass. The timing of melt glass quenching is therefore quite important to determining how much ${ }^{90} \mathrm{Sr}$ is present in the glass. The IAEA estimated that $40 \%$ of the ${ }^{90} \mathrm{Sr}$ would be present in the melt glass and $60 \%$ would occur in the rubble (Table 1.1). This implies that, on average, only $40 \%$ of the mass-90 chain has decayed to ${ }^{90} \mathrm{Sr}$ at the time of melt glass solidification. 
However, depending on the cooling rate of a particular test, this value could vary by a factor of 2 or more.

The partitioning data developed by the IAEA (1998) were adopted by the UGTA project for use in contaminant transport models at the NNSS. In large part, this decision was a matter of necessity. There are no other comprehensive data sets of this type in existence. However, the lack of assigned uncertainties on the partitioning values is a significant shortcoming in the IAEA study. For this reason, it is important to obtain additional experimental data that can be used to independently evaluate the IAEA data, and when possible, assign ranges of values to the partitioning estimates.

There have been relatively few opportunities to acquire radionuclide partitioning data at the NNSS, and correlated data for both nuclear test debris and groundwater samples have not been previously obtained, though some attempts were made. During the early- to mid-1990s, boreholes were drilled into the Baseball (U-7ba) and Ingot (U-2gg) underground test cavities for this purpose. These drilling operations recovered core samples that provided information on the radionuclide distribution in the test debris (Thompson, 1996; Smith et al., 1996; Smith, 1998) but efforts to acquire pumped groundwater samples were unsuccessful (Smith, 2002). Sidewall core and groundwater samples were later collected from satellite wells drilled near the Tybo (U-20y) and Bullion (U-20bd) tests on Pahute Mesa. Data from these wells provided important insight into radionuclide transport (Kersting et al., 1999; Wolfsberg et al., 2002) and prompt injection processes (Rose et al., 2000), but the lack of samples from inside the test cavities precluded an analysis of radionuclide partitioning behavior.

The present investigation grew out of a Lawrence Livermore National Laboratory Defense Program (LLNL-DP) test readiness exercise. LLNL-DP and Bechtel-Nevada carried out a cavity re-entry drilling operation at the Chancellor (U-19ad) underground test site on Pahute Mesa in August 2004. The UGTA project contributed funding for this project in exchange for the opportunity to acquire post-shot core samples and complete the borehole as a sampling well. All of the primary objectives of the drilling and well completion operations were met, and both core samples and pumped groundwater samples were obtained from the Chancellor post-shot hole (U-19ad PS1A). This marks the first time that the UGTA project has recovered a correlated suite of test debris and water samples from an underground test cavity.

The objective of this report is to describe the results of radiochemical analyses of Chancellor melt glass, rubble, and groundwater samples, and to use these data to evaluate the partitioning of radionuclides between these phases. The results are then compared to the IAEA (1998) partitioning data. Consistent values between the two studies tend to increase our confidence in the application of the IAEA data to the NNSS transport models. Significant discrepancies may suggest more variable partitioning behavior, and the need to assign larger uncertainties.

This report is divided into a series of chapters that describe the physical and chemical properties of the test debris samples, the radionuclide activities of the groundwater and 
test debris, and partitioning estimates for selected actinides (U, $\mathrm{Pu}, \mathrm{Am})$, fission products $\left({ }^{99} \mathrm{Tc},{ }^{125} \mathrm{Sb}{ }^{129} \mathrm{I},{ }^{137} \mathrm{Cs},{ }^{155} \mathrm{Eu}\right)$ and activation products $\left({ }^{60} \mathrm{Co},{ }^{152} \mathrm{Eu},{ }^{154} \mathrm{Eu}\right)$. Due to classification issues, the results of $\mathrm{U}$ and $\mathrm{Pu}$ analyses of test debris samples are not reported here, but can be made available to individuals who hold a U.S. Department of Energy " $Q$ " clearance on a need-to-know basis. The absence of these data from this report does not adversely impact our ability to draw conclusions regarding the partitioning behavior of $\mathrm{U}$ and $\mathrm{Pu}$ in the Chancellor test cavity.

\subsection{Description of Study Location}

The Chancellor test was detonated in the U-19ad emplacement hole on 1 September 1983 at a vertical depth of 2,047 ft $(624 \mathrm{~m})$ below the surface of Pahute Mesa. It had an announced yield of $143 \mathrm{kt}$ (DOE/NV, 2000). Pawloski et al. (2002) gives a brief geologic description of the Chancellor site, including a schematic cross-section showing the hydrostratigraphic units that are present in the subsurface. The test was conducted in the Tertiary rhyolite of Echo Peak, a devitrified lava of the Paintbrush Group that erupted from the Claim Canyon Caldera approximately 12.8 million years ago (Sawyer et al., 1994). At this location, the rhyolite of Echo Peak is assigned to the Paintbrush Lava Flow Aquifer, a largely unsaturated hydrostratigraphic unit that underlies the western part of NNSS Area 19 (Bechtel Nevada, 2002). The lower part of the Chancellor test cavity is inferred to extend to within a few meters of the underlying Calico Hills Vitric Tuff Aquifer (Pawloski et al., 2002).

At the U-19ad site, the regional water table lies at depth of $644 \mathrm{~m}$ below the surface, and is situated approximately $20 \mathrm{~m}$ below the working point of the test (see Figure 1.1). Groundwater flow in this area occurs principally along interconnected faults and fractures within the thick sequence of Tertiary volcanic rocks that underlie Pahute Mesa (Blankennagel and Weir, 1973; Laczniak et al., 1996). Multiple lines of evidence indicate that the groundwater beneath Pahute Mesa moves in a southwestward direction toward Oasis Valley, where approximately $2.7 \times 10^{4} \mathrm{~m}^{3} \mathrm{~d}^{-1}$ of groundwater discharge occurs via evapotranspiration and spring flow (Reiner et al., 2002; Rose et al., 2006). The Pahute Mesa underground testing area is located less than $40 \mathrm{~km}$ up gradient from this inhabited area.

\subsection{U-19ad PS1A Drilling and Well Completion}

A post-shot re-entry hole (U-19ad PS1A) and two sidetrack holes were drilled into the Chancellor test cavity during August 2004. The configuration of these boreholes is illustrated in Figure 1.1. The main hole was slant drilled to a depth of 2,478 ft $(755.3 \mathrm{~m})$ as measured along the 21.4 degree borehole angle. Both sidetrack holes were drilled to a measured depth of 2,609 ft (795.2 m). Upon completion of drilling, 5.5-inch casing was installed in the second sidetrack hole to a measured depth of 2,579 $\mathrm{ft}(786.1 \mathrm{~m})$, with a slotted production interval between 2,407 and 2,579 ft. A submersible pump was installed and the well produced $2.04 \times 10^{5}$ gallons of water prior to the collection of groundwater samples on 27 September 2004. 


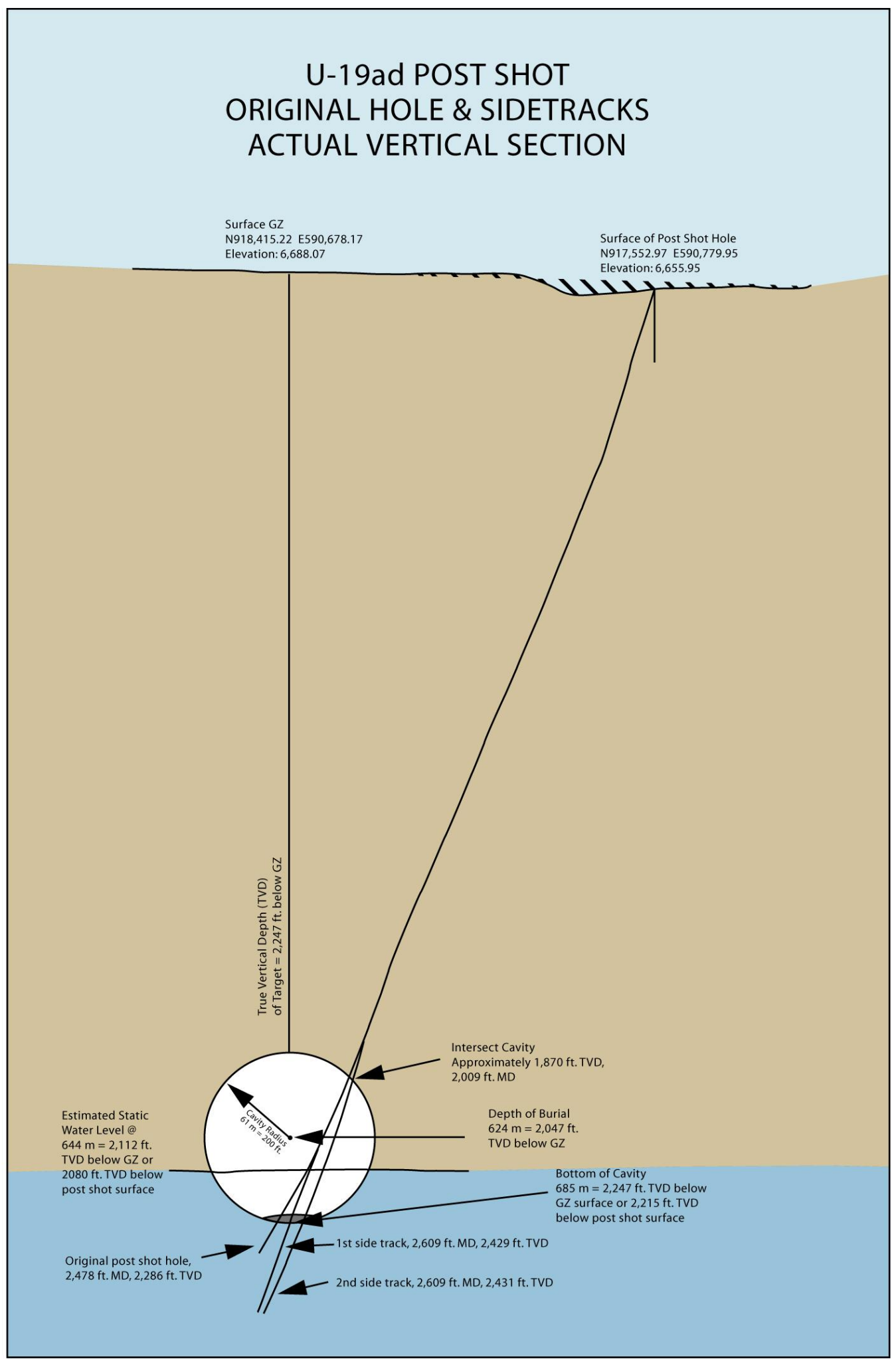

Figure 1.1 Schematic cross section of the Chancellor (U-19ad) test cavity and post-shot boreholes (courtesy of Bechtel Nevada). 


\subsection{Sidewall Core Recovery and Sample Selection}

During drilling operations, sidewall core samples were collected from the main U-19ad PS1A borehole and both sidetrack holes using a Hunt sidewall tool. Attempts to retrieve samples from the lowermost 10 to $15 \mathrm{~m}$ of the cavity were largely unsuccessful in all three boreholes. Nevertheless, around 70 sidewall core samples were recovered from approximately the bottom half of the test cavity. A majority of these samples were collected below the static water level, which lies at a vertical depth of 2,112 ft (643.7 m) below the surface.

Core samples representing 17 discrete depth intervals within the three boreholes were selected for evaluation. Borehole location data for these samples are compiled in Table 1.2, and a schematic diagram of the sample locations is shown in Figure 1.2. Two main selection criteria were used to choose the samples. First, the samples needed to represent the broadest possible geometric distribution of material within the underground test environment. This allows the direct comparison of radionuclide concentrations in the melt glass from the lower part of the cavity and the rubble from the upper part of the cavity. Coring activities were directed by the LLNL-DP staff, and much of the sampling effort was directed toward recovering melt glass samples from the lower part of the cavity. However, a number of samples were collected from 'higher' in the cavity specifically to meet the needs of the UGTA project. Two samples were also retrieved from below the cavity. The locations shown in Figure 1.2 represent the best sample distribution that could be achieved using the materials that were collected.

The other selection criterion was the amount of radioactivity in the sample. Gamma activities measured in the field at the time of sampling permitted the identification of samples with both low and high activity levels (see Table 1.2). The samples with the highest levels of activity generally consisted of dark-brown or black melt glass, whereas lower activity samples consisted of unmelted or partially melted rock. Full descriptions of the samples are found in Appendix A of this report. 


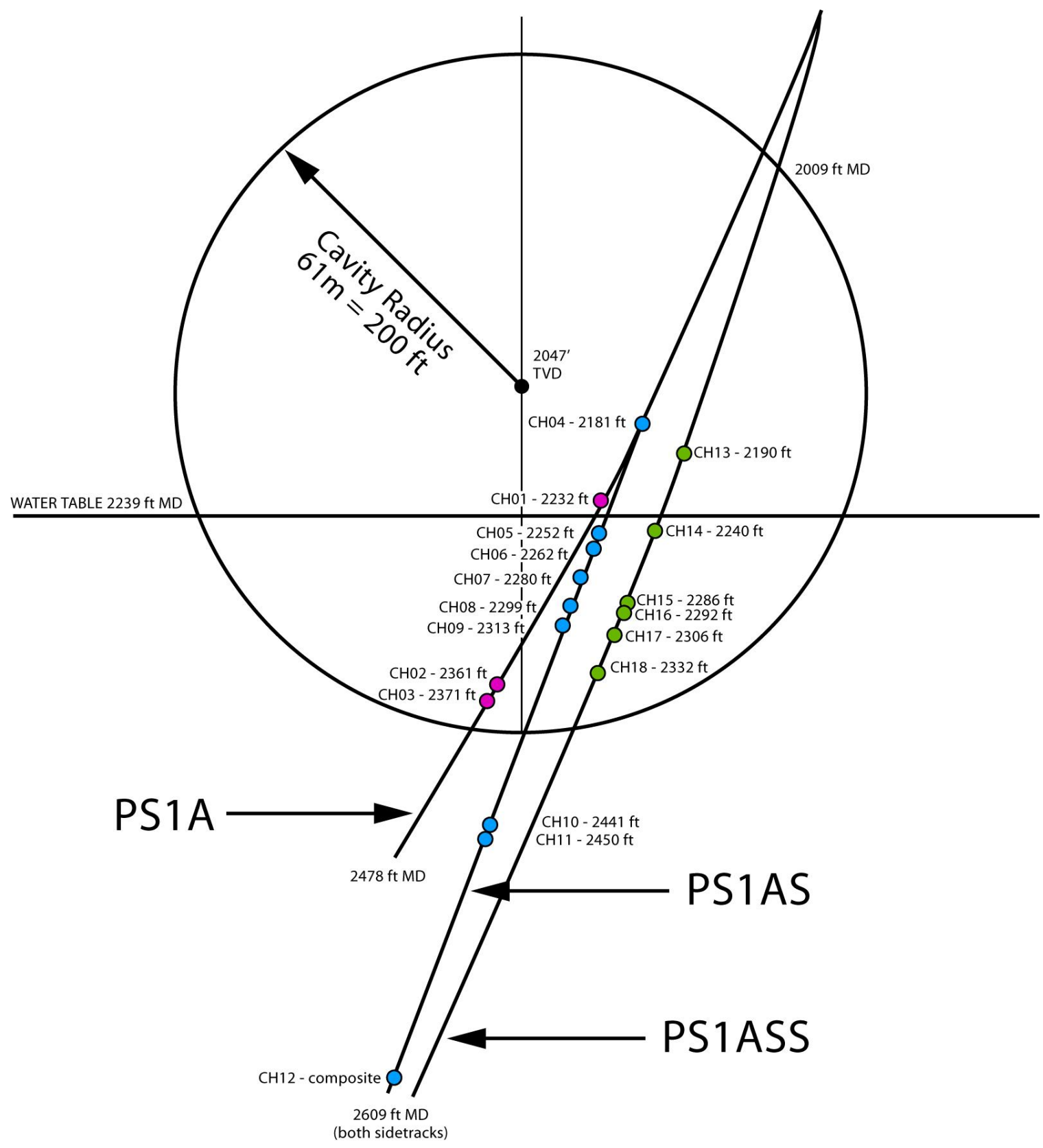

Figure 1.2. Cross section of the Chancellor cavity and post-shot boreholes showing the locations of sidewall core samples that were used in this investigation. Sample locations are color coded according to the borehole from which they were collected: main hole (PS1A): red; first sidetrack (PS1AS): blue; second sidetrack (PS1ASS): green. General sample information is compiled in Table 1.2. The $61 \mathrm{~m}$ cavity radius was estimated from the announced yield found in DOE/NV (2000), the reported depth of burial, and the bulk density of the overlying rock using the equation found in Pawloski (1999). MD = measured depth (along slant); TVD = total vertical depth. 
Table 1.2 Borehole data and field $\gamma$-activity measurements for Chancellor test debris samples

\begin{tabular}{|c|c|c|c|}
\hline Sample ID & Borehole & $\begin{array}{c}\text { Measured Depth } \\
\text { (ft bgs) }\end{array}$ & $\begin{array}{c}\text { Field } \boldsymbol{\gamma} \text {-Activity } \\
\text { (mR/hr on contact) }\end{array}$ \\
\hline CH01 & U-19ad PS1A & 2232 & low \\
CH02 & U-19ad PS1A & 2361 & 0.6 \\
CH03 & U-19ad PS1A & 2371 & 0.15 \\
CH04 & U-19ad PS1AS & 2181 & 0.03 \\
CH05 & U-19ad PS1AS & 2252 & 0.5 \\
CH06 & U-19ad PS1AS & 2262 & 1.1 \\
CH07 & U-19ad PS1AS & 2280 & 0.4 \\
CH08 & U-19ad PS1AS & 2299 & 0.1 \\
CH09 & U-19ad PS1AS & 2313 & 0.8 \\
CH10 & U-19ad PS1AS & 2441 & low \\
CH11 & U-19ad PS1AS & 2450 & low \\
CH12 & U-19ad PS1AS & composite & not reported \\
CH13 & U-19ad PS1ASS & 2190 & low \\
CH14 & U-19ad PS1ASS & 2240 & 0.3 \\
CH15 & U-19ad PS1ASS & 2286 & 0.9 \\
CH16 & U-19ad PS1ASS & 2292 & 1.2 \\
CH17 & U-19ad PS1ASS & 2306 & 0.3 \\
CH18 & U-19ad PS1ASS & 2332 & 0.02 \\
\hline
\end{tabular}

\subsection{Underground Nuclear Test Phenomenology}

The phenomenology of underground nuclear explosions is described in reports by Germain and Kahn (1968), Glasstone and Dolan (1977), the U.S. Congress, Office of Technology Assessment (1989), Smith (1995), and Pawloski (1999), and is briefly summarized here. At zero time, nuclear detonations produce temperatures as high as $10^{8}$ degrees Kelvin, and pressures in excess of $10^{10} \mathrm{~Pa}$. Within milliseconds, the emplacement canister and rock immediately surrounding the device are vaporized and a cavity is formed. The cavity expands spherically for a few tenths of a second until the internal pressure matches the ambient lithostatic overpressure. Concurrently, a compressional shock wave propagates outward from the cavity, fracturing the surrounding rock up to several cavity radii beyond the cavity wall. Once the shock wave has passed, material within 1-2 cavity radii rebounds to create a compressive residual stress field around the cavity.

Within a few seconds after the detonation, molten rock lining the interior of the cavity coalesces to form a puddle at the bottom of the cavity. Gradual condensation of volatilized material causes the pressure within the cavity to decrease until the cavity can no longer support the weight of the overlying rock. At this point, the cavity roof collapses to create a rubble chimney that may extend to the surface. Cavity collapse and chimney formation typically occurs within a few minutes to hours, but may not take place until days or months after the detonation. 
Early hydrodynamic calculations suggested that the shock wave vaporizes approximately 70 metric tons and melts 700 metric tons of rock for each kiloton of explosive yield (Olsen, 1967). These values are frequently quoted in the literature. Later investigations based on a more comprehensive data analysis have revised this estimate upward. For relatively high density, low-porosity rocks like those found at the Chancellor site, the amount of melt produced by the explosion is estimated to be approximately 1,000 metric tons per kiloton (Olsen, 1993). Based on this value, we estimate that $\sim 1.43 \times 10^{8} \mathrm{~kg}$ of melt glass was generated by the Chancellor explosion.

\subsection{Methods Used to Evaluate Radionuclide Partitioning}

Radionuclide partitioning values are simply an estimate of how much of the post-shot radionuclide inventory is contained in each phase (glass, rubble, and groundwater). Although this is a simple concept, partitioning values are difficult to measure because the test debris is heterogeneous in composition, and only a tiny fraction of the total debris field can be sampled during post-shot drilling. For the current study, three different approaches were adopted for calculating radionuclide partitioning values. The calculations are based on (1) the average Area 19 inventory from Bowen et al. (2001); (2) melt glass, rubble, and groundwater mass estimates from Zhao et al. (2008); and (3) fission product mass yield data from England and Rider (1994). Although each approach has limitations, it is hoped that the aggregate results from multiple independent methods will result in a clearer image of radionuclide partitioning behavior. The three methods are described below.

The total post-shot inventory for each underground test conducted at the NNSS is fairly well-known (Miller et al., 2002), but the data are classified because they may reveal sensitive information. To facilitate the development of radionuclide transport models for the UGTA project, an unclassified inventory was published that provides an estimate of the total radioactivity remaining underground in each of the five principal geographic test centers at the NNSS (Bowen et al., 2001). The Bowen inventory can be used to calculate radionuclide partitioning estimates if we assume the average inventory for each geographic testing center can be applied to individual tests. The Chancellor test is one of 36 tests conducted in NNSS Area 19 between 1966 and 1992 (DOE/NV, 2000). If the total inventory reported in Bowen for Area 19 is divided by 36, we obtain an unclassified estimate of the residual radionuclide inventory for the Chancellor test. This approach can be used for any of the 43 radionuclides listed in the Bowen inventory, including actinide fuels, fission products, and activation products. However, it implicitly assumes that all of the Area 19 tests had similar design and performance characteristics.

Since the total mass of the melt glass produced during a nuclear explosion can be reasonably estimated (see section 1.4), the fraction of the total inventory contained in the glass can be determined using the average measured concentration of a radionuclide in the glass. Dividing this value into the average Bowen inventory gives an estimate of the radionuclide partitioning in the glass. For many nuclides, the fraction of the total inventory dissolved in groundwater is very small, and the rubble fraction is 
approximately equal to the difference between the glass fraction and the total inventory. However, this approach cannot be used for radionuclides that are highly soluble in groundwater.

Unlike the melt glass, the total mass of the rubble and groundwater that is 'contaminated' with radionuclides is difficult to assess. Nonetheless, a careful material properties evaluation based on reasonable assumptions can result in acceptable mass estimates for the rubble and groundwater. Zhao et al. (2008) developed mass estimates for the glass, rubble, and groundwater in the Chancellor test cavity that gave plausible partitioning values for ${ }^{99} \mathrm{Tc}$ and ${ }^{129} \mathrm{I}$. These mass estimates will be adopted during this study as an independent means of calculating partitioning values for other nuclides discussed in this report.

For the fission products, there is a third possibility for calculating partitioning values using fission product yields found in the open literature (England and Rider, 1994). If the yield of a nuclear device is known (as is the case for the Chancellor test), the number of atoms of each fission product formed during the explosion can be directly calculated from the fission yield data. However, the precise number of atoms formed depends on the actinide fuel composition and the energy spectrum of the neutrons reacting with that material. Since the fuel and energy spectrum data are classified for individual tests, it is necessary to consider a range of possibilities. Although this can lead to relatively large uncertainties in the partitioning estimates, this approach nonetheless provides a useful comparison with the other two methods.

For simplicity, only two actinide fuels will be considered, ${ }^{235} \mathrm{U}$ and ${ }^{239} \mathrm{Pu}$, and the neutron spectrum data will be divided into three energy groups: thermal, fission spectrum, and high-energy neutrons. The mass-90 fission product chain $\left.{ }^{90} \mathrm{Sr}\right)$ again provides an instructive example (refer to Table 1.3). The middle column in Table 1.3 gives the mass90 fission yields for six actinide fuel + neutron energy combinations (England and Rider, 1994). The values range from $2.05 \%$ for fission spectrum neutrons on ${ }^{239} \mathrm{Pu}$ to $5.78 \%$ for thermal neutrons on ${ }^{235} \mathrm{U}$. The next column calculates the total number of ${ }^{90} \mathrm{Sr}$ atoms that would be produced from each fuel-energy combination for the $143 \mathrm{kt}$ Chancellor device, assuming $1.452 \times 10^{23}$ fissions/kt for $\mathrm{U}$ fuel and $1.405 \times 10^{23}$ fissions/kt for Pu fuel (e.g. Rego, 1979). The last column gives the percentage of ${ }^{90} \mathrm{Sr}$ contained in the melt glass assuming an average ${ }^{90} \mathrm{Sr}$ concentration of $1.50 \times 10^{12}$ at/g in the glass (a hypothetical value). Given that $\sim 1.43 \times 10^{11} \mathrm{~g}$ of melt glass were generated by the Chancellor explosion (section 1.4) the total number of ${ }^{90} \mathrm{Sr}$ atoms in the glass would be $2.15 \times 10^{23}$ atoms. This value is divided by the total number of atoms that were calculated for each fuel-energy combination to obtain the percentages found in the last column. 
Table 1.3 Mass-90 fission product yields for various fuels and neutron energies (England and Rider, 1994). The number of ${ }^{90} \mathrm{Sr}$ atoms produced by $143 \mathrm{kt}$ of fission yield is shown for each fuel + neutron energy combination together with a hypothetical ${ }^{90} \mathrm{Sr}$ mass fraction for the melt glass.

\begin{tabular}{|ll|ccc|}
\hline Fuel Type & Neutron Energy & $\begin{array}{c}\text { Mass-90 } \\
\text { Fission Yield } \\
(\%)\end{array}$ & $\begin{array}{c}\text { Total \# } \\
\text { Sr-90 } \\
\text { atoms }\end{array}$ & $\begin{array}{c}\text { Sr-90 atoms } \\
\text { in melt glass } \\
(\%)\end{array}$ \\
\hline U-235 & Thermal & 5.7824 & $1.201 \mathrm{E}+24$ & 17.9 \\
U-235 & Fission spectrum & 5.4650 & $1.135 \mathrm{E}+24$ & 18.9 \\
U-235 & High Energy & 4.5942 & $9.539 \mathrm{E}+23$ & 22.5 \\
& & & & \\
Pu-239 & Thermal & 2.1043 & $4.228 \mathrm{E}+23$ & 50.7 \\
Pu-239 & Fission spectrum & 2.0485 & $4.116 \mathrm{E}+23$ & 52.1 \\
Pu-239 & High Energy & 2.1028 & $4.225 \mathrm{E}+23$ & 50.8 \\
\hline
\end{tabular}

Despite the fairly small differences in the mass-90 fission yields for the six different fuel + neutron energy combinations, the melt glass partitioning estimates range from $18 \%$ to $52 \%$, with an average of $36 \%$. In comparison, $1 / 36^{\text {th }}$ of the ${ }^{90} \mathrm{Sr}$ inventory for Area 19 is 7.817E+23 atoms (Bowen et al., 2001), or 9.723E+23 atoms at zero time for the Chancellor test (01 Sept 1983). Using the same assumptions described in the preceding paragraph, the estimated melt glass fraction based on the Bowen inventory is $22 \%$. Several fission products will give a tighter range of values than ${ }^{90} \mathrm{Sr}$ using this approach, but most will give broader ranges. In general, the fission products that are best suited for this analysis are those which occur near one of the two peaks on the fission mass yield distribution curve (Friedlander et al., 1981). These two peaks are centered near masses 100 and 140. Thus, for the fission products under consideration during the present study, the fission chain yield method is expected to give the best results for ${ }^{99} \mathrm{Tc}$ and ${ }^{137} \mathrm{Cs}$.

The three methods described in this section are used to calculate partitioning values for the fission products ${ }^{99} \mathrm{Tc},{ }^{125} \mathrm{Sb},{ }^{129} \mathrm{I},{ }^{137} \mathrm{Cs}$, and ${ }^{155} \mathrm{Eu}$, the activation products ${ }^{60} \mathrm{Co},{ }^{152} \mathrm{Eu}$, and ${ }^{154} \mathrm{Eu}$, and the actinide ${ }^{241} \mathrm{Am}$ - though not every method can be applied to all of these nuclides. The results are discussed in Chapters 4 and 6 of this report. Since the concentrations and isotope ratios for uranium and plutonium in the core samples must remain classified, a different approach was used for these elements. The $\mathrm{U}$ and $\mathrm{Pu}$ partitioning ratios were calculated directly from the classified Miller et al. (2002) inventory for the Chancellor event, and only the final results are reported here. This has the advantage of providing a high degree of accuracy for the partitioning values. The results are discussed in Chapter 5. 


\title{
2.0 Geochemical and Radiochemical Characterization of U-19ad PS1A Groundwater Samples
}

\author{
Gail F. Eaton, Timothy P. Rose, Qinhong Hu, Pihong Zhao, Ross W. Williams, \\ Erick C. Ramon, Jean E. Moran, Brian A. Powell, and P. Todd Wooddy \\ Chemical Sciences Division, Lawrence Livermore National Laboratory
}

Groundwater samples were collected from the U-19ad PS1A well on 27 September 2004. The well was purged with a downhole submersible pump for approximately 6 days prior to sample collection, at an average pump rate of 22 gallons per minute. The cumulative purge volume prior to sampling was $2.04 \times 10^{5}$ gallons. Well construction data are summarized in Section 1.2 of this report. The static water level is at a vertical depth of $2,112 \mathrm{ft}(644 \mathrm{~m})$ below the surface, or $65 \mathrm{ft}(20 \mathrm{~m})$ below the working point of the Chancellor test. The calculated cavity radius of $200 \mathrm{ft}$ (61 m; Pawloski, 1999) implies that only the bottom third of the cavity is below the water table.

Analytical results for groundwater samples are reported in Tables 2.1 to 2.4. The water temperature measured at the U-19ad PS1A wellhead during sampling was $75^{\circ} \mathrm{C}$. This implies a significant amount of residual heat remains from the nuclear detonation, even though 21 years elapsed between time zero and the sampling event. The elevated temperatures appear to have modified the major ion chemistry of the water, resulting in high concentrations of dissolved $\mathrm{F}, \mathrm{Cl}, \mathrm{SO}_{4}$ and $\mathrm{Si}$ relative to environmental groundwater samples from this same area. These data are consistent with high temperature leaching of the surrounding rock. The stable isotope $\left(\delta \mathrm{D}\right.$ and $\left.\delta^{18} \mathrm{O}\right)$ composition of the water is similar to that of other regional groundwaters beneath Pahute Mesa. There is no evidence of an ${ }^{18} \mathrm{O}$-enrichment due to high temperature water-rock exchange processes, as previously noted for the Almendro test cavity (Rose et al., 2004).

The tritium activity in U-19ad PS1A groundwater was $2.18 \times 10^{7} \mathrm{pCi} / \mathrm{L}$ at the time of collection, or $7.15 \times 10^{7} \mathrm{pCi} / \mathrm{L}$ when corrected to zero time for the Chancellor test. A gamma spectroscopy analysis was performed on a 1-L water sample to determine the activities of $\gamma$-emitting radionuclides. Analytical results are reported in Table 2.1 for fission products $\left({ }^{125} \mathrm{Sb},{ }^{137} \mathrm{Cs}\right.$, and $\left.{ }^{155} \mathrm{Eu}\right)$ and activation products $\left({ }^{60} \mathrm{Co},{ }^{152} \mathrm{Eu}\right.$, and $\left.{ }^{154} \mathrm{Eu}\right)$, corrected to both the sample date and test date. 
Table 2.1 Gamma Spectroscopy results for U-19ad PS1A groundwater

\begin{tabular}{|c|c|c|c|}
\hline Radionuclide & $\begin{array}{c}\text { Half-life } \\
\text { (yrs) }\end{array}$ & $\begin{array}{c}\text { Activity on 9/27/04 } \\
\text { (pCi/L) }\end{array}$ & $\begin{array}{c}\text { Activity at } \mathbf{t}=\mathbf{0} \\
\text { (pCi/L) }\end{array}$ \\
\hline${ }^{60} \mathrm{Co}$ & 5.27 & $2.30 \times 10^{1}$ & $3.67 \times 10^{2}$ \\
${ }^{125} \mathrm{Sb}$ & 2.76 & $3.63 \times 10^{3}$ & $7.24 \times 10^{5}$ \\
${ }^{137} \mathrm{Cs}$ & 30.07 & $5.31 \times 10^{4}$ & $8.63 \times 10^{4}$ \\
${ }^{152} \mathrm{Eu}$ & 13.54 & $3.32 \times 10^{1}$ & $9.76 \times 10^{1}$ \\
${ }^{154} \mathrm{Eu}$ & 8.59 & $1.32 \times 10^{1}$ & $7.21 \times 10^{1}$ \\
${ }^{155} \mathrm{Eu}$ & 4.75 & $3.63 \times 10^{1}$ & $7.86 \times 10^{2}$ \\
\hline
\end{tabular}

The fission products ${ }^{125} \mathrm{Sb}$ and ${ }^{137} \mathrm{Cs}$ show notably high activities in U-19ad PS1A groundwater. To put this in perspective, ${ }^{137} \mathrm{Cs}$ was plotted against tritium activity for a number of NNSS near-field wells (Figure 2.1; data from Stoller-Navarro Joint Venture, 2004). The data for each test are corrected to their respective zero time. The ${ }^{137} \mathrm{Cs}$ activity in the Chancellor cavity fluid is among the highest observed at the NNSS; only the fluid bailed from the Baseball (U-7ba) cavity showed comparable ${ }^{137} \mathrm{Cs}$ levels (Thompson, 1995). This may be an indication that the residual radioactivity from the test is still largely contained within the cavity environment. High exchange rates with the surrounding groundwater flow field would be expected to lower the ${ }^{137} \mathrm{Cs}$ activity (via sorption effects) and decrease the fluid temperature within the test cavity.

The activation products ${ }^{14} \mathrm{C}$ and ${ }^{36} \mathrm{Cl}$ were analyzed by accelerator mass spectrometry (AMS). U-19ad PS1A groundwater has a ${ }^{14} \mathrm{C}$ value of $3.06 \times 10^{5}$ percent modern carbon (pmc), or approximately 3,000 times the natural atmospheric abundance. This is equivalent to a ${ }^{14} \mathrm{C}$ activity of $404 \mathrm{pCi} / \mathrm{L}$ (at the measured $\mathrm{HCO}_{3}$ concentration), and is near the upper limit of ${ }^{14} \mathrm{C}$ values observed in NNSS near-field waters. The ${ }^{36} \mathrm{Cl} / \mathrm{Cl}$ ratio in U-19ad PS1A groundwater is $6.39 \times 10^{-9}$, which is $\sim 10,000$ times the natural ratio. Although this ratio is fairly typical for near-field waters, the corresponding ${ }^{36} \mathrm{Cl}$ activity $(9.2 \mathrm{pCi} / \mathrm{L})$ is elevated due to the high chloride concentration in the water $(43.5 \mathrm{mg} / \mathrm{L})$.

The uranium concentration in U-19ad PS1A groundwater $(2.6 \mu \mathrm{g} / \mathrm{L})$ is similar to other Pahute Mesa near-field waters, but the ${ }^{235} \mathrm{U} /{ }^{238} \mathrm{U}$ ratio $\left(7.557 \times 10^{-3}\right)$ shows a distinct enrichment in ${ }^{235} \mathrm{U}$ compared to the natural isotope ratio $\left(7.253 \times 10^{-3}\right)$. Although the ${ }^{235} \mathrm{U}$-excess is small, this is the first time that test-derived ${ }^{235} \mathrm{U}$ has been documented in NNSS groundwater. In most cases, the natural uranium in the water effectively 'masks' the uranium contribution from the test. U-19ad PS\#1A groundwater also contains a small amount of test-derived ${ }^{236} \mathrm{U}$, with a measured ${ }^{236} \mathrm{U}^{235} \mathrm{U}$ ratio of 0.004373 and a corresponding ${ }^{236} \mathrm{U}$ activity of $5.5 \times 10^{-3} \mathrm{pCi} / \mathrm{L}$. 


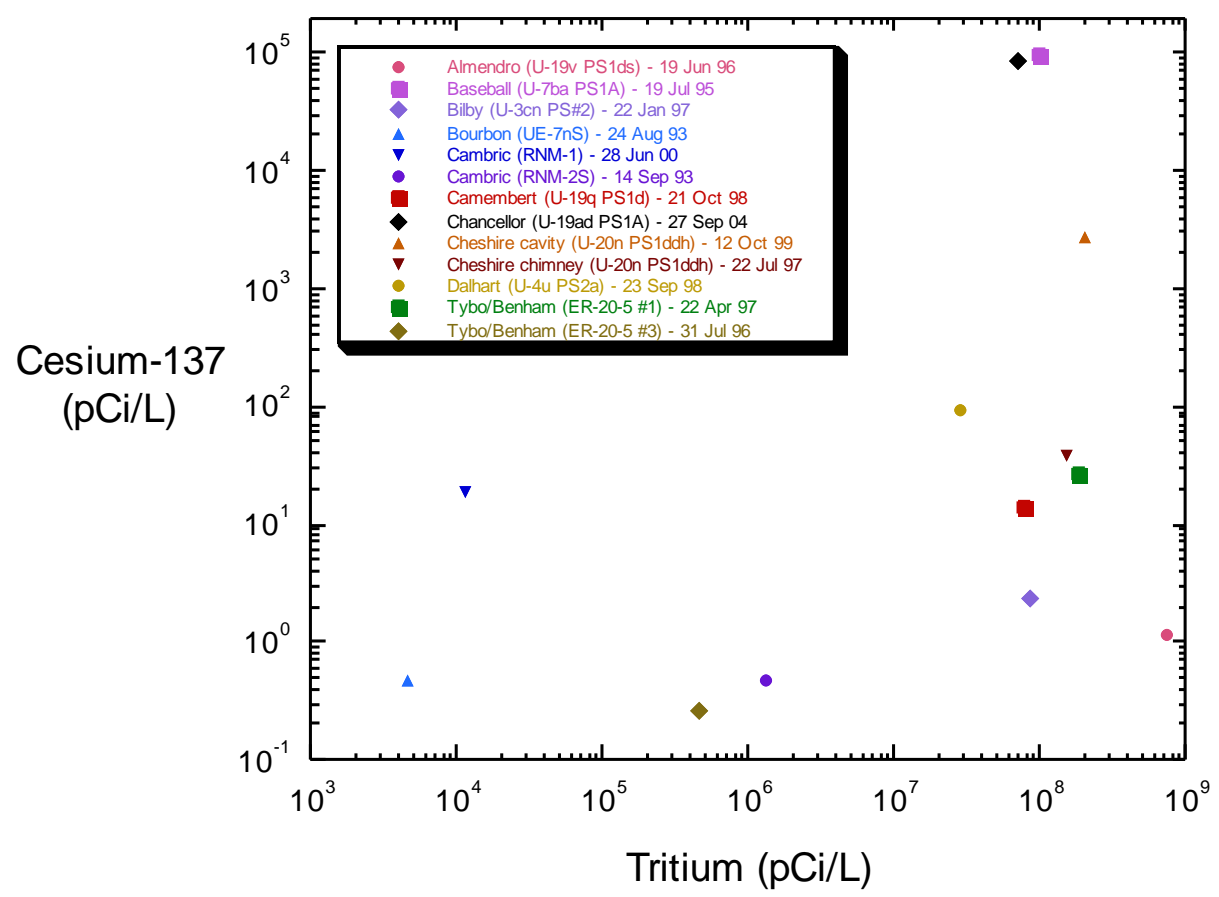

Figure 2.1 Plot of tritium vs. ${ }^{137}$ Cs activity for NNSS near-field groundwaters. Sample collection dates are reported in the legend, but data are corrected to time zero for the given test. The ${ }^{137} \mathrm{Cs}$ activity in U-19ad PS1A groundwater is among the highest observed in NNSS near-field water samples. These data, together with other physical and chemical indicators, suggest the Chancellor cavity fluid is relatively isolated from the surrounding groundwater flow field.

The fission products ${ }^{99} \mathrm{TC}$ and ${ }^{129} \mathrm{I}$ were measured by ICP-MS and AMS, respectively. The ${ }^{99} \mathrm{TC}$ concentration in U-19ad PS1A groundwater is $2.39 \mathrm{ng} / \mathrm{L}$, which is equivalent to an activity of 46.0 $\mathrm{pCi} / \mathrm{L}$. This is near the upper limit of ${ }^{99} \mathrm{Tc}$ values observed in NNSS water samples, though similar levels of ${ }^{99} \mathrm{Tc}$ have been observed in the Bilby $(\mathrm{U}-3 \mathrm{cn})$ and Dalhart $(\mathrm{U}-4 \mathrm{u})$ chimneys. The ${ }^{129} /{ }^{127} \mathrm{I}$ ratio in the water is $5.59 \times 10^{-4}$ and the total iodine concentration is $19.4 \mu \mathrm{g} / \mathrm{L}$, yielding a dissolved ${ }^{129}$ I activity of $1.9 \mathrm{pCi} / \mathrm{L}$. Most NNSS near-field wells have ${ }^{129}$ I activities that are 1 to 3 orders of magnitude lower than this, although similar values were observed in groundwater collected from the Almendro test cavity.

U-19ad PS1A groundwater contains the highest plutonium concentration observed in any NNSS test cavity. Three separate analyses gave total $\mathrm{Pu}$ concentrations of $0.370,0.361$ and $0.358 \mathrm{ng} / \mathrm{L}$, for an average of $0.363 \mathrm{ng} / \mathrm{L}$. The corresponding ${ }^{239,240} \mathrm{Pu}$ activity is 26.8 $\mathrm{pCi} / \mathrm{L}$. Preliminary separation experiments suggested that only $\sim 50 \%$ of the total $\mathrm{Pu}$ was associated with the colloid fraction of the water. However, a second set of careful separation experiments revealed that nearly half the $\mathrm{Pu}$ is associated with very finegrained $(<50 \mathrm{~nm})$ colloids. The results from the second separation experiment are summarized in Table 2.2. Initially, a $>50 \mathrm{~nm}$ size fraction was separated by centrifuging the sample for 13 hours at $4500 \mathrm{rpm}$. This represents $\sim 58 \%$ of the total Pu mass that was eventually recovered. The supernatant fluid from this first step was then centrifuged an additional 13 hours at $4500 \mathrm{rpm}$. This effectively separated the colloid size fraction between about 10 and $50 \mathrm{~nm}$, representing another $30 \%$ of the total $\mathrm{Pu}$ mass. 
Ultrafiltration of the remaining supernatant fluid yielded the $<10 \mathrm{~nm}$ size fraction that could not be separated with a centrifuge - the final $12 \%$ of the total recovered mass.

Table 2.2 Experimental results for Pu colloid separation

\begin{tabular}{|l|ccc|}
\hline Sample Description & $\begin{array}{c}\text { Size Fraction } \\
(\mathbf{n m})\end{array}$ & $\begin{array}{c}\mathbf{P u} \\
(\mathbf{n g} / \mathbf{L})\end{array}$ & $\begin{array}{c}\text { Fraction of } \\
\text { total Pu mass }\end{array}$ \\
\hline centrifuge sediment & $>50$ & 0.207 & $57.7 \%$ \\
centrifuge supernatant & $10-50$ & 0.108 & $30.1 \%$ \\
ultrafiltrate supernatant & $<10$ & 0.044 & $12.2 \%$ \\
Total sample & & $\mathbf{0 . 3 5 8}$ & $\mathbf{1 0 0 . 0 \%}$ \\
\hline
\end{tabular}

It should be noted that two lines of evidence suggest the groundwater within the Chancellor test cavity is moderately reducing. This possibility was first noted during early colloid separation experiments. Excess $\mathrm{Fe}^{3+}$ was added (as $\mathrm{FeCl}_{3}$ ) to the $\mathrm{pH} 9.4$ water in order to form iron (III) hydroxide $\left[\mathrm{Fe}(\mathrm{OH})_{3}\right]$. The $\mathrm{Fe}(\mathrm{OH})_{3}$ was expected to immediately precipitate from solution, carrying the mineral colloids with it. Although a substantial amount of $\mathrm{Fe}^{3+}$ was added to the water $(\sim 100 \mathrm{mg} / \mathrm{L})$, no $\mathrm{Fe}(\mathrm{OH})_{3}$ precipitate formed. There are two possible interpretations of these results. One possibility is that organic compounds in the water acted as chelating agents, preventing the precipitation of iron from solution. The other possibility is that the water was sufficiently reducing that $\mathrm{Fe}^{3+}$ was immediately converted to more soluble $\mathrm{Fe}^{2+}$.

To determine whether redox conditions were controlling the aqueous iron chemistry, the redox potential (Eh value) of the water was measured using an $\mathrm{Ag} / \mathrm{AgCl}$ reference electrode. The results for the U-19ad PS1A sample are compared to Eh values measured for other NNSS near-field samples in Table 2.3. The data show that U-19ad PS1A groundwater has the lowest Eh value of the eight measured samples. The $73.2 \mathrm{mV}$ Eh value suggests that moderately reducing conditions are present within the Chancellor test cavity. Note that all of the Eh values reported in Table 2.3 were determined in the laboratory, and some post-sampling oxidation may have taken place (i.e. in situ conditions in the field may be somewhat more reducing).

In subsequent chapters of this report, comparisons are drawn between the radionuclide concentrations in U-19ad PS1A groundwater and the corresponding values in melt glass and rubble samples. These data provide some insight into the relative partitioning of radionuclides between the solid and aqueous phases in underground test cavities, and are important in terms of defining the radiochemical characteristics of the hydrologic source term. 
Table 2.3 Redox measurements of selected NNSS near-field groundwaters

\begin{tabular}{|l|cc|}
\hline Well Name (Test Name) & $\begin{array}{c}\text { Measured Electrode } \\
\text { Potential }(\mathbf{m V})\end{array}$ & $\begin{array}{c}\text { Redox Potential } \\
(\mathbf{m V})\end{array}$ \\
\hline U-19ad PS1A (Chancellor) & -162.8 & 73.2 \\
U20n PS1ddh (Cheshire) & -117.2 & 118.8 \\
ER-20-5 \#3 (Tybo-Benham) & -94.7 & 141.3 \\
ER-20-5 \#1 (Tybo-Benham) & -92.1 & 143.9 \\
U-3cn PS2A (Bilby) & -77.9 & 158.1 \\
UE-5n (Cambric) & -76.9 & 159.1 \\
UE-7nS (Bourbon) & -62.8 & 173.2 \\
UE-2ce (Nash) & -41.0 & 195.0 \\
\hline
\end{tabular}

* measured using an $\mathrm{Ag} / \mathrm{AgCl}$ reference electrode with a $1 \mathrm{M} \mathrm{KCl}$ fill solution 
Table 2.4 Analytical results for groundwater samples from well U-19ad PS1A

\begin{tabular}{|c|c|}
\hline Sample Date & 27 September 2004 \\
\hline \multicolumn{2}{|l|}{ Water Chemistry } \\
\hline $\mathrm{T}(\stackrel{\circ}{\mathrm{C}})$ & 75 \\
\hline $\mathrm{pH}$ & 9.4 \\
\hline Conductivity $(\mu \mathrm{S} / \mathrm{cm})$ & 941 \\
\hline Dissolved Inorganic Carbon (mg/L as $\left.\mathrm{HCO}_{3}\right)$ & 110 \\
\hline$[\mathrm{F}](\mathrm{mg} / \mathrm{L})$ & 36.0 \\
\hline [Cl] (mg/L) & 43.5 \\
\hline$\left[\mathrm{NO}_{3}\right](\mathrm{mg} / \mathrm{L})$ & 3.0 \\
\hline$\left[\mathrm{SO}_{4}\right](\mathrm{mg} / \mathrm{L})$ & 106.4 \\
\hline$[\mathrm{Na}](\mathrm{mg} / \mathrm{L})$ & 156.2 \\
\hline$[\mathrm{K}](\mathrm{mg} / \mathrm{L})$ & 6.6 \\
\hline [Ca] (mg/L) & 0.8 \\
\hline$[\mathrm{Mg}](\mathrm{mg} / \mathrm{L})$ & 0.03 \\
\hline [Si] (mg/L) & 115.3 \\
\hline$[\mathrm{Fe}](\mathrm{mg} / \mathrm{L})$ & 2.02 \\
\hline [Al] (mg/L) & 9.69 \\
\hline [Sr] (mg/L) & 0.017 \\
\hline \multicolumn{2}{|l|}{ Radiochemistry } \\
\hline${ }^{3} \mathrm{H}$ activity on sample date $(\mathrm{pCi} / \mathrm{L})$ & $2.18 \times 10^{7}$ \\
\hline${ }^{3} \mathrm{H}$ activity at $\mathrm{t}=0(\mathrm{pCi} / \mathrm{L})$ & $7.15 \times 10^{7}$ \\
\hline${ }^{14} \mathrm{C}$ (percent modern carbon) & $3.06 \times 10^{5}$ \\
\hline${ }^{14} \mathrm{C}(\mathrm{pCi} / \mathrm{L})$ & 404 \\
\hline${ }^{36} \mathrm{Cl} / \mathrm{Cl}$ ratio & $6.39 \times 10^{-9}$ \\
\hline${ }^{36} \mathrm{Cl}(\mathrm{pCi} / \mathrm{L})$ & 9.18 \\
\hline${ }^{99} \mathrm{Tc}(\mathrm{pCi} / \mathrm{L})$ & 46.0 \\
\hline Total dissolved iodine $(\mu \mathrm{g} / \mathrm{L})$ & 19.4 \\
\hline${ }^{129} \mid /{ }^{127}$ I ratio & $5.59 \times 10^{-4}$ \\
\hline${ }^{129} \mathrm{I}(\mathrm{pCi} / \mathrm{L})$ & 1.94 \\
\hline Total dissolved uranium $(\mu \mathrm{g} / \mathrm{L})$ & 2.60 \\
\hline${ }^{234} U^{\prime 235} U$ & 0.01177 \\
\hline${ }^{236} U^{\prime 235} U$ & 0.004373 \\
\hline${ }^{238} U^{\prime 235} U$ & 132.32 \\
\hline${ }^{234} \mathrm{U}(\mathrm{pCi} / \mathrm{L})$ & 1.43 \\
\hline${ }^{235} \mathrm{U}(\mathrm{pCi} / \mathrm{L})$ & 0.04 \\
\hline${ }^{236} \mathrm{U}(\mathrm{pCi} / \mathrm{L})$ & 0.0055 \\
\hline${ }^{238} \mathrm{U}(\mathrm{pCi} / \mathrm{L})$ & 0.87 \\
\hline Total plutonium, dissolved + colloidal $(\mathrm{pg} / \mathrm{L})$ & 369.9 \\
\hline${ }^{239,240} \mathrm{Pu}(\mathrm{pCi} / \mathrm{L})$ & 26.8 \\
\hline \multicolumn{2}{|l|}{ Environmental Isotopes } \\
\hline$\delta \mathrm{D}(\%)$ & -112 \\
\hline$\delta^{18} \mathrm{O}(\%)$ & -14.7 \\
\hline$\delta^{13} \mathrm{C}(\%)$ & -8.6 \\
\hline${ }^{87} \mathrm{Sr} /{ }^{86} \mathrm{Sr}$ & 0.71049 \\
\hline$\delta^{87} \mathrm{Sr}(\%)$ & 1.82 \\
\hline
\end{tabular}




\title{
3.0 Physical and Chemical Characterization of Test Debris Samples
}

\author{
Robert Dickerson ${ }^{1}$, Timothy P. Rose ${ }^{2}$, and Frederick J. Ryerson ${ }^{3}$ \\ ${ }^{1}$ Stoller-Navarro Joint Venture, Las Vegas, Nevada \\ ${ }^{2}$ Chemical Sciences Division, Lawrence Livermore National Laboratory \\ ${ }^{3}$ Institute of Geophysics and Planetary Physics, Lawrence Livermore National Laboratory
}

This section of the report describes the physical characteristics and major element chemistry of representative nuclear test debris samples from the U-19ad PS1A borehole. The samples were initially examined using a binocular microscope at magnifications up to 100x. This examination yielded observations regarding the colors, textures, nature of inclusions, and the presence of secondary minerals within the samples. Based on these observations, a suite of samples were selected for Scanning Electron Microscopy (SEM) and electron microprobe analysis. The purpose of the SEM investigation was to search for evidence of secondary alteration minerals in the melt glass, which would indicate melt glass dissolution / mineral precipitation reactions in the post-shot environment. The electron microprobe analysis focused on determining whether selected pairs of samples with different physical attributes show evidence of elemental redistribution during the early stages of melt condensation.

\subsection{Sample Descriptions}

Detailed descriptions of individual samples are found in Appendix A of this report. Samples that were returned to LLNL for analysis consisted of a mixture of drilling mud and test debris. The samples were carefully washed to separate the mud from the larger pieces of test debris. In most cases, the test debris fragments were no more than $\sim 2 \mathrm{~cm}$ in size, and many of the fragments were $<1 \mathrm{~cm}$ in maximum dimension. The test debris exhibits a wide range in physical characteristics. High gamma activity samples are usually dominated by dark-brown or black obsidian-like glass with a low abundance of gas vesicles and inclusions. Lower activity samples are more heterogeneous in composition, and consist of both glass and rubble debris. Melt glass with lower levels of activity is usually lighter in color (gray, green or light brown) and often contains more gas vesicles and inclusions than the dark-colored glass. Most of the inclusions appear to be fragments of the host rock that were not fully assimilated into the melt. Rubble fragments consist of pale gray or grayish-brown rhyolite lava with up to $10 \%$ feldspar phenocrysts, and accessory amounts of biotite and Fe-oxides (magnetite and/or ilmenite). The rhyolite often shows varying degrees of thermal metamorphism, and some samples show a gradation from relatively unaltered rock to fully fused glass over a length scale of a few millimeters. 


\subsection{SEM-EDS Characterization of Test Debris Samples}

The dissolution rate of nuclear melt glass is one of the critical controls on the release of radionuclides into the groundwater environment. Glass dissolution rates depend on a number of variables (cf. Pawloski et al., 2001), but as with most kinetic processes, they are strongly correlated with temperature (Zavarin et al., 2004a). The temperature in the Chancellor test cavity was much higher than expected 21 years after the detonation. Groundwater pumped from the U-19ad PS1A borehole in 2004 had an average temperature at the wellhead of $\sim 75^{\circ} \mathrm{C}$. Empirical evidence indicates that these conditions are highly favorable for the development of secondary alteration minerals at the glasswater interface (Zavarin et al., 2004b). Zeolite minerals are expected to form during glass alteration at temperatures ranging from $\sim 75$ to $250^{\circ} \mathrm{C}$. At lower temperatures, a variety of clays are more likely to form.

To determine whether groundwater interaction with the Chancellor melt glass resulted in the development of alteration minerals, selected test debris samples were examined using a Scanning Electron Microscope equipped with an Energy Dispersive Spectrometer (SEM-EDS). EDS data were collected for individual mineral grains within the samples to determine their elemental compositions. Although these data are semi-quantitative in nature, when coupled with the observed crystal morphology and textural information, it is often possible to make strong inferences regarding the identity of a particular mineral. A total of thirteen melt glass samples were examined on the SEM, seven of which were from the Chancellor drillback. The other samples are from undisclosed underground nuclear tests, and were intended to mask the identity of the Chancellor samples. This had the added benefit of preventing unintentional observational bias during the investigation.

\subsubsection{SEM-EDS Results}

In a majority of the samples that were examined, the coatings on vesicle walls consisted solely of clay minerals, inferred to be derived from drilling mud. In these samples, the clay minerals appeared to be loosely attached to the vesicle surface rather than growing from the glass substrate. Moreover, the glass inside the vesicle wall was characteristically smooth and lacked dissolution textures and surface alteration. In contrast, three samples show strong evidence for the development of secondary alteration minerals. In these samples, the crystal morphology and EDS data are consistent with zeolite minerals. Detailed descriptions of the zeolite-bearing samples are as follows.

\subsubsection{Sample CH16.1 (U19ad PS1ASS - $2292 \mathrm{ft}$ )}

Although some of the gas vesicles in this sample appear to be fresh and unaltered, several vesicles contain well-developed secondary minerals. Figure 3.1A shows a SEM photomicrograph of one of these mineral deposits. The primary mineral occurs as stacked groups of tabular, euhedral crystals up to $\sim 20 \mu \mathrm{m}$ in maximum dimension, and appears to be surrounded by a reaction rim of 'frosted' glass. The interface between the crystals and the altered glass surface is clearly visible on the right-center side of the crystal group in 
Figure 3.1A. Note how the crystal margins conform to the ragged edge of the altered glass. This point of attachment provides strong evidence of in situ mineral growth on the glass surface. EDS spectra for the crystals showed elemental peaks for $\mathrm{Si}, \mathrm{Al}, \mathrm{K}$, and $\mathrm{Na}$. These data coupled with the thin, tabular crystal morphology are consistent with the zeolite mineral clinoptilolite, though we cannot rule out the possibility that it is alkali feldspar. The morphology and EDS data for other secondary phases in this sample were identical to this example.

\subsubsection{Sample CH16.2 (U-19ad PS1ASS - $2292 \mathrm{ft})$}

This sample was collected from the same location as CH16.1, but consists of glass that is much lighter in color, and contains small grains of unmelted host rock. Selected vesicles contain secondary minerals with crystal morphologies and EDS spectral data very similar to that observed in CH16.1. An example is shown in Figure 3.1B. The mineral once again forms parallel aggregates and stacked clusters of tabular, euhedral crystals. Note that the minerals appear to have formed in shallow depressions within the glass. Unaltered vesicles tend to have smooth, featureless surfaces. The occurrence of secondary minerals within pits in this sample may reflect a correlated glass dissolutionmineral precipitation process.

\subsubsection{Sample CH18 (U-19ad PS1ASS - $2332 \mathrm{ft}$ )}

Unlike the previous two examples, the glass alteration in this sample is more widespread, and a different type of secondary mineral has formed. A number of vesicles were found to contain secondary mineral coatings like those illustrated in Figures 3.1C and 3.1D. The mineral occurs as bundles of very fine acicular (needle-like) crystals that formed in parallel growth aggregates. This habit is characteristic of zeolite minerals in the mordenite-erionite group. EDS spectral data appear to be more consistent with the composition of erionite, but both minerals are known to occur in altered silicic volcanic rocks, and this identification must be considered tentative. In addition, the glass surface shows etched and pitted textures in several locations, and the broken margin of the vesicle is ragged rather than smooth. Figure 3.1E shows another example of corroded and pitted glass along a vesicle margin, and the associated growth of secondary minerals. Although the picture is slightly out of focus, the fibrous texture of the secondary mineral bundles is clearly visible. At a different location within this sample, secondary minerals were observed to form in lines and patterns that reveal the presence of preferential nucleation sites (Figure 3.1F). This image also shows that the some of the larger mineral aggregates have formed within small depressions in the glass. As in CH16.2, these depressions may have resulted from glass dissolution and concomitant mineral growth. 

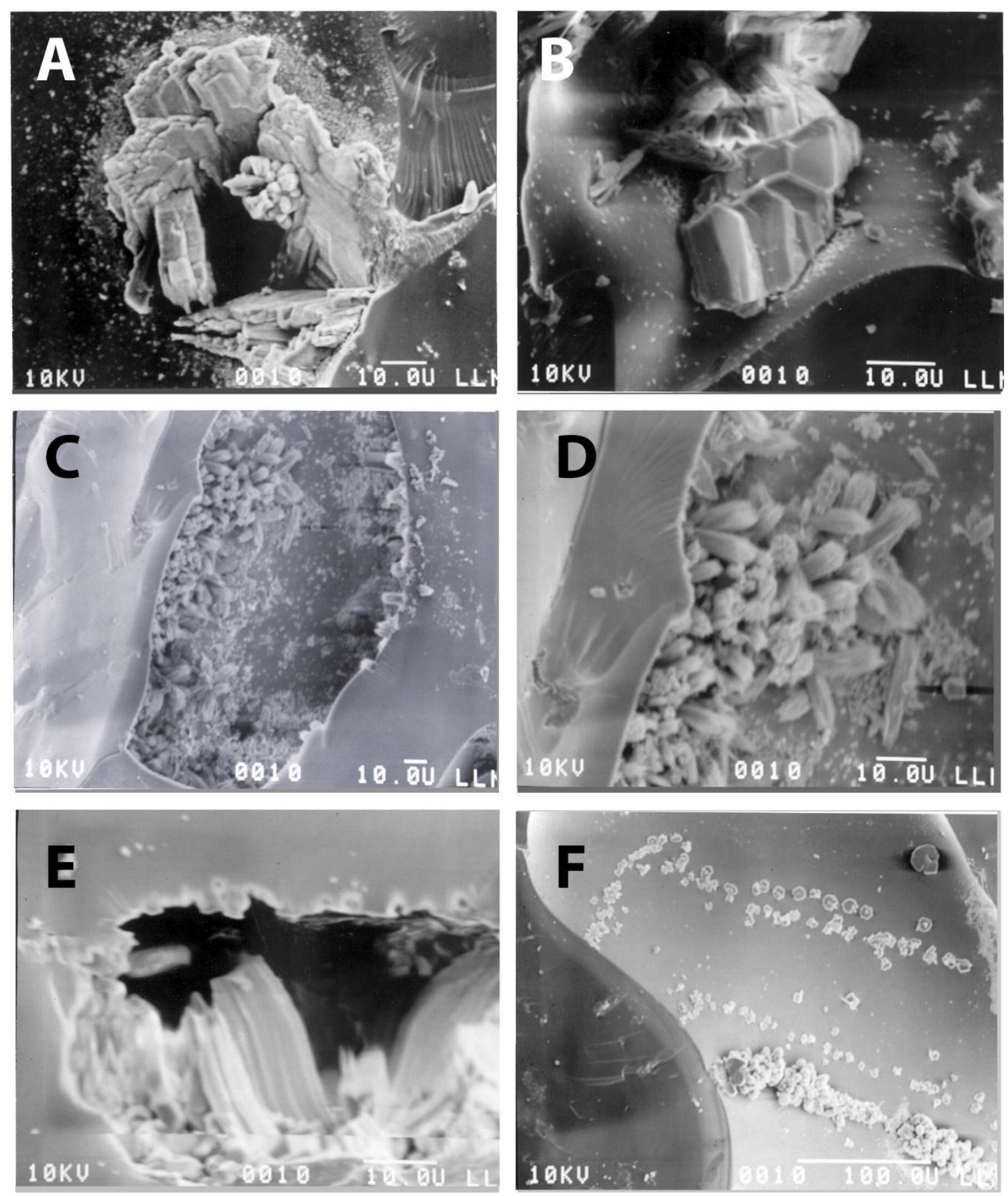

Figure 3.1 SEM photomicrographs of secondary alteration minerals from the U-19ad PS1ASS borehole. A: sample CH16.1 (2292 ft depth); B: sample CH16.2 (2292 ft depth); C through F: sample $\mathrm{CH} 18$ (2332 ft depth). The blocky, euhedral crystals in the $\mathrm{CH} 16$ samples are inferred to be clinoptilolite on the basis of crystal morphology and EDS spectra. Bundles of fibrous crystals in $\mathrm{CH} 18$ are inferred to be erionite or mordenite. Note also the glass pitting and etching, which is particularly evident in images $\mathrm{B}$ and $\mathrm{E}$. 


\subsubsection{Discussion of SEM-EDS Results}

Samples CH16.1, CH16.2, and CH18 show clear evidence of incipient alteration of the nuclear melt glass. These samples are all from the lower part of the second sidetrack hole (PS1ASS). The lack of secondary mineral development in other glass samples indicates the alteration is not pervasive throughout the melt glass zone. This suggests glass alteration is probably controlled by localized zones of higher permeability. In the samples where secondary mineral development was observed, the glass commonly shows evidence of dissolution textures. These include dissolution pits, irregular vesicle edges, and reaction rinds around the secondary minerals. These dissolution textures are similar to the hydration and dissolution textures commonly found in natural obsidians. Although we are unable to definitively identify the secondary minerals in these samples, the available evidence suggests the zeolite minerals clinoptilolite and mordenite/erionite are the dominant alteration phases.

Experimental studies show the principal controls on zeolite formation are (1) temperature, (2) fluid chemistry and $\mathrm{pH}$, (3) glass chemistry, and (4) open vs. closed system behavior (Holler and Wirsching, 1980). The relatively slow cooling rate in the Chancellor cavity has presumably sustained temperatures in the zeolite stability range $\left(\sim 75\right.$ to $\left.250^{\circ} \mathrm{C}\right)$ for an extended period of time. By analogy to thermal models for other underground tests (Carle et al., 2003), it is likely that the mean melt glass temperature in the Chancellor test cavity reached $250^{\circ} \mathrm{C}$ within $\sim 2$ years after the detonation. Since the present cavity temperature is $\sim 75^{\circ} \mathrm{C}$, it appears that conditions favorable for glass zeolitization have been in effect for nearly two decades. Carle et al. (2003) showed that thermal models for slowly cooling tests generally require low permeabilities in the melt glass zone. The lack of more pervasive development of zeolite minerals may therefore be a reflection of low glass permeability.

In general, the chemical composition of the silicic volcanic rocks that underlie Pahute Mesa are favorable for the development of alkalic (Na- and K-rich) zeolite minerals. The natural occurrence of clinoptilolite and mordenite has been widely documented in volcanic rocks from the NNSS (e.g. Sheppard et al., 1988; Bish and Aronson, 1993; Carlos et al., 1995). Since the bulk composition of nuclear melt glass is similar to that of the precursor rock (Schwartz et al., 1984), it is expected that the zeolite minerals formed during glass alteration will be compositionally similar to those observed in NNSS volcanic rocks. In lower temperature environments, clinoptilolite stability is favored over all other zeolites when the chemical activity of $\mathrm{K}^{+}$is greater than $\mathrm{Na}^{+}$or $\mathrm{Ca}^{2+}$ (Chipera and Apps, 2001). Erionite is favored at particularly high $\mathrm{K}^{+}$activities relative to $\mathrm{Ca}^{2+}$. Chemical analyses of the Chancellor test debris (discussed in the next section of this report) showed that $\mathrm{K}>\mathrm{Na} \gg \mathrm{Ca}$ in a majority of samples. We can therefore conclude that the chemical conditions were favorable for the development of clinoptilolite, but it is less certain whether the K-enrichment was sufficient to favor the development of erionite over mordenite. Confirmatory X-ray diffraction analyses were not attempted due to the paucity of secondary minerals in the samples. 


\subsection{Major Element Compositions of Test Debris Samples}

Four different pairs of test debris samples were selected for major element chemical analysis using an electron microprobe. Each sample pair represents material collected from the same depth interval, but one sample consists of dark-colored melt glass while the other consists of volcanic rock debris \pm light-colored glass. Brief sample descriptions are summarized in Table 3.1, and full descriptions are found in Appendix A.

Polished, epoxy-mounted samples were analyzed for their major element compositions on a JEOL 8200 electron microprobe using a $7.5 \mathrm{nA}, 15 \mathrm{keV}$ electron beam defocused to a diameter of $30 \mu \mathrm{m}$. X-ray intensities were converted to element concentrations using a CITZAF algorithm. Reference standards included a variety of silicate and oxide minerals. Analytical results are reported as oxide weight percents in Table 3.2, and include the compositional average, standard deviation, minimum and maximum value, and the number of analyses performed on each sample.

Table 3.1 Brief descriptions of samples analyzed for major element chemistry

\begin{tabular}{|l|l|l|}
\hline Sample ID & $\begin{array}{l}\text { Borehole / } \\
\text { Depth Interval }\end{array}$ & Description \\
\hline CH03.1 & PS1A 2371' & reddish-brown melt glass, non-vesicular \\
CH03.2 & PS1A 2371' & pale-gray volcanic rock showing some evidence of incipient melting \\
$\mathrm{CH} 04.1$ & PS1AS 2181' & vesicular brown melt glass \\
$\mathrm{CH} 04.2$ & PS1AS 2181' & volcanic rock, some partially melted to form light-colored vesicular glass \\
$\mathrm{CH} 14.1$ & PS1ASS 2240' & reddish-brown melt glass, non-vesicular \\
$\mathrm{CH} 14.3$ & PS1ASS 2240' & volcanic rock, some partially melted to form light-colored non-vesicular glass \\
$\mathrm{CH} 16.1$ & PS1ASS 2292' & dark brown / black melt glass \\
$\mathrm{CH} 16.2$ & PS1ASS 2292' & heterogeneous mixture of light-colored glass w/ fused volcanic rock inclusions \\
\hline
\end{tabular}

In general, the average major element chemistry of the test debris samples overlaps with reported compositions of rhyolitic lavas and tuffs found on Pahute Mesa (e.g. Broxton et al., 1989). However, the range in maximum and minimum values for individual analyses reveals fine-scale heterogeneities within the samples, some of which are quite distinct. For example, the melt glass $\mathrm{CH} 14.1$ has an average composition like that of a high-silica rhyolite, but contains small inclusions with compositions that vary from 55.8 to $98.1 \%$ $\mathrm{SiO}_{2}$ (Table 3.2). The glass inclusions with the lowest $\mathrm{SiO}_{2}$ content also show the greatest enrichment in 'refractory' elements, with up to $2.7 \% \mathrm{TiO}_{2}, 7.2 \% \mathrm{MgO}$, and $10.6 \% \mathrm{FeO}$. This may reflect the presence of microscopic rust-colored inclusions in the $\mathrm{CH} 14.1$ glass. On the other hand, the high $\mathrm{SiO}_{2}$ inclusions may represent the small grains of unmelted host rock that commonly occur in the many of the glass samples.

Comparison of the average compositions of sample pairs from a given depth interval reveals that the dark-colored glass samples tend to be enriched in $\mathrm{SiO}_{2}, \mathrm{TiO}_{2}$, and $\mathrm{FeO}$, but depleted in $\mathrm{Al}_{2} \mathrm{O}_{3}, \mathrm{CaO}$, and $\mathrm{Na}_{2} \mathrm{O}$ relative to the coexisting rubble and light-colored 
glass. Figure 3.2 shows a plot of the average $\mathrm{SiO}_{2}$ vs. $\mathrm{FeO}$ concentrations in all eight samples. For each pair of samples, the dark-colored melt glass is uniformly enriched in both $\mathrm{SiO}_{2}$ and $\mathrm{FeO}$ compared to the rubble/light-glass. Previous studies have suggested the iron enrichment in the dark glass reflects the presence of vaporized material from the device canister and other iron-bearing materials that were present in the emplacement hole (e.g. Schwartz et al., 1984). The dark-colored glass also tends to contain the highest levels of radioactivity.

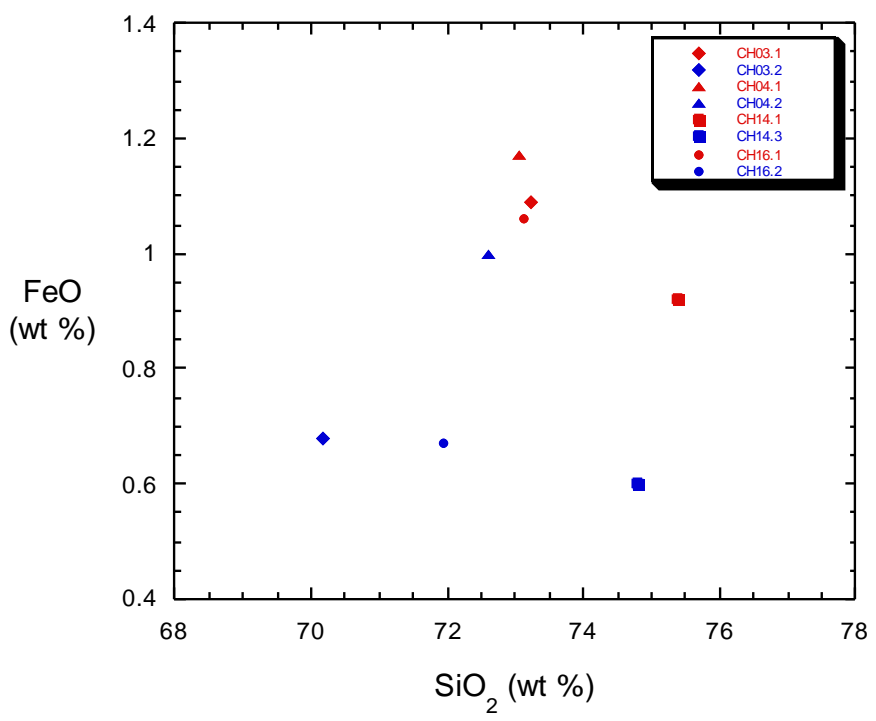

Figure 3.2 Plot of $\mathrm{SiO}_{2}$ vs. $\mathrm{FeO}$ concentrations in pairs of test debris samples from four different depth intervals. Sample pairs from a given location are represented by the same type of symbol. Red symbols represent dark-colored melt glass, and blue symbols represent co-existing rubble or light-colored melt glass. See text for discussion.

The $\mathrm{SiO}_{2}$ and $\mathrm{FeO}$ enrichment in the dark-colored glass appears to be balanced by small losses of other elements. This probably reflects partitioning effects that occurred during the initial condensation of the glass. For example, three of the four sample pairs show a nearly linear trend in decreasing $\mathrm{Na}_{2} \mathrm{O}$ with increasing $\mathrm{SiO}_{2}$ concentration (Figure 3.3). This trend is readily explained by the high temperature redistribution of volatile $\mathrm{Na}_{2} \mathrm{O}$ in the test cavity. The apparent loss of $\mathrm{Al}_{2} \mathrm{O}_{3}$ and $\mathrm{CaO}$ from the melt glass is less easily explained because these oxides have relatively high boiling points. We can speculate that low oxygen fugacities in the early cavity environment may have initially inhibited the condensation of these species. In the case of $\mathrm{CaO}$, there is indirect evidence that this may occur based on analog studies of $\mathrm{SrO}$ and $\mathrm{BaO}$ volatilities. At $2500^{\circ} \mathrm{K}$, if the oxygen fugacity is lowered from $1 \mathrm{~atm}$ to $10^{-10} \mathrm{~atm}$, the vapor concentrations of $\mathrm{SrO}$ and $\mathrm{BaO}$ will increase by more than two orders of magnitude (Bedford and Jackson, 1965). Since $\mathrm{CaO}$ is chemically similar to these elements, it would be expected to show a similar response to low oxygen fugacities. Previous investigations of the redox state of nuclear melt glass samples (Borg, 1975; Rose et al., 2003) suggest that low oxygen fugacities may be common during the early stages of melt glass condensation. 


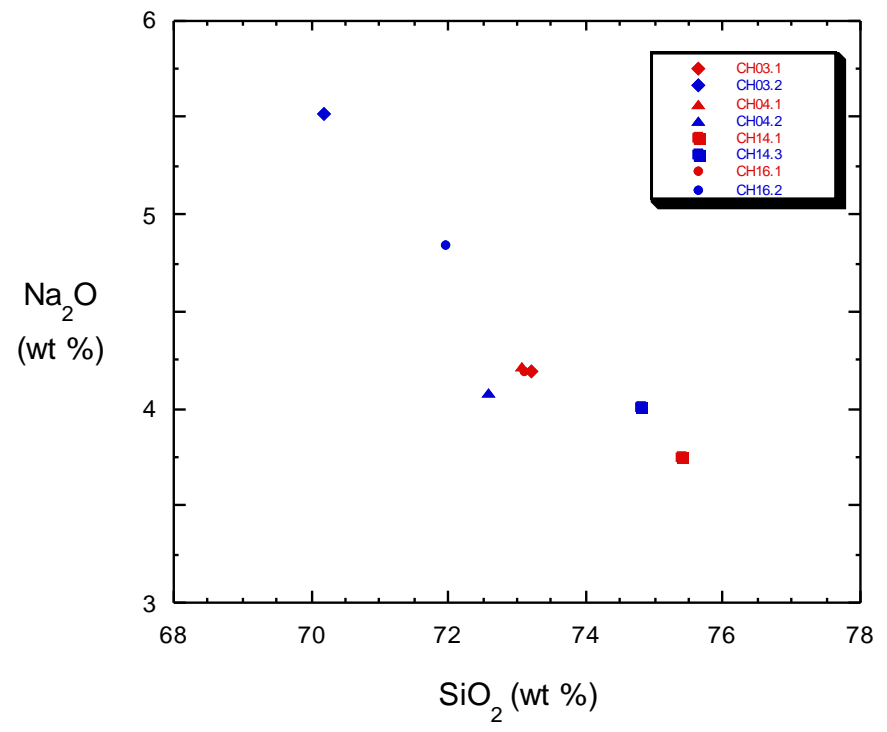

Figure 3.3 Plot of $\mathrm{SiO}_{2}$ vs. $\mathrm{Na}_{2} \mathrm{O}$ concentrations for the same set of samples shown in Figure 3.2. 
Table 3.2. Major element compositions of selected test debris samples

\begin{tabular}{|c|c|c|c|c|c|c|c|c|c|c|c|}
\hline Sample & Sample Statistics & $\begin{array}{c}\mathrm{SiO}_{2} \\
(\mathrm{wt} \%)\end{array}$ & $\begin{array}{c}\mathrm{TiO}_{2} \\
\text { (wt \%) }\end{array}$ & $\begin{array}{l}\mathbf{A l}_{2} \mathbf{O}_{3} \\
\text { (wt \%) }\end{array}$ & $\begin{array}{c}\mathrm{FeO} \\
\text { (wt \%) }\end{array}$ & $\begin{array}{c}\text { MnO } \\
\text { (wt \%) }\end{array}$ & $\begin{array}{c}\text { MgO } \\
\text { (wt \%) }\end{array}$ & $\begin{array}{c}\mathrm{CaO} \\
\text { (wt \%) }\end{array}$ & $\begin{array}{c}\mathbf{K}_{2} \mathbf{O} \\
(w t \%)\end{array}$ & $\begin{array}{l}\mathrm{Na}_{2} \mathrm{O} \\
\text { (wt \%) }\end{array}$ & $\begin{array}{l}\text { Total } \\
\text { (wt \%) }\end{array}$ \\
\hline $\mathrm{CH} 03.1$ & $\begin{array}{l}\text { Average } \\
\text { Std. Dev. } \\
\text { Minimum } \\
\text { Maximum } \\
\text { No. of Analyses = } 25\end{array}$ & $\begin{array}{c}73.22 \\
0.61 \\
71.79 \\
74.54\end{array}$ & $\begin{array}{l}0.22 \\
0.05 \\
0.13 \\
0.32\end{array}$ & $\begin{array}{c}13.36 \\
0.44 \\
12.19 \\
14.47\end{array}$ & $\begin{array}{l}1.09 \\
0.27 \\
0.51 \\
1.59\end{array}$ & $\begin{array}{l}0.11 \\
0.10 \\
0.00 \\
0.36\end{array}$ & $\begin{array}{l}0.14 \\
0.06 \\
0.05 \\
0.28\end{array}$ & $\begin{array}{l}0.59 \\
0.11 \\
0.37 \\
0.88\end{array}$ & $\begin{array}{l}5.14 \\
0.12 \\
4.99 \\
5.53\end{array}$ & $\begin{array}{l}4.19 \\
0.14 \\
3.98 \\
4.45\end{array}$ & $\begin{array}{c}98.06 \\
0.73 \\
97.03 \\
99.69\end{array}$ \\
\hline $\mathrm{CH} 03.2$ & $\begin{array}{l}\text { Average } \\
\text { Std. Dev. } \\
\text { Minimum } \\
\text { Maximum } \\
\text { No. of Analyses = } 25\end{array}$ & $\begin{array}{c}70.19 \\
2.02 \\
65.61 \\
75.39\end{array}$ & $\begin{array}{l}0.12 \\
0.09 \\
0.03 \\
0.35\end{array}$ & $\begin{array}{c}15.83 \\
0.86 \\
13.39 \\
16.99\end{array}$ & $\begin{array}{l}0.68 \\
0.83 \\
0.00 \\
4.44\end{array}$ & $\begin{array}{l}0.17 \\
0.19 \\
0.00 \\
0.75\end{array}$ & $\begin{array}{l}0.08 \\
0.17 \\
0.00 \\
0.81\end{array}$ & $\begin{array}{l}0.62 \\
0.21 \\
0.22 \\
1.02\end{array}$ & $\begin{array}{l}5.39 \\
0.49 \\
4.18 \\
6.23\end{array}$ & $\begin{array}{l}5.52 \\
0.46 \\
4.39 \\
6.44\end{array}$ & $\begin{array}{c}98.61 \\
1.14 \\
97.03 \\
101.99\end{array}$ \\
\hline $\mathrm{CH} 04.1$ & $\begin{array}{l}\text { Average } \\
\text { Std. Dev. } \\
\text { Minimum } \\
\text { Maximum } \\
\text { No. of Analyses = } 59\end{array}$ & $\begin{array}{c}73.06 \\
0.81 \\
71.41 \\
74.39\end{array}$ & $\begin{array}{l}0.24 \\
0.07 \\
0.11 \\
0.55\end{array}$ & $\begin{array}{c}13.44 \\
0.41 \\
12.52 \\
14.27\end{array}$ & $\begin{array}{l}1.17 \\
0.26 \\
0.71 \\
1.78\end{array}$ & $\begin{array}{l}0.12 \\
0.11 \\
0.00 \\
0.48\end{array}$ & $\begin{array}{l}0.15 \\
0.07 \\
0.00 \\
0.44\end{array}$ & $\begin{array}{l}0.58 \\
0.12 \\
0.29 \\
0.93\end{array}$ & $\begin{array}{l}5.12 \\
0.11 \\
4.88 \\
5.42\end{array}$ & $\begin{array}{l}4.22 \\
0.14 \\
3.83 \\
4.56\end{array}$ & $\begin{array}{c}98.10 \\
1.03 \\
95.47 \\
101.39\end{array}$ \\
\hline $\mathrm{CH} 04.2$ & $\begin{array}{l}\text { Average } \\
\text { Std. Dev. } \\
\text { Minimum } \\
\text { Maximum } \\
\text { No. of Analyses = } 15\end{array}$ & $\begin{array}{c}72.59 \\
0.62 \\
71.82 \\
73.53\end{array}$ & $\begin{array}{l}0.22 \\
0.05 \\
0.12 \\
0.29\end{array}$ & $\begin{array}{c}13.61 \\
0.69 \\
12.10 \\
14.56\end{array}$ & $\begin{array}{l}1.00 \\
0.23 \\
0.48 \\
1.35\end{array}$ & $\begin{array}{l}0.14 \\
0.12 \\
0.00 \\
0.38\end{array}$ & $\begin{array}{l}0.16 \\
0.06 \\
0.07 \\
0.26\end{array}$ & $\begin{array}{l}0.67 \\
0.09 \\
0.52 \\
0.81\end{array}$ & $\begin{array}{l}5.06 \\
0.16 \\
4.76 \\
5.30\end{array}$ & $\begin{array}{l}4.08 \\
0.16 \\
3.82 \\
4.42\end{array}$ & $\begin{array}{c}97.52 \\
0.52 \\
97.02 \\
99.05\end{array}$ \\
\hline $\mathrm{CH} 14.1$ & $\begin{array}{l}\text { Average } \\
\text { Std. Dev. } \\
\text { Minimum } \\
\text { Maximum } \\
\text { No. of Analyses = } 20\end{array}$ & $\begin{array}{c}75.40 \\
9.04 \\
55.75 \\
98.10\end{array}$ & $\begin{array}{l}0.29 \\
0.57 \\
0.05 \\
2.69\end{array}$ & $\begin{array}{c}12.49 \\
4.25 \\
0.58 \\
17.11\end{array}$ & $\begin{array}{c}0.92 \\
2.31 \\
0.00 \\
10.59\end{array}$ & $\begin{array}{l}0.16 \\
0.14 \\
0.00 \\
0.44\end{array}$ & $\begin{array}{l}0.40 \\
1.61 \\
0.00 \\
7.23\end{array}$ & $\begin{array}{l}0.37 \\
0.24 \\
0.00 \\
0.97\end{array}$ & $\begin{array}{l}5.03 \\
1.74 \\
0.11 \\
6.30\end{array}$ & $\begin{array}{l}3.75 \\
1.47 \\
0.14 \\
6.23\end{array}$ & $\begin{array}{c}98.81 \\
0.87 \\
97.29 \\
100.22\end{array}$ \\
\hline $\mathrm{CH} 14.3$ & $\begin{array}{l}\text { Average } \\
\text { Std. Dev. } \\
\text { Minimum } \\
\text { Maximum } \\
\text { No. of Analyses = } 59\end{array}$ & $\begin{array}{c}74.81 \\
1.30 \\
72.04 \\
78.93\end{array}$ & $\begin{array}{l}0.17 \\
0.06 \\
0.05 \\
0.40\end{array}$ & $\begin{array}{c}12.93 \\
0.66 \\
10.70 \\
14.64\end{array}$ & $\begin{array}{l}0.60 \\
0.72 \\
0.00 \\
4.12\end{array}$ & $\begin{array}{l}0.06 \\
0.09 \\
0.00 \\
0.36\end{array}$ & $\begin{array}{l}0.05 \\
0.07 \\
0.00 \\
0.31\end{array}$ & $\begin{array}{l}0.40 \\
0.14 \\
0.16 \\
0.84\end{array}$ & $\begin{array}{l}5.28 \\
0.59 \\
3.48 \\
6.39\end{array}$ & $\begin{array}{l}4.01 \\
0.38 \\
3.27 \\
5.08\end{array}$ & $\begin{array}{c}98.31 \\
0.92 \\
97.02 \\
100.67\end{array}$ \\
\hline $\mathrm{CH} 16.1$ & $\begin{array}{l}\text { Average } \\
\text { Std. Dev. } \\
\text { Minimum } \\
\text { Maximum } \\
\text { No. of Analyses = } 30\end{array}$ & $\begin{array}{c}73.12 \\
0.77 \\
71.52 \\
74.87\end{array}$ & $\begin{array}{l}0.22 \\
0.06 \\
0.13 \\
0.33\end{array}$ & $\begin{array}{c}13.64 \\
0.26 \\
13.16 \\
14.08\end{array}$ & $\begin{array}{l}1.06 \\
0.27 \\
0.44 \\
1.77\end{array}$ & $\begin{array}{l}0.12 \\
0.12 \\
0.00 \\
0.33\end{array}$ & $\begin{array}{l}0.17 \\
0.06 \\
0.04 \\
0.26\end{array}$ & $\begin{array}{l}0.56 \\
0.13 \\
0.34 \\
0.87\end{array}$ & $\begin{array}{l}5.17 \\
0.15 \\
4.86 \\
5.48\end{array}$ & $\begin{array}{l}4.19 \\
0.11 \\
3.92 \\
4.37\end{array}$ & $\begin{array}{c}98.25 \\
0.88 \\
97.01 \\
100.64\end{array}$ \\
\hline $\mathrm{CH} 16.2$ & $\begin{array}{l}\text { Average } \\
\text { Std. Dev. } \\
\text { Minimum } \\
\text { Maximum } \\
\text { No. of Analyses = } 66\end{array}$ & $\begin{array}{c}71.96 \\
3.19 \\
63.83 \\
77.04\end{array}$ & $\begin{array}{l}0.14 \\
0.11 \\
0.00 \\
0.62\end{array}$ & $\begin{array}{c}14.72 \\
2.61 \\
11.51 \\
21.35\end{array}$ & $\begin{array}{l}0.67 \\
0.33 \\
0.10 \\
2.02\end{array}$ & $\begin{array}{l}0.09 \\
0.10 \\
0.00 \\
0.43\end{array}$ & $\begin{array}{l}0.08 \\
0.06 \\
0.00 \\
0.30\end{array}$ & $\begin{array}{l}0.70 \\
0.79 \\
0.03 \\
2.90\end{array}$ & $\begin{array}{l}5.07 \\
1.64 \\
1.28 \\
6.58\end{array}$ & $\begin{array}{l}4.84 \\
1.68 \\
3.41 \\
8.90\end{array}$ & $\begin{array}{c}98.27 \\
0.83 \\
97.04 \\
101.41\end{array}$ \\
\hline
\end{tabular}




\title{
4.0 Gamma Spectroscopy Analysis of Test Debris Samples
}

\author{
Timothy P. Rose, P. Todd Wooddy and Cynthia L. Conrado \\ Chemical Sciences Division, Lawrence Livermore National Laboratory
}

In this chapter, gamma spectroscopy data are presented for 16 test debris samples from the Chancellor post-shot boreholes. Laboratory analyses of gamma spectra using fixed high purity $\mathrm{Ge}(\mathrm{Li})$ detectors provided data for ${ }^{60} \mathrm{Co},{ }^{125} \mathrm{Sb},{ }^{137} \mathrm{Cs},{ }^{152} \mathrm{Eu},{ }^{154} \mathrm{Eu},{ }^{155} \mathrm{Eu}$, and ${ }^{241} \mathrm{Am}$, though not all species were present at detectable levels in every sample. Spectral data were processed using the Gamanal code to make peak assignments and to convert raw count rates to activity values. Measured activities are reported in Table 4.1 (in $\mathrm{pCi} / \mathrm{g}$ ) for both the zero time of the nuclear detonation (1 Sept 1983) and the groundwater sampling date (27 Sept 2004).

Most of the gamma spectroscopy analyses were performed on bulk test debris samples. Separation of material with different physical characteristics was carried out on only one sample (CH16) prior to analysis. However, many samples were dominated by only one type of material (glass or rubble), as reflected in the total gamma activity of the sample. Samples that consisted largely of a single phase were used to represent the glass or rubble compositions in the radionuclide partitioning calculations, as described below.

In general, variations in gamma activities appear to be more-or-less independent of radionuclide volatility. Samples with high activities of refractory species (Co, Eu, Am) also tend to contain high activities of volatile species ( $\mathrm{Sb}, \mathrm{Cs}$ ). Not surprisingly, the test debris samples with the highest levels of gamma activity were typically found in the lower part of the cavity, whereas low activity samples tended to occur at stratigraphically higher levels (or outside the cavity in the case of CH11). One notable exception is sample CH04 (PS1AS $2181 \mathrm{ft}$ ) which shows surprisingly high levels of activity considering its location near the center of the cavity (see Figure 1.2). CH04 consists of a mixture of rubble and melt glass with a wide range in textures (Appendix A) and may represent material that was redistributed during the initial stages of chimney collapse.

It is interesting to compare the covariance in volatile and refractory elements within the test debris to determine whether a systematic correlation is observed. The fission product ${ }^{137} \mathrm{Cs}$ has a gaseous precursor $\left({ }^{137} \mathrm{Xe}\right)$ with a 3.8 minute half life, and is a good indicator of volatile behavior. In contrast, europium is a highly refractory element that is strongly concentrated into the melt glass. Data are available for the fission product ${ }^{155} \mathrm{Eu}$ and two activation products, ${ }^{152} \mathrm{Eu}$ and ${ }^{154} \mathrm{Eu}$. Since ${ }^{155} \mathrm{Eu}$ does not have any volatile precursors in its mass chain, its partitioning behavior is nearly the same as that of ${ }^{152} \mathrm{Eu}$ and ${ }^{154} \mathrm{Eu}$. We will therefore draw the comparison using ${ }^{152} \mathrm{Eu}$, since more data are available for this nuclide compared to the other two europium isotopes. For test debris samples where measurable levels of both ${ }^{137} \mathrm{Cs}$ and ${ }^{152} \mathrm{Eu}$ are present, the ${ }^{137} \mathrm{Cs} /{ }^{152} \mathrm{Eu}$ activity ratio may provide insight into the relative enrichment in volatile versus refractory species. Decay corrected ${ }^{137} \mathrm{Cs} /{ }^{152} \mathrm{Eu}$ activity ratios are reported in Table 4.1, and the variation in ${ }^{137} \mathrm{Cs}$ vs. ${ }^{152} \mathrm{Eu}$ activities (in $\mathrm{pCi} / \mathrm{g}$ ) is plotted in Figure 4.1. 


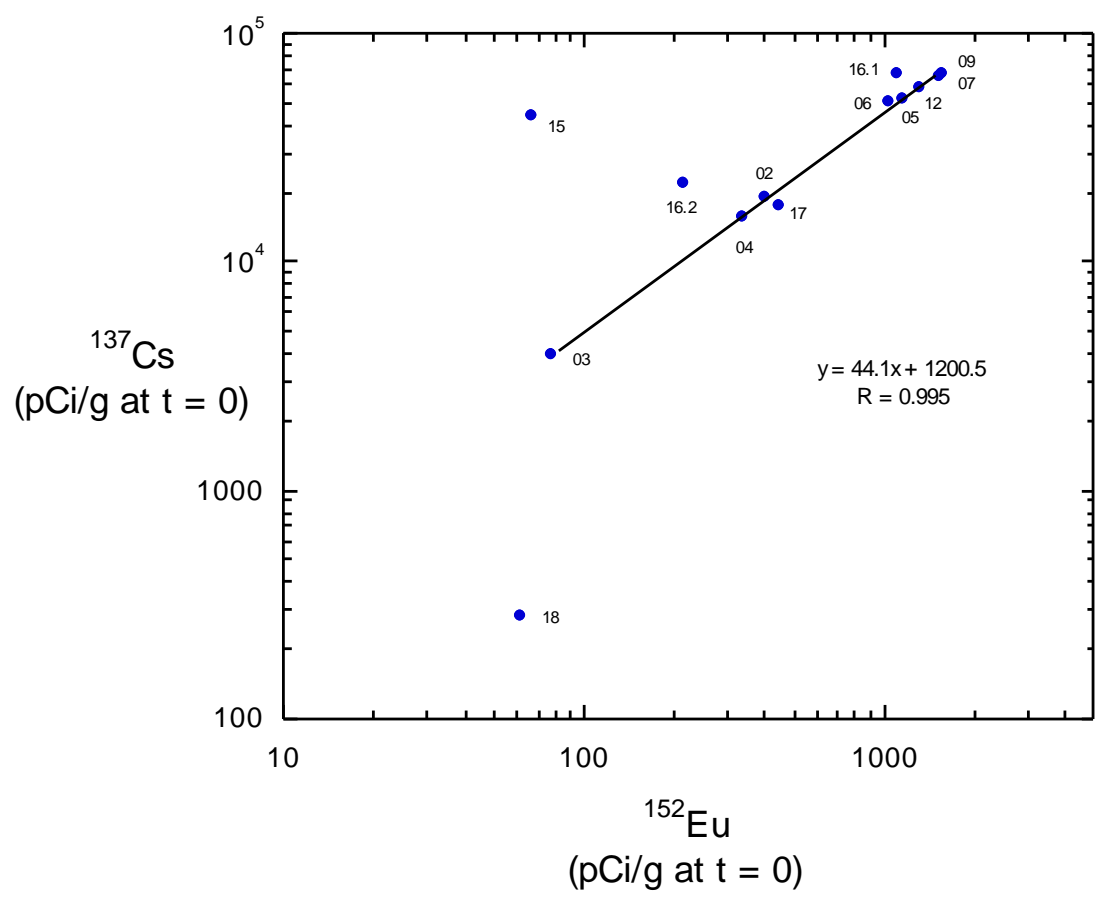

Figure 4.1 Log-log plot of ${ }^{137} \mathrm{Cs}$ vs. ${ }^{152} \mathrm{Eu}$ activities for nuclear test debris samples from U-19ad boreholes (in $\mathrm{pCi} / \mathrm{g}$ at time zero); individual data points are labeled according to sample number. See text for discussion.

A total of 13 of the 16 samples analyzed by gamma spectroscopy contain detectable amounts of both ${ }^{137} \mathrm{Cs}$ and ${ }^{152} \mathrm{Eu}$. Nine of these samples have ${ }^{137} \mathrm{Cs} /{ }^{152} \mathrm{Eu}$ activity ratios between 41 and 51 that plot along a linear trend with a slope of 44 (Figure 4.1). This ratio is inferred to represent the relative production rates of these two species during the nuclear detonation. The high activity samples that plot at the upper end of this trend (with ${ }^{152} \mathrm{Eu}>1000 \mathrm{pCi} / \mathrm{g}$ ) are all dominated by dark melt glass, while the lower activity samples $\left({ }^{152} \mathrm{Eu}<1000 \mathrm{pCi} / \mathrm{g}\right)$ consist of rubble debris and/or varicolored melt glass.

Four samples have ${ }^{137} \mathrm{Cs} /{ }^{152} \mathrm{Eu}$ activity ratios that fall off the linear trend in Figure 4.1, with ratios between 5 and 670. Samples CH15, CH16.1, and CH16.2 are all enriched in ${ }^{137} \mathrm{Cs}$ relative to ${ }^{152} \mathrm{Eu}$, and all were collected from a narrow $(6 \mathrm{ft})$ depth interval in the second sidetrack hole (PS1ASS). Sample CH15 (2286 ft) is a mixture of altered rubble and green-colored glass that shows a strong ${ }^{137} \mathrm{Cs}$ enrichment $(\mathrm{Cs} / \mathrm{Eu}=670)$. Sample $\mathrm{CH} 16$ consists of coexisting light- and dark-colored melt glass from $2292 \mathrm{ft}$ depth. The two different glass fractions were analyzed separately, and the lighter-colored CH16.2 has a slightly higher $\mathrm{Cs} / \mathrm{Eu}$ ratio than the dark-colored $\mathrm{CH} 16.1(\mathrm{Cs} / \mathrm{Eu}=104$ and 62, respectively). Both $\mathrm{CH} 16.1$ and 16.2 show the incipient development of secondary zeolite minerals (Section 3.2), and we cannot rule out the possibility that some of the ${ }^{137} \mathrm{Cs}$ enrichment in these samples represents material that was redistributed under hydrothermal conditions. 
Table 4.1 Gamma spectroscopy results for Chancellor test debris samples

\begin{tabular}{|c|c|c|c|c|c|c|c|c|c|}
\hline Radionuclide & half-life (yr) & $\begin{array}{l}\text { CH01 } \\
\text { PS1A 2232' }\end{array}$ & $\begin{array}{c}\text { CH02 } \\
\text { PS1A 2361' }\end{array}$ & $\begin{array}{c}\text { CH03 } \\
\text { PS1A 2371' }\end{array}$ & $\begin{array}{c}\text { CH04 } \\
\text { PS1AS 2181' }\end{array}$ & $\begin{array}{c}\text { CH05 } \\
\text { PS1AS 2252' }\end{array}$ & $\begin{array}{c}\text { CH06 } \\
\text { PS1AS 2262' }\end{array}$ & $\begin{array}{c}\text { CH07 } \\
\text { PS1AS 2280' }\end{array}$ & $\begin{array}{c}\text { CHO9 } \\
\text { PS1AS 2313' }\end{array}$ \\
\hline $\begin{array}{l}{ }^{60} \mathrm{Co}(\mathrm{pCi} / \mathrm{g} \text { at } \mathrm{t}=0) \\
{ }^{60} \mathrm{Co}(\mathrm{pCi} / \mathrm{g} \text { on } 09 / 27 / 04)\end{array}$ & 5.27 & $\begin{array}{l}\text { n.d. } \\
\text { n.d. }\end{array}$ & $\begin{array}{l}2.12 \mathrm{E}+03 \\
1.33 \mathrm{E}+02\end{array}$ & $\begin{array}{l}3.97 \mathrm{E}+02 \\
2.49 \mathrm{E}+01\end{array}$ & $\begin{array}{l}1.77 \mathrm{E}+03 \\
1.11 \mathrm{E}+02\end{array}$ & $\begin{array}{l}6.14 \mathrm{E}+03 \\
3.84 \mathrm{E}+02\end{array}$ & $\begin{array}{l}5.47 \mathrm{E}+03 \\
3.42 \mathrm{E}+02\end{array}$ & $\begin{array}{l}8.06 \mathrm{E}+03 \\
5.05 \mathrm{E}+02\end{array}$ & $\begin{array}{l}8.09 \mathrm{E}+03 \\
5.06 \mathrm{E}+02\end{array}$ \\
\hline $\begin{array}{l}{ }^{125} \mathrm{Sb}(\mathrm{pCi} / \mathrm{g} \text { at } \mathrm{t}=0) \\
{ }^{125} \mathrm{Sb}(\mathrm{pCi} / \mathrm{g} \text { on } 09 / 27 / 04)\end{array}$ & 2.76 & $\begin{array}{l}\text { n.d. } \\
\text { n.d. }\end{array}$ & $\begin{array}{l}1.39 \mathrm{E}+04 \\
6.96 \mathrm{E}+01\end{array}$ & $\begin{array}{l}2.24 \mathrm{E}+03 \\
1.12 \mathrm{E}+01\end{array}$ & $\begin{array}{l}1.21 \mathrm{E}+04 \\
6.07 \mathrm{E}+01\end{array}$ & $\begin{array}{l}3.65 \mathrm{E}+04 \\
1.83 \mathrm{E}+02\end{array}$ & $\begin{array}{l}3.33 \mathrm{E}+04 \\
1.67 \mathrm{E}+02\end{array}$ & $\begin{array}{l}4.71 \mathrm{E}+04 \\
2.36 \mathrm{E}+02\end{array}$ & $\begin{array}{l}4.81 \mathrm{E}+04 \\
2.41 \mathrm{E}+02\end{array}$ \\
\hline $\begin{array}{l}{ }^{137} \mathrm{Cs}(\mathrm{pCi} / \mathrm{g} \text { at } \mathrm{t}=0) \\
{ }^{13 /} \mathrm{Cs}(\mathrm{pCi} / \mathrm{g} \text { on } 09 / 27 / 04)\end{array}$ & 30.07 & $\begin{array}{l}5.58 \mathrm{E}+02 \\
3.43 \mathrm{E}+02\end{array}$ & $\begin{array}{l}1.97 \mathrm{E}+04 \\
1.21 \mathrm{E}+04\end{array}$ & $\begin{array}{l}3.96 \mathrm{E}+03 \\
2.44 \mathrm{E}+03\end{array}$ & $\begin{array}{l}1.58 \mathrm{E}+04 \\
9.72 \mathrm{E}+03\end{array}$ & $\begin{array}{l}5.26 \mathrm{E}+04 \\
3.24 \mathrm{E}+04\end{array}$ & $\begin{array}{l}5.11 E+04 \\
3.15 E+04\end{array}$ & $\begin{array}{l}6.49 \mathrm{E}+04 \\
4.00 \mathrm{E}+04\end{array}$ & $\begin{array}{l}6.76 \mathrm{E}+04 \\
4.16 \mathrm{E}+04\end{array}$ \\
\hline $\begin{array}{l}{ }^{152} \mathrm{Eu}(\mathrm{pCi} / \mathrm{g} \text { at } \mathrm{t}=0) \\
{ }^{152} \mathrm{Eu}(\mathrm{pCi} / \mathrm{g} \text { on 09/27/04) }\end{array}$ & 13.54 & $\begin{array}{l}\text { n.d. } \\
\text { n.d. }\end{array}$ & $\begin{array}{l}3.97 \mathrm{E}+02 \\
1.35 \mathrm{E}+02\end{array}$ & $\begin{array}{l}7.74 \mathrm{E}+01 \\
2.63 \mathrm{E}+01\end{array}$ & $\begin{array}{l}3.36 \mathrm{E}+02 \\
1.14 \mathrm{E}+02\end{array}$ & $\begin{array}{l}1.15 \mathrm{E}+03 \\
3.92 \mathrm{E}+02\end{array}$ & $\begin{array}{l}1.02 \mathrm{E}+03 \\
3.48 \mathrm{E}+02\end{array}$ & $\begin{array}{l}1.51 \mathrm{E}+03 \\
5.12 \mathrm{E}+02\end{array}$ & $\begin{array}{l}1.54 \mathrm{E}+03 \\
5.23 \mathrm{E}+02\end{array}$ \\
\hline $\begin{array}{l}{ }^{154} \mathrm{Eu}(\mathrm{pCi} / \mathrm{g} \text { at } \mathrm{t}=0) \\
{ }^{154} \mathrm{Eu}(\mathrm{pCi} / \mathrm{g} \text { on } 09 / 27 / 04)\end{array}$ & 8.59 & $\begin{array}{l}\text { n.d. } \\
\text { n.d. }\end{array}$ & $\begin{array}{l}4.81 \mathrm{E}+02 \\
8.79 \mathrm{E}+01\end{array}$ & $\begin{array}{l}8.67 \mathrm{E}+01 \\
1.58 \mathrm{E}+01\end{array}$ & $\begin{array}{l}4.02 \mathrm{E}+02 \\
7.35 \mathrm{E}+01\end{array}$ & $\begin{array}{l}1.38 \mathrm{E}+03 \\
2.53 \mathrm{E}+02\end{array}$ & $\begin{array}{l}1.24 \mathrm{E}+03 \\
2.27 \mathrm{E}+02\end{array}$ & $\begin{array}{l}1.81 \mathrm{E}+03 \\
3.32 \mathrm{E}+02\end{array}$ & $\begin{array}{l}1.84 \mathrm{E}+03 \\
3.37 \mathrm{E}+02\end{array}$ \\
\hline $\begin{array}{l}{ }^{155} \mathrm{Eu}(\mathrm{pCi} / \mathrm{g} \text { at } \mathrm{t}=0) \\
{ }^{155} \mathrm{Eu}(\mathrm{pCi} / \mathrm{g} \text { on } 09 / 27 / 04)\end{array}$ & 4.75 & $\begin{array}{l}\text { n.d. } \\
\text { n.d. }\end{array}$ & $\begin{array}{l}2.14 \mathrm{E}+03 \\
9.89 \mathrm{E}+01\end{array}$ & $\begin{array}{l}4.07 \mathrm{E}+02 \\
1.88 \mathrm{E}+01\end{array}$ & $\begin{array}{l}1.87 \mathrm{E}+03 \\
8.65 \mathrm{E}+01\end{array}$ & $\begin{array}{l}6.24 \mathrm{E}+03 \\
2.88 \mathrm{E}+02\end{array}$ & $\begin{array}{l}5.41 \mathrm{E}+03 \\
2.50 \mathrm{E}+02\end{array}$ & $\begin{array}{l}8.19 \mathrm{E}+03 \\
3.79 \mathrm{E}+02\end{array}$ & $\begin{array}{l}8.32 \mathrm{E}+03 \\
3.85 \mathrm{E}+02\end{array}$ \\
\hline $\begin{array}{l}{ }^{241} \mathrm{Am}(\mathrm{pCi} / \mathrm{g} \text { at } \mathrm{t}=0) \\
{ }^{241} \mathrm{Am}(\mathrm{pCi} / \mathrm{g} \text { on } 09 / 27 / 04)\end{array}$ & 432.7 & $\begin{array}{l}\text { n.d. } \\
\text { n.d. }\end{array}$ & $\begin{array}{l}3.21 \mathrm{E}+01 \\
3.10 \mathrm{E}+01\end{array}$ & $\begin{array}{l}4.54 \mathrm{E}+00 \\
4.39 \mathrm{E}+00\end{array}$ & $\begin{array}{l}2.93 \mathrm{E}+01 \\
2.83 \mathrm{E}+01\end{array}$ & $\begin{array}{l}9.07 \mathrm{E}+01 \\
8.77 \mathrm{E}+01\end{array}$ & $\begin{array}{l}7.56 \mathrm{E}+01 \\
7.31 \mathrm{E}+01\end{array}$ & $\begin{array}{l}1.09 \mathrm{E}+02 \\
1.05 \mathrm{E}+02\end{array}$ & $\begin{array}{l}1.19 \mathrm{E}+02 \\
1.15 \mathrm{E}+02\end{array}$ \\
\hline${ }^{13 /} \mathrm{Cs} /{ }^{152} \mathrm{Eu}$ ratio $($ at $\mathrm{t}=0$ ) & & --- & 50 & 51 & 47 & 46 & 50 & 43 & 44 \\
\hline
\end{tabular}

\begin{tabular}{|c|c|c|c|c|c|c|c|c|c|}
\hline Radionuclide & half-life (yr) & $\begin{array}{c}\text { CH11 } \\
\text { PS1AS 2450, }\end{array}$ & $\begin{array}{c}\text { CH12 } \\
\text { PS1AS comp. }\end{array}$ & $\begin{array}{c}\text { CH14 } \\
\text { PS1ASS 2240' }\end{array}$ & $\begin{array}{c}\text { CH15 } \\
\text { PS1ASS 2286 }\end{array}$ & $\begin{array}{c}\text { CH16.1 } \\
\text { PS1ASS 2292' }\end{array}$ & $\begin{array}{c}\text { CH16.2 } \\
\text { PS1ASS 2292' }\end{array}$ & $\begin{array}{c}\text { CH17 } \\
\text { PS1ASS 2306' }\end{array}$ & $\begin{array}{c}\text { CH18 } \\
\text { PS1ASS 2332' }\end{array}$ \\
\hline $\begin{array}{l}{ }^{60} \mathrm{Co}(\mathrm{pCi} / \mathrm{g} \text { at } \mathrm{t}=0) \\
{ }^{60} \mathrm{Co}(\mathrm{pCi} / \mathrm{g} \text { on 09/27/04) }\end{array}$ & 5.27 & $\begin{array}{l}\text { n.d. } \\
\text { n.d. }\end{array}$ & $\begin{array}{l}6.97 \mathrm{E}+03 \\
4.36 \mathrm{E}+02\end{array}$ & $\begin{array}{l}3.11 \mathrm{E}+01 \\
1.95 \mathrm{E}+00\end{array}$ & $\begin{array}{l}3.45 \mathrm{E}+02 \\
2.16 \mathrm{E}+01\end{array}$ & $\begin{array}{l}5.94 \mathrm{E}+03 \\
3.72 \mathrm{E}+02\end{array}$ & $\begin{array}{l}8.81 \mathrm{E}+02 \\
5.52 \mathrm{E}+01\end{array}$ & $\begin{array}{l}2.14 \mathrm{E}+03 \\
1.34 \mathrm{E}+02\end{array}$ & $\begin{array}{l}2.15 \mathrm{E}+01 \\
1.34 \mathrm{E}+00\end{array}$ \\
\hline $\begin{array}{l}{ }^{125} \mathrm{Sb}(\mathrm{pCi} / \mathrm{g} \text { at } \mathrm{t}=0) \\
{ }^{125} \mathrm{Sb}(\mathrm{pCi} / \mathrm{g} \text { on } 09 / 27 / 04)\end{array}$ & 2.76 & $\begin{array}{l}\text { n.d. } \\
\text { n.d. }\end{array}$ & $\begin{array}{l}4.17 \mathrm{E}+04 \\
2.09 \mathrm{E}+02\end{array}$ & $\begin{array}{l}2.57 \mathrm{E}+03 \\
1.29 \mathrm{E}+01\end{array}$ & $\begin{array}{l}1.63 \mathrm{E}+04 \\
8.15 \mathrm{E}+01\end{array}$ & $\begin{array}{l}4.05 E+04 \\
2.03 E+02\end{array}$ & $\begin{array}{l}9.11 \mathrm{E}+03 \\
4.57 \mathrm{E}+01\end{array}$ & $\begin{array}{l}1.24 \mathrm{E}+04 \\
6.21 \mathrm{E}+01\end{array}$ & $\begin{array}{l}3.72 \mathrm{E}+02 \\
1.86 \mathrm{E}+00\end{array}$ \\
\hline $\begin{array}{l}{ }^{13 /} \mathrm{Cs}(\mathrm{pCi} / \mathrm{g} \text { at } \mathrm{t}=0) \\
{ }^{13 /} \mathrm{Cs}(\mathrm{pCi} / \mathrm{g} \text { on } 09 / 27 / 04)\end{array}$ & 30.07 & $\begin{array}{l}5.00 \mathrm{E}+01 \\
3.08 \mathrm{E}+01\end{array}$ & $\begin{array}{l}5.93 \mathrm{E}+04 \\
3.65 \mathrm{E}+04\end{array}$ & $\begin{array}{l}8.97 \mathrm{E}+03 \\
5.52 \mathrm{E}+03\end{array}$ & $\begin{array}{l}4.43 \mathrm{E}+04 \\
2.73 \mathrm{E}+04\end{array}$ & $\begin{array}{l}6.73 \mathrm{E}+04 \\
4.14 \mathrm{E}+04\end{array}$ & $\begin{array}{l}2.22 \mathrm{E}+04 \\
1.36 \mathrm{E}+04\end{array}$ & $\begin{array}{l}1.78 \mathrm{E}+04 \\
1.10 \mathrm{E}+04\end{array}$ & $\begin{array}{l}2.87 \mathrm{E}+02 \\
1.77 \mathrm{E}+02\end{array}$ \\
\hline $\begin{array}{l}{ }^{152} \mathrm{Eu}(\mathrm{pCi} / \mathrm{g} \text { at } \mathrm{t}=0) \\
{ }^{152} \mathrm{Eu}(\mathrm{pCi} / \mathrm{g} \text { on } 09 / 27 / 04)\end{array}$ & 13.54 & $\begin{array}{l}\text { n.d. } \\
\text { n.d. }\end{array}$ & $\begin{array}{l}1.29 \mathrm{E}+03 \\
4.40 \mathrm{E}+02\end{array}$ & $\begin{array}{l}\text { n.d. } \\
\text { n.d. }\end{array}$ & $\begin{array}{l}6.60 \mathrm{E}+01 \\
2.25 \mathrm{E}+01\end{array}$ & $\begin{array}{l}1.09 \mathrm{E}+03 \\
3.71 \mathrm{E}+02\end{array}$ & $\begin{array}{l}2.12 \mathrm{E}+02 \\
7.22 \mathrm{E}+01\end{array}$ & $\begin{array}{l}4.39 \mathrm{E}+02 \\
1.49 \mathrm{E}+02\end{array}$ & $\begin{array}{l}6.11 \mathrm{E}+01 \\
2.08 \mathrm{E}+01\end{array}$ \\
\hline $\begin{array}{l}{ }^{154} \mathrm{Eu}(\mathrm{pCi} / \mathrm{g} \text { at } \mathrm{t}=0) \\
{ }^{154} \mathrm{Eu}(\mathrm{pCi} / \mathrm{g} \text { on } 09 / 27 / 04)\end{array}$ & 8.59 & $\begin{array}{l}\text { n.d. } \\
\text { n.d. }\end{array}$ & $\begin{array}{l}1.57 \mathrm{E}+03 \\
2.87 \mathrm{E}+02\end{array}$ & $\begin{array}{l}\text { n.d. } \\
\text { n.d. }\end{array}$ & $\begin{array}{l}6.29 \mathrm{E}+01 \\
1.15 \mathrm{E}+01\end{array}$ & $\begin{array}{l}1.37 \mathrm{E}+03 \\
2.51 \mathrm{E}+02\end{array}$ & $\begin{array}{l}1.99 \mathrm{E}+02 \\
3.65 \mathrm{E}+01\end{array}$ & $\begin{array}{l}4.90 \mathrm{E}+02 \\
8.95 \mathrm{E}+01\end{array}$ & $\begin{array}{l}\text { n.d. } \\
\text { n.d. }\end{array}$ \\
\hline $\begin{array}{l}{ }^{155} \mathrm{Eu}(\mathrm{pCi} / \mathrm{g} \text { at } \mathrm{t}=0) \\
{ }^{155} \mathrm{Eu}(\mathrm{pCi} / \mathrm{g} \text { on } 09 / 27 / 04)\end{array}$ & 4.75 & $\begin{array}{l}\text { n.d. } \\
\text { n.d. }\end{array}$ & $\begin{array}{l}6.78 \mathrm{E}+03 \\
3.13 \mathrm{E}+02\end{array}$ & $\begin{array}{l}\text { n.d. } \\
\text { n.d. }\end{array}$ & $\begin{array}{l}2.82 \mathrm{E}+02 \\
1.30 \mathrm{E}+01\end{array}$ & $\begin{array}{l}6.13 E+03 \\
2.83 E+02\end{array}$ & $\begin{array}{l}7.38 \mathrm{E}+02 \\
3.41 \mathrm{E}+01\end{array}$ & $\begin{array}{l}2.42 \mathrm{E}+03 \\
1.12 \mathrm{E}+02\end{array}$ & $\begin{array}{l}\text { n.d. } \\
\text { n.d. }\end{array}$ \\
\hline $\begin{array}{l}{ }^{241} \mathrm{Am}(\mathrm{pCi} / \mathrm{g} \text { at } \mathrm{t}=0) \\
{ }^{241} \mathrm{Am}(\mathrm{pCi} / \mathrm{g} \text { on 09/27/04) }\end{array}$ & 432.7 & $\begin{array}{l}\text { n.d. } \\
\text { n.d. }\end{array}$ & $\begin{array}{l}1.07 \mathrm{E}+02 \\
1.03 \mathrm{E}+02\end{array}$ & $\begin{array}{l}\text { n.d. } \\
\text { n.d. }\end{array}$ & $\begin{array}{l}\text { n.d. } \\
\text { n.d. }\end{array}$ & $\begin{array}{l}\text { n.d. } \\
\text { n.d. }\end{array}$ & $\begin{array}{l}\text { n.d. } \\
\text { n.d. }\end{array}$ & $\begin{array}{l}4.08 \mathrm{E}+01 \\
3.94 \mathrm{E}+01\end{array}$ & $\begin{array}{l}\text { n.d. } \\
\text { n.d. }\end{array}$ \\
\hline${ }^{13 /} \mathrm{Cs} /{ }^{152}$ Eu ratio (at $\mathrm{t}=0$ ) & & --- & 46 & --- & 670 & 62 & 104 & 41 & 5 \\
\hline
\end{tabular}

n.d. $=$ not detected 
Sample CH18 (PS1ASS $2232 \mathrm{ft}$ ) has a ${ }^{137} \mathrm{Cs} /{ }^{152} \mathrm{Eu}$ activity ratio of 5, and is the only sample that plots below the linear trend in Figure 4.1. $\mathrm{CH} 18$ is a porous mixture of varicolored glass that has undergone fairly extensive hydrothermal alteration, resulting in the development of secondary zeolite minerals on vesicle surfaces. We infer that the low $\mathrm{Cs} / \mathrm{Eu}$ ratio in this sample may reflect the preferential leaching of cesium ions from the glass matrix. Europium should be less mobile than cesium during hydrothermal alteration due to its smaller ionic radius and higher valence state.

${ }^{241} \mathrm{Am}$ was not detected in the four samples with 'anomalous' $\mathrm{Cs} / \mathrm{Eu}$ activity ratios, but is present in all of the samples that plot along the line in Figure 4.1. Americium is a refractory element and should be strongly concentrated in the dark melt glass puddle that forms during the earliest stages of cooling. The absence of ${ }^{241} \mathrm{Am}$ in $\mathrm{CH} 16.1$ is unusual given the high europium activity in this sample (IAEA, 1998, estimates that $95 \%$ of both isotopes will be partitioned into the melt glass). This may suggest that the $\mathrm{CH} 16$ glass formed from post-detonation melting of material that fell into the puddle glass soon after the explosion, as opposed to glass that formed during the explosion itself.

\subsection{Radionuclide Partitioning}

Gamma spectroscopy data were acquired for activation products $\left({ }^{60} \mathrm{Co},{ }^{152} \mathrm{Eu},{ }^{154} \mathrm{Eu}\right)$, fission products $\left({ }^{125} \mathrm{Sb},{ }^{137} \mathrm{Cs},{ }^{155} \mathrm{Eu}\right)$, and the actinide ${ }^{241} \mathrm{Am}$ (Table 4.1). Partitioning of these nuclides between the melt glass, rubble and groundwater was evaluated using three different methods described in Section 1.5. The calculations are based on (1) the average Area 19 inventory from Bowen et al. (2001); (2) melt glass, rubble, and groundwater mass estimates from Zhao et al. (2008); and (3) fission product mass yield data from England and Rider (1994). Each approach has limitations, and some approaches cannot be used for certain nuclides. For example, the Bowen inventory includes only those isotopes with half-lives greater than 10 years (with the exception of ${ }^{154} \mathrm{Eu}$, with a half-life of 8.59 years). This means that data are unavailable for ${ }^{60} \mathrm{Co},{ }^{125} \mathrm{Sb}$, and ${ }^{155} \mathrm{Eu}$ in the Bowen report. The method described in Zhao et al. (2008) can be applied to any of the nuclides for which data are available, but the England and Rider (1994) data can only be used to evaluate fission product partitioning.

Table 4.2 summarizes the melt glass partitioning values calculated from the average Area 19 inventory in Bowen et al. (2001), decay corrected to time zero for the Chancellor test. The average concentration of each radionuclide in the melt glass (in atoms/gram) was calculated using the average of the five highest activity samples that plot along the linear trend in Figure 4.1 (samples $\mathrm{CH}-05,-06,-07,-09$, and -12). This average concentration was then multiplied by the total mass of the melt glass $\left(1.43 \times 10^{11} \mathrm{~g}\right)$ to obtain an estimate of the total number of atoms of each nuclide in the melt glass. Dividing this value by the average Area 19 inventory gives the partitioning estimate for the melt glass. As a first order approximation, the rubble fraction is equal to the difference between the total inventory and the melt glass fraction. We will discuss the groundwater fraction in the section that follows. 
Table 4.2 Melt glass partitioning estimates calculated using the average NNSS Area 19 radionuclide inventory from Bowen et al. (2001)

\begin{tabular}{|c|c|c|c|c|c|}
\hline Radionuclide & $\begin{array}{c}\text { Average } \\
\text { Area 19 } \\
\text { inventory } \\
\text { (atoms) }^{*}\end{array}$ & $\begin{array}{c}\text { Average } \\
\text { concentration in } \\
\text { dark melt glass } \\
(\mathbf{a t} / \mathbf{g})^{* *}\end{array}$ & $\begin{array}{c}\text { Total } \\
\text { concentration in } \\
\text { dark melt glass } \\
\text { (atoms) }\end{array}$ & $\begin{array}{c}\text { Calculated } \\
\text { melt glass } \\
\text { partitioning } \\
(\%)\end{array}$ & $\begin{array}{c}\text { IAEA } \\
\text { melt glass } \\
\text { partitioning } \\
(\%)\end{array}$ \\
\hline${ }^{137} \mathrm{Cs}$ & $1.209 \times 10^{24}$ & $2.996 \times 10^{12}$ & $4.285 \times 10^{23}$ & 35.5 & $25-40$ \\
${ }^{152} \mathrm{Eu}$ & $1.160 \times 10^{22}$ & $2.963 \times 10^{10}$ & $4.237 \times 10^{21}$ & 36.5 & 95 \\
${ }^{154} \mathrm{Eu}$ & $5.930 \times 10^{21}$ & $2.272 \times 10^{10}$ & $3.248 \times 10^{21}$ & 54.8 & 95 \\
${ }^{241} \mathrm{Am}$ & $2.668 \times 10^{22}$ & $7.305 \times 10^{10}$ & $1.045 \times 10^{22}$ & 39.2 & 98 \\
\hline
\end{tabular}

Only ${ }^{137} \mathrm{Cs}$ has a melt glass partitioning value that is consistent with the IAEA values (last column in Table 4.2). The partitioning estimates for the refractory nuclides ${ }^{152} \mathrm{Eu}$, ${ }^{154} \mathrm{Eu}$, and ${ }^{241} \mathrm{Am}$ are $\sim 1.7$ to 2.6 times lower than the corresponding IAEA values. Assuming the IAEA values are approximately correct, this suggests the average Area 19 inventory for these nuclides is too high to be usefully applied to the Chancellor test. The calculation could be refined somewhat by re-distributing the Bowen inventory according to cavity volume, using the announced yields for Area 19 tests found in DOE/NV-209. This might change the absolute values of the partitioning estimates, but the relative differences between nuclides would scale proportionally. Unfortunately, there is little that can be done to improve this estimate without using the classified inventory data for the Chancellor test found in Miller et al. (2002).

Next we will calculate partitioning values using the mass estimates for the Chancellor melt glass, rubble, and groundwater found in Zhao et al. (2008). These data were originally used to assess the partitioning of ${ }^{99} \mathrm{Tc}$ and ${ }^{129} \mathrm{I}$, as discussed in Chapter 6 of this report. The total mass of the melt glass, rubble, and groundwater was estimated to be $1.43 \times 10^{11}, 1.52 \times 10^{12}$, and $1.80 \times 10^{11} \mathrm{~g}$, respectively, based on cavity volume, material density, and porosity calculations (Zhao et al., 2008). We will again assume the radionuclide concentration in the melt glass is the average of the five highest activity glass samples $(\mathrm{CH}-05,-06,-07,-09$, and -12). The 'rubble' end-member will be represented by sample $\mathrm{CH}-03$, which consists of $\sim 90 \%$ rhyolite and $10 \%$ light brown glass and contains low-level concentrations of all the gamma-emitting radionuclides that were detected in the dark melt glasses. The data used in the calculation and the resulting partitioning values are summarized in Table 4.3.

The calculated melt glass-rubble partitioning values show remarkable consistency among all radionuclides (Table 4.3). Melt glass values range from $58.3 \%$ for ${ }^{137} \mathrm{Cs}$ to $67.4 \%$ for ${ }^{241} \mathrm{Am}$. This narrow range of overlapping values for both volatile and refractory nuclides suggests there is a problem with this calculation. Uncertainty in the mass estimates for 
the rubble and groundwater may contribute to the problem, but the key issue lies in how the radionuclide inventory for the rubble is represented.

Table 4.3 Radionuclide partitioning between melt glass, rubble, and groundwater using the approach described by Zhao et al. (2008). The melt glass composition is represented by the average of five dark glass samples $(\mathrm{CH}-05,-06,-07,-09$, and -12) and the rubble concentration is represented by sample $\mathrm{CH}-03$.

\begin{tabular}{|c|c|c|c|}
\hline Radionuclide & $\begin{array}{c}\text { Concentration in dark } \\
\text { melt glass (at/g) }\end{array}$ & $\begin{array}{c}\text { Concentration in rubble } \\
\text { (at/g) }\end{array}$ & $\begin{array}{c}\text { Concentration in } \\
\text { groundwater (at/g) }\end{array}$ \\
\hline${ }^{60} \mathrm{Co}$ & $6.138 \times 10^{10}$ & $3.512 \times 10^{9}$ & $3.257 \times 10^{6}$ \\
${ }^{125} \mathrm{Sb}$ & $1.898 \times 10^{11}$ & $1.030 \times 10^{10}$ & $3.363 \times 10^{9}$ \\
${ }^{137} \mathrm{Cs}$ & $2.996 \times 10^{12}$ & $2.008 \times 10^{11}$ & $4.371 \times 10^{9}$ \\
${ }^{152} \mathrm{Eu}$ & $2.963 \times 10^{10}$ & $1.764 \times 10^{9}$ & $2.225 \times 10^{6}$ \\
${ }^{154} \mathrm{Eu}$ & $2.272 \times 10^{10}$ & $1.254 \times 10^{9}$ & $1.044 \times 10^{6}$ \\
${ }^{155} \mathrm{Eu}$ & $5.556 \times 10^{10}$ & $3.236 \times 10^{9}$ & $6.287 \times 10^{6}$ \\
${ }^{241} \mathrm{Am}$ & $7.305 \times 10^{10}$ & $3.325 \times 10^{9}$ & n.d. \\
\hline & Total concentration in & Total concentration in & Total concentration in \\
& melt glass (atoms) * & rubble (atoms)* & groundwater (atoms) * \\
\hline & $8.777 \times 10^{21}$ & $5.339 \times 10^{21}$ & $5.862 \times 10^{17}$ \\
${ }^{60} \mathrm{Co}$ & $2.715 \times 10^{22}$ & $1.566 \times 10^{22}$ & $6.054 \times 10^{20}$ \\
${ }^{125} \mathrm{Sb}$ & $4.285 \times 10^{23}$ & $3.052 \times 10^{23}$ & $7.867 \times 10^{20}$ \\
${ }^{137} \mathrm{Cs}$ & $4.237 \times 10^{21}$ & $2.682 \times 10^{21}$ & $4.005 \times 10^{17}$ \\
${ }^{152} \mathrm{Eu}$ & $3.248 \times 10^{21}$ & $1.906 \times 10^{21}$ & $1.879 \times 10^{17}$ \\
${ }^{154} \mathrm{Eu}$ & $7.945 \times 10^{21}$ & $4.919 \times 10^{21}$ & $1.132 \times 10^{18}$ \\
${ }^{155} \mathrm{Eu}$ & $1.045 \times 10^{22}$ & $5.053 \times 10^{21}$ & n.d. \\
${ }^{241} \mathrm{Am}$ & Calculated melt glass & Calculated rubble & Calculated groundwater \\
partitioning (\%)
\end{tabular}

Sample $\mathrm{CH}-03$ was used to represent the rubble inventory because it is the only 'rubblelike' sample that contains measurable amounts of all the radionuclides of interest. However, the presence of detectable amounts of refractory species such as Eu and Am is probably atypical for most of the rubble. The upper portion of the cavity and chimney is more likely to be enriched in volatile fission products such as ${ }^{125} \mathrm{Sb}$ and ${ }^{137} \mathrm{Cs}$, and strongly depleted in refractory nuclides. $\mathrm{CH}-03$ was collected from a location very near the bottom of the cavity, and probably represents only the rubble that is present in this region. Other samples may be more characteristic of the bulk composition of the rubble (notably $\mathrm{CH}-14$ and $\mathrm{CH}-01$ ), but simply averaging these with $\mathrm{CH}-03$ will not necessarily yield a representative bulk rubble composition. A better estimate of the rubble inventory can be obtained using a weighted average, which accounts for the heterogeneous 
radionuclide content of the rubble by factoring in our assumptions regarding the relative abundance of volatile and refractory nuclides in this material.

Zhao et al. (2008) estimated the total mass of rubble to be $\sim 10$ times that of the melt glass zone. We will assume that sample $\mathrm{CH}-03$ is representative of the rubble within the bottom $10 \%$ of the cavity, where refractory nuclides are concentrated. The remaining $90 \%$ of the rubble is assumed to have a composition like that of $\mathrm{CH}-14$, which is enriched in volatile radionuclides $\left({ }^{125} \mathrm{Sb}\right.$ and $\left.{ }^{137} \mathrm{Cs}\right)$, and contains only minor amounts of refractory nuclides $\left({ }^{60} \mathrm{Co}\right)$. Using this 'mixture' of $10 \% \mathrm{CH}-03$ and $90 \% \mathrm{CH}-14$ to represent the rubble inventory, the partitioning values in Table 4.3 were recalculated. The inventories for the melt glass and groundwater, and the total mass of each phase were not changed in the new calculation. The results are summarized in Table 4.4.

Table 4.4 Revised radionuclide partitioning values between melt glass, rubble, and groundwater using the same approach as in Table 4.3. In this case, the bulk radionuclide inventory for the rubble is represented by $90 \% \mathrm{CH}-14$ and $10 \% \mathrm{CH}-03$; all other parameters are unchanged.

\begin{tabular}{|c|c|c|c|}
\hline Radionuclide & $\begin{array}{l}\text { Concentration in dark } \\
\text { melt glass (at } / \mathrm{g})\end{array}$ & $\begin{array}{l}\text { Concentration in rubble } \\
\text { (at } / g)\end{array}$ & $\begin{array}{l}\text { Concentration in } \\
\text { groundwater (at/g) }\end{array}$ \\
\hline \multirow[t]{2}{*}{$\begin{array}{l}{ }^{60} \mathrm{Co} \\
{ }^{125} \mathrm{Sb} \\
{ }^{137} \mathrm{Cs} \\
{ }^{152} \mathrm{Eu} \\
{ }^{154} \mathrm{Eu} \\
{ }^{155} \mathrm{Eu} \\
{ }^{241} \mathrm{Am}\end{array}$} & $\begin{array}{l}6.138 \times 10^{10} \\
1.898 \times 10^{11} \\
2.996 \times 10^{12} \\
2.963 \times 10^{10} \\
2.272 \times 10^{10} \\
5.556 \times 10^{10} \\
7.305 \times 10^{10}\end{array}$ & $\begin{array}{l}5.987 \times 10^{8} \\
1.166 \times 10^{10} \\
4.292 \times 10^{11} \\
1.764 \times 10^{8} \\
1.254 \times 10^{8} \\
3.236 \times 10^{8} \\
3.325 \times 10^{8}\end{array}$ & $\begin{array}{c}3.257 \times 10^{6} \\
3.363 \times 10^{9} \\
4.371 \times 10^{9} \\
2.225 \times 10^{6} \\
1.044 \times 10^{6} \\
6.287 \times 10^{6} \\
\text { n.d. }\end{array}$ \\
\hline & $\begin{array}{l}\text { Total concentration in } \\
\text { melt glass (atoms) * }\end{array}$ & $\begin{array}{l}\text { Total concentration in } \\
\text { rubble (atoms) * }\end{array}$ & $\begin{array}{l}\text { Total concentration in } \\
\text { groundwater (atoms) * }\end{array}$ \\
\hline \multirow[t]{2}{*}{$\begin{array}{l}{ }^{60} \mathrm{Co} \\
{ }^{125} \mathrm{Sb} \\
{ }^{137} \mathrm{Cs} \\
{ }^{152} \mathrm{Eu} \\
{ }^{154} \mathrm{Eu} \\
{ }^{155} \mathrm{Eu} \\
{ }^{241} \mathrm{Am}\end{array}$} & $\begin{array}{l}8.777 \times 10^{21} \\
2.715 \times 10^{22} \\
4.285 \times 10^{23} \\
4.237 \times 10^{21} \\
3.248 \times 10^{21} \\
7.945 \times 10^{21} \\
1.045 \times 10^{22}\end{array}$ & $\begin{array}{l}9.100 \times 10^{20} \\
1.722 \times 10^{22} \\
6.524 \times 10^{23} \\
2.682 \times 10^{20} \\
1.906 \times 10^{20} \\
4.919 \times 10^{20} \\
5.053 \times 10^{20}\end{array}$ & $\begin{array}{c}5.862 \times 10^{17} \\
6.054 \times 10^{20} \\
7.867 \times 10^{20} \\
4.005 \times 10^{17} \\
1.879 \times 10^{17} \\
1.132 \times 10^{18} \\
\text { n.d. }\end{array}$ \\
\hline & $\begin{array}{l}\text { Calculated melt glass } \\
\text { partitioning }(\%)\end{array}$ & $\begin{array}{l}\text { Calculated rubble } \\
\text { partitioning (\%) }\end{array}$ & $\begin{array}{l}\text { Calculated groundwater } \\
\text { partitioning (\%) }\end{array}$ \\
\hline $\begin{array}{l}{ }^{60} \mathrm{Co} \\
{ }^{125} \mathrm{Sb} \\
{ }^{137} \mathrm{Cs} \\
{ }^{152} \mathrm{Eu} \\
{ }^{154} \mathrm{Eu} \\
{ }^{155} \mathrm{Eu} \\
{ }^{241} \mathrm{Am}\end{array}$ & $\begin{array}{l}90.6 \\
59.7 \\
39.6 \\
94.0 \\
94.5 \\
94.2 \\
95.4\end{array}$ & $\begin{array}{c}9.4 \\
39.0 \\
60.3 \\
6.0 \\
5.5 \\
5.8 \\
4.6\end{array}$ & $\begin{array}{c}0.006 \\
1.33 \\
0.072 \\
0.009 \\
0.005 \\
0.013 \\
\text { n.d. }\end{array}$ \\
\hline
\end{tabular}


The revised partitioning values in Table 4.4 are remarkably consistent with the IAEA values for $\mathrm{Eu}, \mathrm{Am}$ and Cs. Approximately $95 \%$ of the ${ }^{152} \mathrm{Eu},{ }^{154} \mathrm{Eu},{ }^{155} \mathrm{Eu}$, and ${ }^{241} \mathrm{Am}$ is estimated to be in the melt glass, and $\sim 5 \%$ is in the rubble. For ${ }^{137} \mathrm{Cs}$, the melt glassrubble partitioning is $40-60$, and for the refractory activation product ${ }^{60} \mathrm{Co}$, the ratio is approximately $90-10$. The predicted amount of ${ }^{125} \mathrm{Sb}$ in the melt glass $(60 \%)$ is somewhat higher than expected for a volatile nuclide, but this simply reflects the fact that a significant fraction of the mass 125 fission chain is 'born' as indium and tin, both of which are chemically more refractory than antimony.

The results in Table 4.4 indicate the amount of radioactivity in the groundwater is quite small compared to the melt glass and rubble fractions. Only ${ }^{125} \mathrm{Sb}$ has a groundwater concentration that exceeds $1 \%$ of its inventory. The next highest concentration in water $\left({ }^{137} \mathrm{Cs}\right)$ represents $<0.1 \%$ of the nuclide inventory. In general, groundwater partitioning is difficult to estimate due to uncertainty in the amount of radioactivity transported beyond the cavity boundary. However, the water temperature within the Chancellor test cavity is still very warm 21 years after the event, which may imply little groundwater turnover, and by extension, little contaminant migration.

An independent estimate of the melt glass partitioning values for fission products can be obtained using the fission chain yield data reported in England and Rider (1994), as described in Section 1.5. This approach is more limited in scope than the preceding calculations, but provides some useful comparative information. The data used in the calculation and the resulting partitioning estimates are summarized in Table 4.5. The middle column of Table 4.5 shows the range in fission chain yields (in \%) for ${ }^{125} \mathrm{Sb}$, ${ }^{137} \mathrm{Cs}$, and ${ }^{155} \mathrm{Eu}$ as a function of neutron energy (thermal, fission, or high energy) and actinide fuel type $\left({ }^{235} \mathrm{U}\right.$ or $\left.{ }^{239} \mathrm{Pu}\right)$. The fission chain yields were converted to total number of atoms produced from 143 of yield (fourth column from the left) using the fissions per kiloton yield conversions for $\mathrm{U}$ and $\mathrm{Pu}$ (see Section 1.5). The average number of atoms measured in the melt glass is then divided by the theoretical number of atoms from the fission chain yield to obtain a partitioning value.

For ${ }^{125} \mathrm{Sb}$ and ${ }^{155} \mathrm{Eu}$, the calculated melt glass fractions show wide variations with fuel type and neutron energy (Table 4.5) that sometimes exceeds physical limits (i.e. values $>100 \%$ ). This is because the fission yields for these nuclides are strongly dependent on neutron energy. For example, the ${ }^{125} \mathrm{Sb}$ fission yield for high energy neutron reactions on ${ }^{235} \mathrm{U}$ is 43 times greater than that for thermal neutrons $(1.4605 \%$ vs. $0.0340 \%)$. The true neutron energy spectrum of the device encompasses a broad range of energies that can be approximated by a linear combination of the thermal, fission, and high energy neutron groups. In the absence of device-specific neutron spectrum data, it is not possible to reliably estimate melt glass partitioning values for ${ }^{125} \mathrm{Sb}$ and ${ }^{155} \mathrm{Eu}$ using this approach.

In contrast, ${ }^{137} \mathrm{Cs}$ shows a fairly tight clustering of data with an average melt glass partitioning value of $(36.6 \pm 6.2) \%$ ( $1 \sigma$ standard deviation). The fission yield of ${ }^{137} \mathrm{Cs}$ is far less sensitive to differences in neutron energy and fuel type because it is a 'peak' fission product on the well-known double-humped mass yield distribution curve 
(Friedlander et al., 1981). In comparison, ${ }^{125} \mathrm{Sb}$ is located in the 'valley' between the two humps, and ${ }^{155} \mathrm{Eu}$ is located on the high mass 'wing' of the distribution curve. The variation in fission product mass-yields for different fuels and energies is much smaller at the 'peaks' as compared to the 'valley' and 'wing' regions. The ${ }^{137} \mathrm{Cs}$ partitioning value obtained from the fission chain yield data lies within the reported range of IAEA values (25-40\%). Moreover, it is consistent with the values determined from the average Area 19 Bowen inventory (35.5\%; Table 4.2), and weighted average rubble composition (39.6\%; Table 4.4). Most of the remaining ${ }^{137} \mathrm{Cs}$ inventory is inferred to be distributed within the rubble zone, with only a small fraction associated with the groundwater.

Table 4.5 Percentage of the fission products ${ }^{125} \mathrm{Sb},{ }^{137} \mathrm{Cs}$, and ${ }^{155} \mathrm{Eu}$ in melt glass based on fission yield data from England and Rider (1994) for ${ }^{235} U$ and ${ }_{239} \mathrm{Pu}$ at different neutron energies.

\begin{tabular}{|c|c|c|c|c|}
\hline $\begin{array}{l}\text { Fission } \\
\text { Product } \\
\text { (fuel type) }\end{array}$ & Neutron Energy & $\begin{array}{c}\text { Fission Yield } \\
(\%)\end{array}$ & $\begin{array}{l}\text { Total \# } \\
\text { atoms } \\
\text { produced }\end{array}$ & $\begin{array}{l}\text { Proportion of } \\
\text { atoms in melt } \\
\text { glass (\%) }\end{array}$ \\
\hline \multicolumn{5}{|c|}{$\begin{array}{l}{ }^{125} \mathrm{Sb} \\
\text { average melt glass concentration }=1.898 \mathrm{E}+11 \mathrm{at} / \mathrm{g} \\
\text { total atoms in melt glass }=2.715 \mathrm{E}+22 \text { atoms }\end{array}$} \\
\hline $\begin{array}{l}(\mathrm{U}-235) \\
(\mathrm{U}-235) \\
(\mathrm{U}-235)\end{array}$ & $\begin{array}{l}\text { Thermal } \\
\text { Fission spectrum } \\
\text { High Energy }\end{array}$ & $\begin{array}{l}0.0340 \\
0.0680 \\
1.4605\end{array}$ & $\begin{array}{l}7.064 \mathrm{E}+21 \\
1.413 \mathrm{E}+22 \\
3.033 \mathrm{E}+23\end{array}$ & $\begin{array}{c}384.3 \\
192.2 \\
9.0\end{array}$ \\
\hline $\begin{array}{l}\text { (Pu-239) } \\
\text { (Pu-239) } \\
\text { (Pu-239) }\end{array}$ & $\begin{array}{l}\text { Thermal } \\
\text { Fission spectrum } \\
\text { High Energy }\end{array}$ & $\begin{array}{l}0.1117 \\
0.1778 \\
1.9549\end{array}$ & $\begin{array}{l}2.243 \mathrm{E}+22 \\
3.573 \mathrm{E}+22 \\
3.928 \mathrm{E}+23\end{array}$ & $\begin{array}{c}121.0 \\
76.0 \\
6.9\end{array}$ \\
\hline \multicolumn{5}{|c|}{$\begin{array}{l}{ }^{137} \text { Cs } \\
\text { average melt glass concentration }=2.996 \mathrm{E}+12 \mathrm{at} / \mathrm{g} \\
\text { total atoms in melt glass }=4.285 \mathrm{E}+23 \text { atoms }\end{array}$} \\
\hline $\begin{array}{l}(U-235) \\
(U-235) \\
(U-235)\end{array}$ & $\begin{array}{l}\text { Thermal } \\
\text { Fission spectrum } \\
\text { High Energy }\end{array}$ & $\begin{array}{l}6.1889 \\
6.2216 \\
4.9488\end{array}$ & $\begin{array}{l}1.285 \mathrm{E}+24 \\
1.292 \mathrm{E}+24 \\
1.028 \mathrm{E}+24\end{array}$ & $\begin{array}{l}33.3 \\
33.2 \\
41.7\end{array}$ \\
\hline $\begin{array}{l}\text { (Pu-239) } \\
\text { (Pu-239) } \\
\text { (Pu-239) }\end{array}$ & $\begin{array}{l}\text { Thermal } \\
\text { Fission spectrum } \\
\text { High Energy }\end{array}$ & $\begin{array}{l}6.6138 \\
6.5902 \\
4.5458\end{array}$ & $\begin{array}{l}1.329 \mathrm{E}+24 \\
1.324 \mathrm{E}+24 \\
9.133 \mathrm{E}+23\end{array}$ & $\begin{array}{l}32.2 \\
32.4 \\
46.9\end{array}$ \\
\hline \multicolumn{5}{|c|}{$\begin{array}{l}{ }^{155} \mathrm{Eu} \\
\text { average melt glass concentration }=5.556 \mathrm{E}+10 \text { at } / \mathrm{g} \\
\text { total atoms in melt glass }=7.945 \mathrm{E}+21 \text { atoms }\end{array}$} \\
\hline $\begin{array}{l}(\mathrm{U}-235) \\
(\mathrm{U}-235) \\
(\mathrm{U}-235)\end{array}$ & $\begin{array}{l}\text { Thermal } \\
\text { Fission spectrum } \\
\text { High Energy }\end{array}$ & $\begin{array}{l}0.0321 \\
0.0394 \\
0.0787\end{array}$ & $\begin{array}{l}6.673 \mathrm{E}+21 \\
8.196 \mathrm{E}+21 \\
1.635 \mathrm{E}+22\end{array}$ & $\begin{array}{c}119.1 \\
96.9 \\
48.6\end{array}$ \\
\hline $\begin{array}{l}\text { (Pu-239) } \\
\text { (Pu-239) } \\
\text { (Pu-239) }\end{array}$ & $\begin{array}{l}\text { Thermal } \\
\text { Fission spectrum } \\
\text { High Energy }\end{array}$ & $\begin{array}{l}0.1657 \\
0.2088 \\
0.2332\end{array}$ & $\begin{array}{l}3.330 \mathrm{E}+22 \\
4.196 \mathrm{E}+22 \\
4.684 \mathrm{E}+22\end{array}$ & $\begin{array}{l}23.9 \\
18.9 \\
17.0\end{array}$ \\
\hline
\end{tabular}




\subsection{Comparison with Groundwater Data}

Water-rock activity ratios afford insight into the relative proportion of the total inventory that is present in groundwater. Water-rock ratios were calculated by dividing the $\mathrm{pCi} / \mathrm{g}$ activity in the pumped cavity fluid sample by that of each core sample, assuming a water density of $1 \mathrm{~g} / \mathrm{cm}^{3}$. The results show the range in abundance of a radionuclide in equal masses of each material. It is assumed that the measured gamma activities in the water are representative of the volumetric average within the cavity fluid.

Note that these ratios effectively represent the water-rock partitioning at the time of cavity fluid sampling (27 Sept 2004) rather than the initial partitioning conditions. Whereas glass-rubble partitioning is determined during the first minutes after the test, the hydrologic source term slowly evolves over time. Only highly volatile radionuclides (such as ${ }^{3} \mathrm{H}$ and ${ }^{14} \mathrm{C}$ ) are expected to be immediately incorporated into a condensing aqueous phase at early times.

Table 4.6 summarizes the water-rock activity ratios for ${ }^{60} \mathrm{Co},{ }^{125} \mathrm{Sb},{ }^{137} \mathrm{Cs},{ }^{152} \mathrm{Eu},{ }^{154} \mathrm{Eu}$ and ${ }^{155} \mathrm{Eu}$. Activity ratios were calculated for both the dark melt glass $(\mathrm{CH}-05,-06,-07$, $-09,-12$, and -16.1) and rubble/light-colored glass (all remaining samples). The mean and standard deviation are reported along with the range in activity ratios (maximum and minimum values) for each radionuclide. In general, the mean water-rock ratios are approximately 1 to 2 orders of magnitude lower for the dark melt glass as compared with the rubble. Not surprisingly, the refractory radionuclides $\left({ }^{60} \mathrm{Co}\right.$ and the Eu isotopes) tend to have lower water-rock ratios than the more volatile nuclides $\left({ }^{125} \mathrm{Sb}\right.$ and $\left.{ }^{137} \mathrm{Cs}\right)$. Note also that the standard deviation tends to be much smaller for the dark melt glass than for the rubble, which reflects the fact that the rubble shows a much broader range in activities.

Table 4.6 Water-rock activity ratios for gamma-emitting radionuclides

\begin{tabular}{|l|c|c|c|c|c|c|}
\hline & ${ }^{60} \mathbf{C o}$ & ${ }^{125} \mathbf{S b}$ & ${ }^{137} \mathbf{C s}$ & ${ }^{152} \mathrm{Eu}$ & ${ }^{154} \mathrm{Eu}$ & ${ }^{155} \mathrm{Eu}$ \\
\hline Dark Melt Glass & & & & & & \\
mean & $5.54 \mathrm{E}-05$ & $1.79 \mathrm{E}-02$ & $1.45 \mathrm{E}-03$ & $7.89 \mathrm{E}-05$ & $4.79 \mathrm{E}-05$ & $1.18 \mathrm{E}-04$ \\
standard deviation (\%) & 16.2 & 14.5 & 12.6 & 16.7 & 15.9 & 16.8 \\
minimum & $4.54 \mathrm{E}-05$ & $1.51 \mathrm{E}-02$ & $1.28 \mathrm{E}-03$ & $6.35 \mathrm{E}-05$ & $3.91 \mathrm{E}-05$ & $9.45 \mathrm{E}-05$ \\
maximum & $6.71 \mathrm{E}-05$ & $2.18 \mathrm{E}-02$ & $1.69 \mathrm{E}-03$ & $9.54 \mathrm{E}-05$ & $5.81 \mathrm{E}-05$ & $1.45 \mathrm{E}-04$ \\
& & & & & & \\
Rubble & & & & & & \\
mean & $3.98 \mathrm{E}-03$ & $3.56 \mathrm{E}-01$ & $2.23 \mathrm{E}-01$ & $7.93 \mathrm{E}-04$ & $4.70 \mathrm{E}-04$ & $1.15 \mathrm{E}-03$ \\
standard deviation (\%) & 166.3 & 183.4 & 240.4 & 78.4 & 90.0 & 88.2 \\
minimum & $1.71 \mathrm{E}-04$ & $4.46 \mathrm{E}-02$ & $1.95 \mathrm{E}-03$ & $2.22 \mathrm{E}-04$ & $1.47 \mathrm{E}-04$ & $3.25 \mathrm{E}-04$ \\
maximum & $1.71 \mathrm{E}-02$ & $1.95 \mathrm{E}+00$ & $1.72 \mathrm{E}+00$ & $1.60 \mathrm{E}-03$ & $1.15 \mathrm{E}-03$ & $2.79 \mathrm{E}-03$ \\
\hline
\end{tabular}


Cobalt-60 shows a mean water-rock activity ratio of $5.54 \times 10^{-5}$ for the dark glass, and $3.98 \times 10^{-3}$ for the rubble. In other words, compared to the dark glass, only $\sim 0.006 \%$ of the ${ }^{60} \mathrm{Co}$ source term is dissolved in groundwater (on an equal mass basis). For the rubble, this value is $0.4 \%$. Water-rock ratios in the rubble vary by a factor of 100 , but only by a factor of 1.5 in the dark glass (Table 4.6). Cobalt is soluble as the $\mathrm{Co}^{2+}$ ion and as the hydrolytic species $\mathrm{Co}(\mathrm{OH})_{2}$ under slightly alkaline $\mathrm{pH}$ conditions like those found in the Chancellor test cavity (cf. Krupka and Serne, 2002). The sorption of cobalt to mineral surfaces is largely controlled by the presence of iron and manganese oxides and clay minerals (e.g. Chen and Hayes, 1999; Gunnarsson et al., 2000; Dyer et al., 2000). The high sorption affinity of $\mathrm{Co}^{2+}$ in the presence of these minerals suggests that ${ }^{60} \mathrm{Co}$ transport will be minimal except in the presence of Fe-Mn oxide or clay colloids.

The europium isotopes have mean water-rock activity ratios ranging from $0.005 \%$ to $0.01 \%$ for the dark glass, and $0.05 \%$ to $0.1 \%$ for the rubble. As with ${ }^{60} \mathrm{Co}$, the europium isotopes are strongly concentrated in the solid phase relative to the groundwater. The average activity ratio is somewhat higher for the fission product ${ }^{155} \mathrm{Eu}$ as compared to the activation products ${ }^{152} \mathrm{Eu}$ and ${ }^{154} \mathrm{Eu}$, which may indicate ${ }^{155} \mathrm{Eu}$ is more widely dispersed throughout the cavity. Thermodynamic calculations indicate that $\mathrm{Eu}^{+3}$ will readily form soluble carbonate complexes in the $\mathrm{pH}$ range of the Chancellor cavity fluid (Krupka and Serne, 2002). However, europium also exhibits a strong tendency to sorb to mineral surfaces (e.g. Adeleye et al., 1994), and its transport in aqueous systems may be largely controlled by sorption to mineral colloids.

The mean rock/water activity ratios for ${ }^{137} \mathrm{Cs}$ are $0.15 \%$ for the dark glass and $22.3 \%$ for the rubble, which is roughly one to two orders of magnitude above that of the Co and Eu isotopes (Table 4.6). It is important to remember that these comparisons are on an equal mass basis. The actual mass of contaminated rubble is perhaps 10 times that of the groundwater in the cavity, and the true activity ratio for the rubble-groundwater system will be $\sim 10$ times smaller. In contrast, the mass of melt glass and groundwater in the cavity are probably much closer to unity, and the $0.15 \%$ water-glass ratio may be close to the actual ratio. The ${ }^{137} \mathrm{Cs}$ source term is expected to be widely distributed throughout the cavity-chimney environment due to the high volatility of its fission chain precursors $\left({ }^{137} \mathrm{I}\right.$ and $\left.{ }^{137} \mathrm{Xe}\right)$. The $\mathrm{Cs}^{+}$ion is highly soluble in groundwater, and ${ }^{137} \mathrm{Cs}$ that is loosely bound to the surfaces of rubble blocks may be readily dissolved in groundwater. As with $\mathrm{Co}$ and $\mathrm{Eu}$, cesium is strongly sorbed to mineral surfaces, particularly zeolites and clays (e.g. Lieser and Steinkopff, 1989; Ohnuki and Kozai, 1994; Rajec et al., 1998), and its transport characteristics will be strongly influenced by the presence of colloids.

Antimony-125 shows the highest water-rock activity ratios of all the gamma-emitting nuclides, with a mean ratio of $1.8 \%$ for the dark glass and $35.6 \%$ for the rubble. Under oxidizing conditions, $\mathrm{Sb}(\mathrm{OH})_{6}{ }^{-}$is the dominant aqueous antimony species over a wide range of $\mathrm{pH}$ conditions (Krupka and Serne, 2002). The adsorption of $\mathrm{Sb}^{5+}$ to mineral surfaces is negligible at neutral to basic $\mathrm{pH}$ conditions, and as a result, ${ }^{125} \mathrm{Sb}$ is relatively mobile in groundwater systems (Buddemeier et al., 1991). 


\subsection{Summary of Partitioning Results}

Partitioning ratios for gamma-emitting radionuclides were evaluated using the three different approaches outlined in Section 1.5. Calculations based on the average NNSS Area 19 radionuclide inventory from Bowen et al. (2001) generally gave unsatisfactory results compared to IAEA (1998) partitioning values, except for ${ }^{137} \mathrm{Cs}$ (Table 4.2). This suggests that, in general, the average Bowen inventory does not adequately represent the source term for the Chancellor test. Calculations based on fission chain yields from England and Rider (1994) gave reasonable results for ${ }^{137} \mathrm{Cs}$, but poor results for ${ }^{125} \mathrm{Sb}$ and ${ }^{155} \mathrm{Eu}$ (Table 4.5). This is explained by the fact that the fission chain yield of ${ }^{137} \mathrm{Cs}$ is fairly insensitive to the actinide fuel and neutron spectrum characteristics of the nuclear device, whereas ${ }^{125} \mathrm{Sb}$ and ${ }^{155} \mathrm{Eu}$ are much more sensitive to these parameters.

Partitioning values were also calculated using the mass estimates for the Chancellor melt glass, rubble, and groundwater found in Zhao et al. (2008). In this case, the manner in which the rubble source term was defined had a significant impact on the results. Good agreement with IAEA (1998) partitioning values was achieved for all nuclides using a weighted average rubble composition consisting of $10 \% \mathrm{CH}-03$ (rubble from the melt glass zone in the lower cavity) and $90 \% \mathrm{CH}-14$ (rubble from a stratigraphically-higher position in the cavity; see Table 4.4).

The amount of radioactivity transferred from the Chancellor test debris to the cavity fluid varies significantly for the different radionuclides. Water-rock activity ratios were calculated on an equal mass basis for both the dark melt glass and rubble (Table 4.6). As expected, the ratios are lowest for the refractory nuclides $\left({ }^{60} \mathrm{Co}\right.$ and $\mathrm{Eu}$ isotopes), and higher for the more volatile nuclides $\left({ }^{125} \mathrm{Sb}\right.$ and $\left.{ }^{137} \mathrm{Cs}\right)$. For all nuclides, the water-rock ratios are generally 1 to 2 orders of magnitude lower for the dark glass as compared to the rubble. A significant fraction of the ${ }^{60} \mathrm{Co},{ }^{137} \mathrm{Cs}$, and Eu isotopes that are present in the groundwater may be associated with mineral colloids. Gamma spectroscopy measurements on colloid filtrates would be required to quantify the colloid fraction for these nuclides. 


\subsection{Uranium and Plutonium Analysis of Test Debris Samples \\ Pihong Zhao, Ross W. Williams, Qinhong Hu, Timothy P. Rose \\ Chemical Sciences Division, Lawrence Livermore National Laboratory}

This chapter describes the results of uranium (U) and plutonium $(\mathrm{Pu})$ analyses of test debris samples, and provides an unclassified discussion of the partitioning estimates developed from these data. Although $\mathrm{U}$ and $\mathrm{Pu}$ are known to be strongly partitioned into the melt glass, glass-rubble partitioning values have not been previously reported for underground nuclear tests at the NNSS. The measured concentrations and isotope ratios for $\mathrm{U}$ and $\mathrm{Pu}$ in the test debris are classified at the Secret / Restricted Data level and will not be presented in this report. The data are available upon request to individuals with a U.S. Department of Energy "Q" clearance who have a demonstrable "need to know".

\subsection{Analytical Methods}

Melt glass and rubble samples were hand picked from washed test debris for $\mathrm{U}$ and $\mathrm{Pu}$ analysis. The selection process emphasized obtaining co-existing glass and rubble from a single depth interval. Photographs of representative sample materials are shown in Figure 5.1. Selected samples were powdered and digested in strong acids, after which the dissolved $\mathrm{U}$ and $\mathrm{Pu}$ were separated and purified on ion exchange resin columns. The samples were analyzed for their $\mathrm{U}$ and $\mathrm{Pu}$ concentrations and isotope ratios using a multicollector magnetic sector ICP-MS. Details of the analytical procedures are fully described in Appendix B of this report.

\subsection{Uranium Analytical Results and Partitioning Estimate}

A total of 16 sidewall core samples from the Chancellor test were analyzed for uranium. Of these samples, 12 represented pairs of coexisting samples from a given depth interval (rubble-glass pairs or light glass-dark glass pairs). Most of the samples have similar uranium concentrations, regardless of the physical characteristics of the sample. This is a reflection of the high natural background of uranium in the volcanic host rock. Samples that contain very little test-derived uranium show ${ }^{238} \mathrm{U} /{ }^{235} \mathrm{U}$ ratios close to the natural ratio. Samples with higher concentrations of test-derived uranium have lower ${ }^{238} U{ }^{235} U$ ratios and contain ${ }^{236} \mathrm{U}$, which is not found in nature.

On a plot of ${ }^{238} \mathrm{U} /{ }^{235} \mathrm{U}$ vs. uranium concentration, the data plot in two distinct groups with a significant gap between the two ${ }^{238} \mathrm{U} /{ }^{235} \mathrm{U}$ sample populations (Figure 5.2). This gap could reflect sampling bias, but this is considered to be unlikely because the samples represent the full range in physical characteristics of the test debris. The two sample populations are interpreted to reflect limited mixing between the dark melt glass, which contains high concentrations test-derived of $\mathrm{U}$ and $\mathrm{Pu}$, and the remainder of the test debris. 

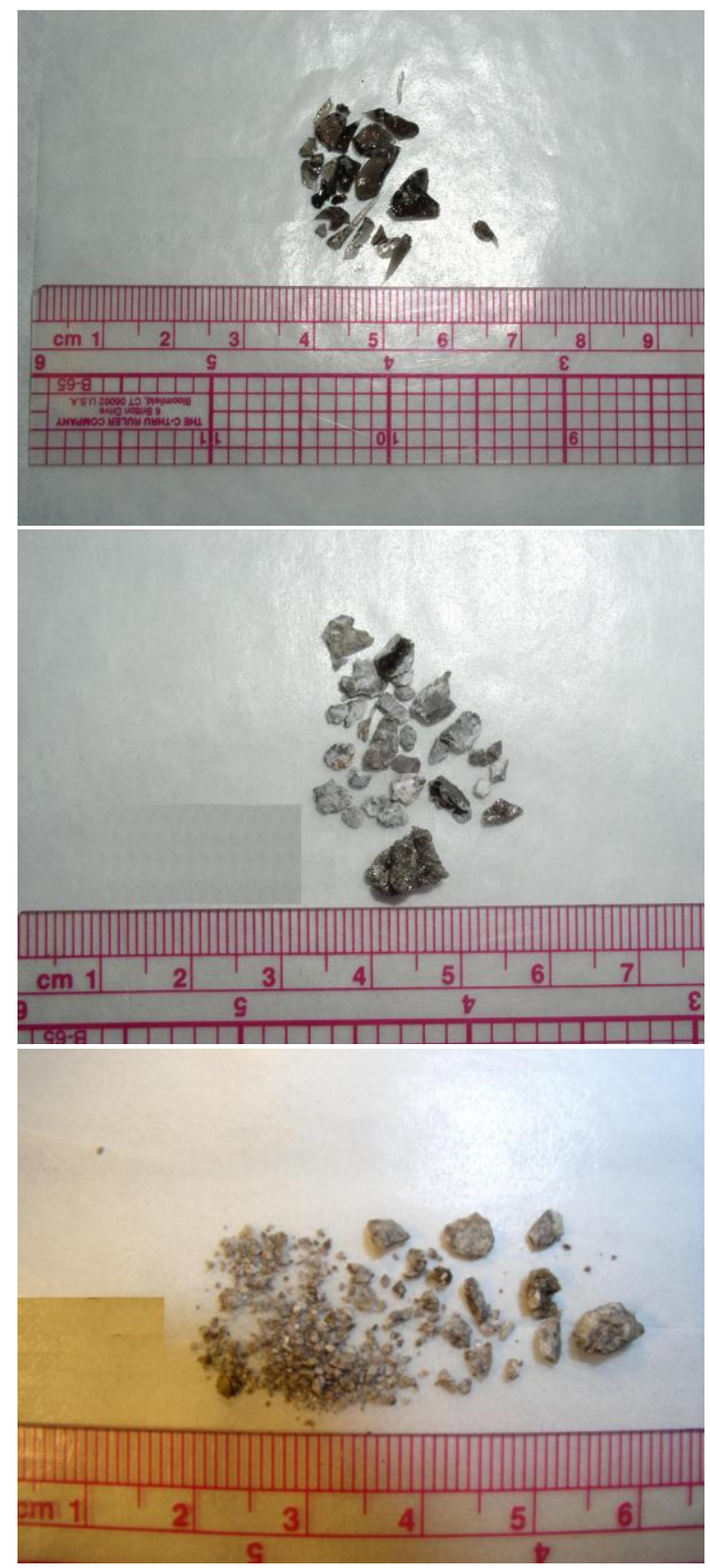

Figure 5.1. Photographs illustrating the typical size and textural characteristics of nuclear test debris samples used in this study. The upper photo shows dark-colored melt glass (sample $\mathrm{CH}$ 04.1) exhibiting typical 'obsidian-like' textures. The middle photo shows gray-colored rhyolite with admixed lighter-colored glass (sample $\mathrm{CH}$ 04.2). Note the fragment of test debris at the top center of the middle picture, which contains a band of dark-colored glass sandwiched between unmelted rhyolite. The lower photo shows relatively unaltered rhyolite fragments from a stratigraphically higher position within the cavity (sample $\mathrm{CH} 13$ ). 


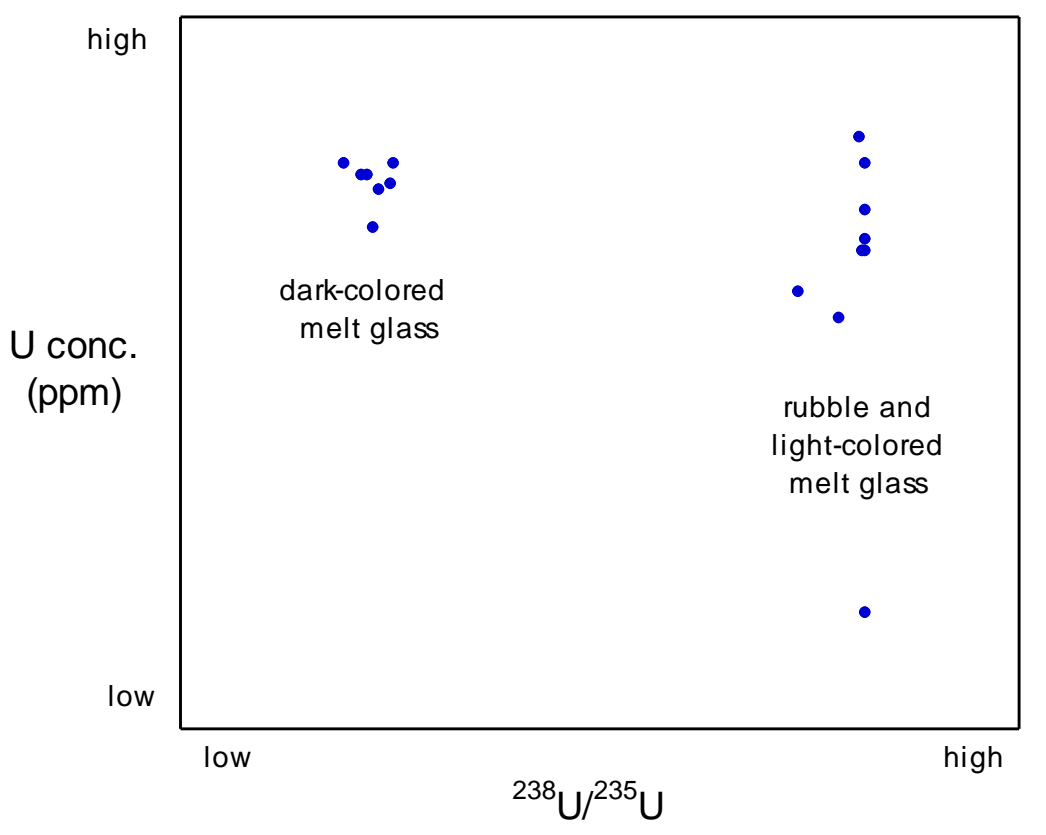

Figure 5.2. Plot of ${ }^{238} \mathrm{U} /{ }^{235} \mathrm{U}$ isotope ratios versus uranium concentrations (in ppm) for test debris samples. Axis labels are intentionally omitted. Dark-colored melt glass samples show lower ${ }^{238} \mathrm{U} /{ }^{235} \mathrm{U}$ ratios than the rubble and light-colored melt glass samples. The gap in isotope ratios between the two sample populations is interpreted to reflect the early condensation of a majority of the test-derived uranium in the dark glass, with only limited chemical mixing between this material and the rubble + light-colored glass.

Several of the samples with natural or near-natural ${ }^{238} \mathrm{U} /{ }^{235} \mathrm{U}$ ratios are largely comprised of light-colored melt glass. The presence of melt glass containing very little test-derived uranium indicates that melting of the host rock continues to occur even after the more refractory radionuclides have condensed. This material probably formed by melting of the cavity wall rock, or by melting of material that fell into the puddle glass. In general, only the melt glass that is very dark in color (black or dark brown) shows a strong enrichment in test-derived uranium. Electron microprobe analyses show the darker glass contains a proportionally higher concentration of iron, which is probably derived from the device casing and other materials that were present in the emplacement hole. Although dark glass with low ${ }^{238} \mathrm{U} /{ }^{235} \mathrm{U}$ ratios tends to be concentrated in the lower part of the cavity, it was not exclusively found in this area.

The partitioning of test-derived uranium between the dark melt glass and rubble (+ light glass) was calculated for two different uranium isotopes: ${ }^{235} \mathrm{U}$ and ${ }^{236} \mathrm{U}$. Nearly all of the ${ }^{236} \mathrm{U}$ originated from the nuclear device (with the exception of a negligible amount produced by neutron capture on natural ${ }^{235} \mathrm{U}$ ), which simplifies the calculation for this isotope. The average measured concentration of ${ }^{236} \mathrm{U}$ in the dark melt glass was multiplied by the mass of melt glass produced in the explosion to obtain the total mass of ${ }^{236} \mathrm{U}$ in the melt glass. This value was then divided by the classified ${ }^{236} \mathrm{U}$ inventory for the Chancellor test from Miller et al. (2002). The result indicates that $73 \%$ of the testderived uranium is contained in the dark melt glass. By difference, the amount of test- 
derived uranium in the rubble + light-colored glass is inferred to be $27 \%$. The calculation for ${ }^{235} \mathrm{U}$ was performed in much the same manner. However, it was first necessary to apply a correction for natural ${ }^{235} \mathrm{U}$ in the rock. Once the background ${ }^{235} \mathrm{U}$ was subtracted out, the remainder of the calculation was performed as described above. In this case, the same fraction $(73 \%)$ of the test-derived uranium was predicted to be in the dark melt glass.

The agreement between the ${ }^{235} \mathrm{U}$ and ${ }^{236} \mathrm{U}$ partitioning estimates is remarkable; the two sets of calculations vary by only $0.3 \%$. The estimated fraction of uranium in the melt glass is substantially lower than the IAEA (1998) prediction of 90\%. This suggests less of the uranium from the device condensed with the dark glass, as compared to the IAEA average. It should be emphasized that the melt glass partitioning estimate is based only on the dark glass samples containing high concentrations of test-derived uranium. Lighter-colored glass that contains relatively small amounts of test-derived uranium is assumed to be part of the rubble fraction in this calculation. This approach results in the most conservative estimate of uranium glass/rubble partitioning.

The test-derived uranium fraction in coexisting dark glass and rubble (or light glass) from the same depth interval shows variable glass/rubble partitioning ratios ranging from $>99 \%$ to $89 \%$ (on an equal mass basis). These ratios are higher than the $73 \%$ glass/rubble ratio described above because the uranium in the rubble debris is distributed throughout a much larger volume of material compared to the melt glass. The partitioning of test-derived uranium between the dark melt glass and the groundwater was calculated for both ${ }^{235} \mathrm{U}$ and ${ }^{236} \mathrm{U}$. For both isotopes, the fraction of test-derived uranium in the groundwater was found to be $<0.005 \%$ of the amount present in the glass.

\subsection{Plutonium Analytical Results and Partitioning Estimate}

The 16 test debris samples that were measured for uranium were also analyzed for their plutonium concentrations and isotope ratios. As expected, plutonium is strongly concentrated into the dark melt glass. Dark melt glass samples typically contain between two and three orders of magnitude more plutonium than rubble or light-colored glass samples from the same depth interval. The dark melt glass samples with the greatest enrichment in $\mathrm{Pu}$ also show the lowest ${ }^{238} \mathrm{U} /{ }^{235} \mathrm{U}$ ratios.

On a plot of ${ }^{240} \mathrm{Pu} /{ }^{239} \mathrm{Pu}$ vs. plutonium concentration, the data show an L-shaped pattern with uniform isotope ratios at higher concentrations, but increasing isotope ratios at low concentrations (Figure 5.3). The increase in isotope ratios at low concentrations probably reflects inefficient stripping of the $\mathrm{Pu}$-spike during sample preparation. The $\mathrm{Pu}$-spike contains small amounts of ${ }^{240} \mathrm{Pu}$, which can adversely affect the measured ${ }^{240} \mathrm{Pu} /{ }^{239} \mathrm{Pu}$ ratio when the total $\mathrm{Pu}$ concentration is low. Inaccuracies introduced by inefficient spike stripping have much less influence on ${ }^{239} \mathrm{Pu}$ because the concentration of ${ }^{239} \mathrm{Pu}$ is very low in the spike solution, and ${ }^{239} \mathrm{Pu}$ is more abundant than ${ }^{240} \mathrm{Pu}$ in the samples. 


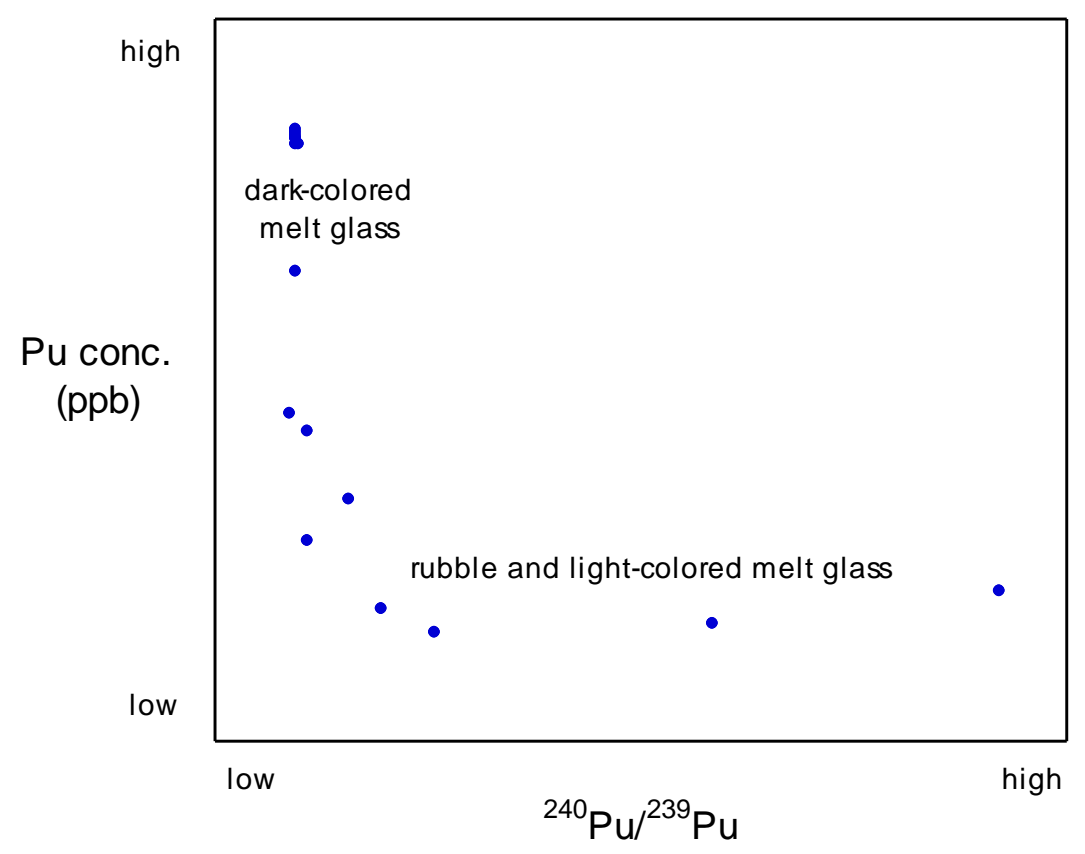

Figure 5.3 Plot of ${ }^{240} \mathrm{Pu} /{ }^{239} \mathrm{Pu}$ isotope ratios versus plutonium concentrations (in ppb) for test debris samples. Axis labels are intentionally omitted, but the $y$-axis is plotted on a logarithmic scale. Dark-colored melt glass samples have fairly uniform $\mathrm{Pu}$ concentrations and ${ }^{240} \mathrm{Pu} /{ }^{239} \mathrm{Pu}$ ratios. The apparent increase in the isotope ratio at low $\mathrm{Pu}$ concentrations is inferred to reflect the presence of tiny amounts of ${ }^{240} \mathrm{Pu}$ introduced with the ${ }^{244} \mathrm{Pu}$ spike solution during sample preparation.

The partitioning of plutonium between the dark melt glass and rubble (+ light glass) was calculated using ${ }^{239} \mathrm{Pu}$ data, following the same approach that was used for ${ }^{236} \mathrm{U}$ in the preceding section. The result indicates that $96 \%$ of the plutonium inventory is contained in the dark melt glass, and only $4 \%$ is present in the rubble + light-colored glass. This is in good agreement with the IAEA (1998) glass / rubble partitioning ratio of $98 \%$ / $2 \%$.

The $\mathrm{Pu}$ concentration in the groundwater is $<0.005 \%$ of the $\mathrm{Pu}$ concentration in the dark melt glass. Both $\mathrm{U}$ and $\mathrm{Pu}$ have very similar partitioning ratios between the melt glass and groundwater, which suggests that the release rate for both elements is dominated by the same mechanism (glass dissolution).

\subsection{Summary of Partitioning Results}

Melt glass/rubble partitioning estimates for uranium and plutonium have a higher degree of confidence than those reported for gamma-emitting radionuclides (Chapter 4) because (1) analytical work was performed on hand-picked samples, and (2) the partitioning estimates were determined by calculating the ratio of the average concentration in the dark-colored melt glass to the total classified inventory for the Chancellor test reported in Miller et al. (2002). The fraction of the inventory in the rubble + light colored melt glass was calculated by difference. In this case, the light-colored glass is 'lumped' with the 
rubble debris because the concentrations of test-derived $\mathrm{U}$ and $\mathrm{Pu}$ tend to be similar in these materials, whereas dark-colored glass shows markedly higher concentrations.

Uranium partitioning between the dark glass and rubble (+ light glass) was calculated independently for both ${ }^{235} \mathrm{U}$ and ${ }^{236} \mathrm{U}$. The results of both calculations were statistically equivalent. Approximately $73 \%$ of the test-derived uranium is contained in the dark melt glass, and $27 \%$ is in the rubble + light-colored glass. Hence, for the Chancellor test, the uranium fraction in the melt glass is notably lower than the IAEA (1998) estimate of $90 \%$. This implies that uranium partitioning in the glass can vary over a wider range than previously assumed.

For plutonium, $96 \%$ of the inventory is contained in the dark-colored melt glass, and only $4 \%$ is present in the rubble + light-colored melt glass. These results are in good agreement with the IAEA (1998) estimate (98\% glass, $2 \%$ rubble). The partitioning ratio between the dark-colored melt glass and the groundwater was $<0.005 \%$ for both uranium and plutonium. 


\title{
6.0 Distribution of Long-Lived Soluble Fission Products
}

\author{
Pihong Zhao, Qinhong Hu, Gregory Nimz, Brian Powell, and Timothy Rose
}

Chemical Sciences Division, Lawrence Livermore National Laboratory

This chapter describes the distribution of technetium-99 $\left({ }^{99} \mathrm{Tc}\right)$ and iodine-129 $\left({ }^{129} \mathrm{I}\right)$ in the Chancellor nuclear test cavity, and provides new data on the concentration and activity of these nuclides in NNSS near-field groundwaters. Prior to this study, only a small number of ${ }^{99} \mathrm{Tc}$ and ${ }^{129} \mathrm{I}$ analyses had been run on NNSS water samples (Daniels, 1981; Silva et al., 1988; Finkel et al., 1992; Schroeder et al., 1993; McAninch et al., 2000). This earlier work showed that ${ }^{99} \mathrm{Tc}$ and ${ }^{129} \mathrm{I}$ tend to occur at low activities in NNSS near-field waters (typically $<100 \mathrm{pCi} / \mathrm{L}$ for ${ }^{99} \mathrm{Tc}$ and $<10 \mathrm{pCi} / \mathrm{L}$ for ${ }^{129} \mathrm{I}$ ). The present work was motivated by the need for a more comprehensive evaluation of ${ }^{99} \mathrm{Tc}$ and ${ }^{129} \mathrm{I}$, based on the following rationale: (1) ${ }^{99} \mathrm{Tc}$ and ${ }^{129} \mathrm{I}$ are abundant fission products with long half-lives; (2) both nuclides are highly soluble in groundwater, and show little tendency for retardation due to water-mineral reactions; (3) both are redox sensitive elements, i.e., their chemical form changes depending on the amount of free oxygen that is present in the system; and (4) ${ }^{129}$ I may factor prominently in the overall radiation dose calculation for contaminated groundwater because of its tendency to bio-accumulate in the human thyroid (e.g., VanMiddlesworth et al. 2000).

The dissolution and transport behavior of ${ }^{99} \mathrm{Tc}$ and ${ }^{129} \mathrm{I}$ in groundwater will be strongly influenced by the initial distribution of these radionuclides in the test cavity and chimney. Very few data are available on the concentrations of ${ }^{99} \mathrm{Tc}$ or ${ }^{129} \mathrm{I}$ in test debris samples. Measurements of these long-lived nuclides were not performed on core samples during the weapons testing program, though the short-lived ${ }^{99} \mathrm{Tc}$-precursor ${ }^{99} \mathrm{Mo}$ was measured on some samples. The UGTA project currently relies on IAEA (1998) data from French underground tests in the Pacific Islands to model the distribution of ${ }^{99} \mathrm{Tc}$ and ${ }^{129} \mathrm{I}$ within the test cavity-chimney. These data indicate the fraction of ${ }^{99} \mathrm{Tc}$ and ${ }^{129} \mathrm{I}$ in the melt glass puddle is $80 \%$ and $50 \%$, respectively.

When ${ }^{235} \mathrm{U}$ fissions, the cumulative fission chain yield at mass 99 is $6.11 \%$, most of which is formed as ${ }^{99} \mathrm{Y}$ and ${ }^{99} \mathrm{Zr}$ (England and Rider, 1994). Almost none of the mass chain is actually 'born' as ${ }^{99} \mathrm{Tc}$. $\mathrm{Y}$ and $\mathrm{Zr}$ are refractory in their chemical behavior, but their half-lives are very short. ${ }^{99} \mathrm{Zr}$ decays to either ${ }^{99} \mathrm{Nb}$ or ${ }^{99 \mathrm{~m}} \mathrm{Nb}$, with half-lives of 15 sec. and $2.6 \mathrm{~min}$. respectively, and both niobium nuclides decay to ${ }^{99} \mathrm{Mo}\left(\mathrm{t}_{1 / 2}=2.75\right.$ days $)$. Both $\mathrm{Nb}$ and Mo behave as 'semi-volatile' elements during test debris condensation. This means that a small but significant fraction of these elements are not retained in the dark melt glass, similar to the behavior of uranium (see also Bedford and Jackson, 1965).

In a similar manner, a significant fraction of the mass 129 fission chain is born as semivolatile tin isotopes $\left({ }^{129} \mathrm{Sn}\right.$ and $\left.{ }^{129 \mathrm{~m}} \mathrm{Sn}\right)$, with half-lives of 2.4 and 6.9 minutes, respectively. A smaller fraction of the mass chain is formed as ${ }^{129} \mathrm{Sb}\left(\mathrm{t}_{1 / 2}=4.4 \mathrm{hrs}\right)$, which tends to be more volatile than the Sn isotopes. Hence, the chemical distribution of 
the long-lived ${ }^{129} \mathrm{I}$ isotope is largely determined by the chemical behavior of tin, and to a lesser degree, antimony.

Once the test cavity has cooled and groundwater has infiltrated the system, the transport behavior of ${ }^{99} \mathrm{Tc}$ and ${ }^{129} \mathrm{I}$ will be influenced by the redox conditions in the cavity and surrounding environment. Technetium forms the soluble pertechnetate ion $\left(\mathrm{TcO}_{4}{ }^{-}\right)$under oxidizing conditions, but is relatively insoluble under moderately reducing conditions (Lieser, 1993). The most common dissolved iodine species are the soluble iodide $\left(\mathrm{I}^{-}\right)$and iodate $\left(\mathrm{IO}_{3}{ }^{-}\right)$anions, but iodine may also be reduced to less soluble forms in the presence of organic carbon (e.g. Moran et al., 1995).

The main objectives of this investigation are to: (1) measure the ${ }^{99} \mathrm{Tc}$ and ${ }^{129} \mathrm{I}$ concentrations in melt glass and rubble samples from the Chancellor test cavity, and compare the results to the IAEA (1998) glass-rubble partitioning estimates; (2) measure ${ }^{99} \mathrm{Tc}$ and ${ }^{129} \mathrm{I}$ in groundwater samples from a number of NNSS near-field sampling sites; (3) compare groundwater and test debris data to determine water-rock partitioning, and (4) to make inferences regarding redox conditions in the test cavity.

\subsection{Analytical Methods}

Standardized methods for the analysis of ${ }^{99} \mathrm{Tc}$ and ${ }^{129} \mathrm{I}$ in test debris samples did not exist when this project was initiated. As a result, a substantial amount of research and development work was carried out to determine reliable methodologies for making these measurements. Details of the methods that were developed and used are described in Appendix $\mathrm{C}$ of this report. A brief review of these techniques is given here.

In preparation for ${ }^{99} \mathrm{Tc}$ analysis, hand-selected samples were powdered, mixed with a strongly oxidizing flux, and fused at $700{ }^{\circ} \mathrm{C}$ to produce a glass. This approach is believed to greatly reduce the volatile loss of ${ }^{99} \mathrm{Tc}$ that occurs during ordinary acid digestion of test debris samples. Samples were spiked with a rhenium tracer prior to fusion to monitor the chemical yield recovery of ${ }^{99} \mathrm{Tc}$. The fused glass sample was then dissolved in weak acid, and ${ }^{99} \mathrm{Tc}$ was separated using an ion exchange resin. The purified ${ }^{99} \mathrm{Tc}$ solution was analyzed by isotope dilution ICP-MS.

Iodine-129 was extracted from powdered test debris samples by microwave digestion in the presence of a strong complexing agent (tetra-methyl ammonium hydroxide). The resulting solution was analyzed by ICP-MS to determine the total iodine concentration in the sample. On a few samples, the total iodine concentration was independently measured by pyrohydrolysis. The extracted iodine was precipitated as silver iodide, and the ${ }^{129} \mathrm{I} /{ }^{127}$ I ratio was analyzed on an accelerator mass spectrometer (AMS).

Technetium-99 in groundwater samples was measured by ICP-MS, with comparative measurements by liquid scintillation counting. In low activity samples, the ${ }^{99} \mathrm{Tc}$ was preconcentrated on an ion exchange resin in order to increase the amount of material to a level greater than the analytical detection limit. The total iodine concentration in 
groundwater was measured by ICP-MS, and the iodide $\left(\mathrm{I}^{-}\right)$concentration was determined by ion chromatography. The ${ }^{129} \mathrm{I} /{ }^{127} \mathrm{I}$ ratio was again measured by AMS. Further details are given in Appendix $\mathrm{C}$.

\subsection{Analytical Results}

\subsubsection{Groundwater Samples}

The ${ }^{99} \mathrm{Tc}$ concentration in U-19ad PS1A groundwater was measured using a standard addition method wherein multiple sample aliquots were spiked with varying amounts of a ${ }^{99} \mathrm{Tc}$ reference standard and analyzed on the ICP-MS. The final concentration is determined by linear regression. Figure 6.1 shows the analytical results for one set of standard addition measurements on the ICP-MS, which yielded a ${ }^{99} \mathrm{Tc}$ concentration of $5.88 \mathrm{ng} / \mathrm{L}$, equivalent to $46.4 \mathrm{pCi} / \mathrm{L}$. This procedure was repeated a total of four times, resulting in a mean ${ }^{99} \mathrm{Tc}$ activity of $46.0 \pm 0.15 \mathrm{pCi} / \mathrm{L}$ for $\mathrm{U}-19 \mathrm{ad}$ PS1A groundwater.

ICP-MS analyses of ${ }^{99} \mathrm{Tc}$ were also performed on archival groundwater samples from other NNSS wells. The results are compiled Table 6.1. The data were converted from concentration to activity values for ease of comparison with other analytical methods. The highest value was observed in well U-3cn PS2a (the Bilby test), which had a ${ }^{99} \mathrm{Tc}$ concentration equivalent to $83 \mathrm{pCi} / \mathrm{L}$ in a 2001 sample, and $63 \mathrm{pCi} / \mathrm{L}$ in a 2004 sample. U-3cn PS2a is the only NNSS well with a groundwater ${ }^{99} \mathrm{Tc}$ activity greater than that of U-19ad PS1A. Only three other near-field wells have produced water with ${ }^{99} \mathrm{Tc}$ activities above $1 \mathrm{pCi} / \mathrm{L}$ (see Table 6.1). As discussed in the methods section (Appendix C), ICP-MS analysis of samples with activities $<1 \mathrm{pCi} / \mathrm{L}$ was achieved by pre-concentrating and purifying the samples using a TEVA resin column. Concentrations as low as $\sim 3.4 \times$ $10^{-3} \mathrm{pCi} / \mathrm{L}$ (activity equivalent) were measured using this approach. 


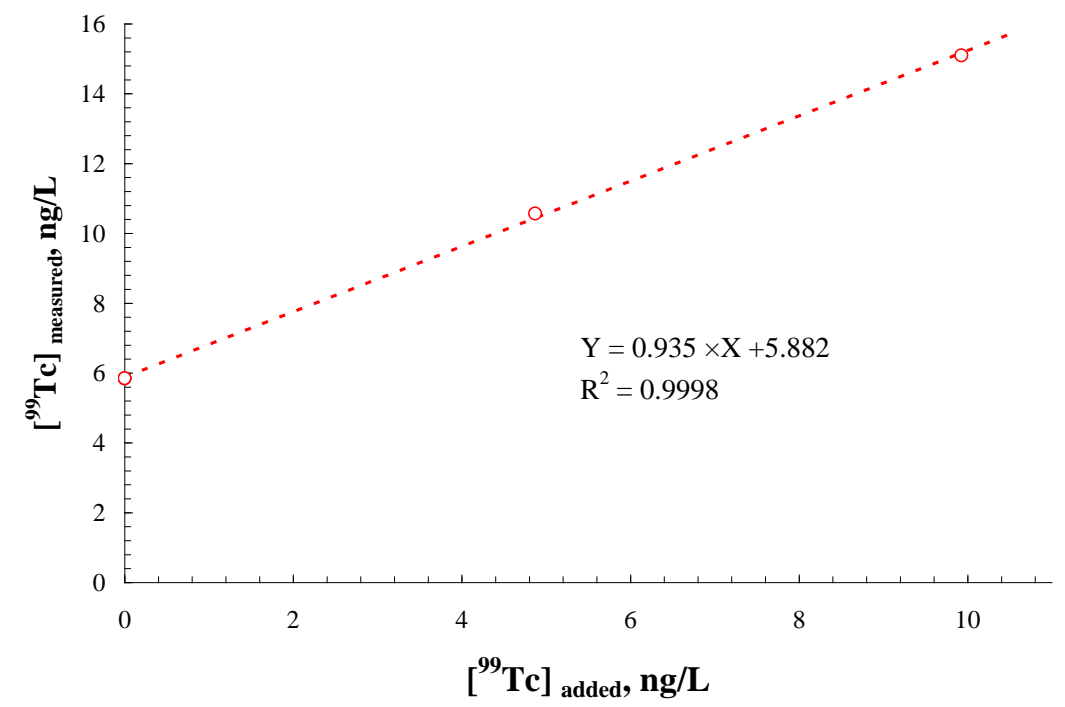

Figure 6.1. Analytical results for one set of ${ }^{99} \mathrm{TC}$ measurements on the ICP-MS using the standard addition method. The $y$-intercept at $\left[{ }^{99} \mathrm{Tc}\right]_{\text {added }}=0$ gives the actual sample concentration of $5.88 \mathrm{ng} / \mathrm{L}$, which is equivalent to $46.4 \mathrm{pCi} / \mathrm{L}$.

The results of liquid scintillation counting (LSC) and AMS analyses of ${ }^{99} \mathrm{Tc}$ are also included in Table 6.1. The ICP-MS and LSC methods provide similar analytical results for those samples that did not require a pre-concentration step. The detection limit for LSC analysis of ${ }^{99} \mathrm{Tc}$ is about $1 \mathrm{pCi} / \mathrm{L}$. In comparison, the reported detection limit for ${ }^{99} \mathrm{Tc}$ on the AMS is $\sim 2.7 \times 10^{-4} \mathrm{pCi} / \mathrm{L}\left(10 \mu \mathrm{Bq}\right.$ or $1 \times 10^{-8}$ atoms $)$ with $\sim 15-25 \%$ precision on a 1-L sample (Berquist et al., 2000). This is roughly a factor of ten lower than the ICP-MS detection limit, but the AMS sample preparation and analysis is more labor intensive.

Total iodine and iodide $\left(\mathrm{I}^{-}\right)$concentrations in NNSS groundwaters, and their corresponding ${ }^{129} \mathrm{I} /{ }^{127} \mathrm{I}$ ratios are reported in Table 6.1. Near-field waters have total iodine concentrations that vary between 4 and $26 \mu \mathrm{g} / \mathrm{L}$, but with ${ }^{129} \mathrm{I}^{127} \mathrm{I}$ ratios that span nearly six orders of magnitude, from $3.5 \times 10^{-9}$ to $1.4 \times 10^{-3}$. U-19ad PS1A groundwater has a relatively high total iodine concentration $(19.4 \mu \mathrm{g} / \mathrm{L})$, and contains $13.1 \mu \mathrm{g} / \mathrm{L}$ dissolved iodide ( $68 \%$ of the total iodine). This implies the remainder of the iodine is present as iodate $\left(\mathrm{IO}_{3}{ }^{-}\right)$, organically-bound iodine, or other ionic species. The ${ }^{129} \mathrm{I} /{ }^{127} \mathrm{I}$ ratio in U-19ad PS1A groundwater is $5.6 \times 10^{-4}$, which corresponds to an ${ }^{129}$ I activity of $1.9 \mathrm{pCi} / \mathrm{L}$. The maximum observed ${ }^{129} \mathrm{I}$ activities in NNSS groundwater are $\sim 2.5$ pCi/L (Table 6.1).

\subsubsection{Technetium-99 melt glass/rubble partitioning}

The results of ${ }^{99} \mathrm{Tc}$ analyses of sidewall core samples from the Chancellor drillback are reported in Table 6.2. Technetium-99 concentrations vary from 0.009 to $0.75 \mathrm{ng} / \mathrm{g}$, with 
corresponding activities that range from 0.15 to $12.7 \mathrm{pCi} / \mathrm{g}$. The activities of the dark melt glass samples are between 10.1 and $12.7 \mathrm{pCi} / \mathrm{g}$, whereas the rubble samples all have activities of $1 \mathrm{pCi} / \mathrm{g}$ or less. The ratio of the average atoms/gram in the melt glass relative to the rubble samples is approximately 19:1 (using data from Table 6.2). However, atom/gram comparisons of glass and rubble do not provide an accurate measure of the melt glass/rubble partitioning because the total mass of the glass and rubble produced by the nuclear detonation are not equal.

As discussed in Section 1.5, three different approaches will be used to estimate partitioning values. These calculations are based on (1) the average Area 19 inventory from Bowen et al. (2001); (2) melt glass, rubble, and groundwater mass estimates from Zhao et al. (2008); and (3) fission product mass yield data from England and Rider (1994). The Bowen inventory and fission chain yield calculations give estimates for only the melt glass fraction.

Partitioning estimates based on the Bowen et al. (2001) inventory assume that the average inventory for each geographic testing center can be applied to individual tests. The Chancellor test is one of 36 tests conducted in NNSS Area 19 (DOE/NV, 2000). Hence, the average Area 19 inventory for ${ }^{99} \mathrm{Tc}$ is found by dividing the total Area 19 inventory by the number of tests conducted in that area, i.e., $134.4 \mathrm{Ci}{ }^{99} \mathrm{Tc} / 36$ tests $=3.73 \mathrm{Ci}$ per test (as of September 23, 1992). Decay correcting to the date of the Chancellor test does not change this value due to the long half-life of ${ }^{99} \mathrm{Tc}$.

For the present study, it is assumed that the 143-kiloton Chancellor test (DOE/NV, 2000) produced $10^{6} \mathrm{~kg}$ of melt glass per kiloton of yield (Olsen, 1993), resulting in a total of $1.43 \times 10^{8} \mathrm{~kg}$ melt glass. The average ${ }^{99} \mathrm{Tc}$ activity in the melt glass is $11.6 \pm 1.0 \mathrm{pCi} / \mathrm{g}$ (or $0.682 \pm 0.055 \mathrm{ng} / \mathrm{g}$ ) based on eight measured values reported in Table 6.2. Multiplying this average activity by the total amount of glass gives an estimate of the total ${ }^{99} \mathrm{Tc}$ activity in the melt glass: $(11.6 \mathrm{pCi} / \mathrm{g}) \times\left(1.43 \times 10^{11} \mathrm{~g}\right)=1.66 \pm 0.14 \mathrm{Ci}$. Given the average ${ }^{99} \mathrm{Tc}$ inventory for all Area 19 tests is $3.73 \mathrm{Ci}$ per test, these calculations imply that the fractional amount of the ${ }^{99} \mathrm{Tc}$ inventory contained in the Chancellor melt glass is $1.66 / 3.73=0.445$, or $45 \%$. It is assumed that the rubble fraction is approximately equal to the difference between the total inventory and the melt glass fraction, or $55 \%$. 
Table 6.1 Technetium and iodine data for NNSS groundwater samples

\begin{tabular}{|c|c|c|c|c|c|c|c|c|}
\hline Test Name & Sampling Well & $\begin{array}{l}\text { Sampling } \\
\text { Date }\end{array}$ & $\begin{array}{l}{ }^{99} \mathrm{Tc}(\mathrm{ICP}-\mathrm{MS}) \\
(\mathrm{pCi} / \mathrm{L})\end{array}$ & $\begin{array}{c}{ }^{99} \mathrm{Tc} \text { (other methods) } \\
(\mathrm{pCi} / \mathrm{L})\end{array}$ & $\begin{array}{l}\text { Total lodine } \\
\qquad(\mu \mathrm{g} / \mathrm{L})\end{array}$ & $\begin{array}{l}\text { lodide } \\
(\mu \mathrm{g} / \mathrm{L})\end{array}$ & ${ }^{129} I /{ }^{127} I$ & $\begin{array}{c}{ }^{129} \mathrm{I} \\
(\mathrm{pCi} / \mathrm{L})\end{array}$ \\
\hline Aleman & UE-3e \#4 & 9/23/98 & $8.58 \pm 0.26$ & $13.0 \pm 1.8^{a}$ & 11.3 & 5.0 & n.a. & n.a. \\
\hline Almendro & U-19v PS1ds & 8/18/99 & 0.075 & n.a. & 7.4 & 8.5 & $1.06 \mathrm{E}-03$ & 1.39 \\
\hline Almendro & U-19v PS1ds & $7 / 23 / 03$ & 0.011 & n.a. & 10.1 & 6.3 & $1.41 \mathrm{E}-03$ & 2.54 \\
\hline Bilby & U-3cn PS2 & $12 / 18 / 01$ & $82.6 \pm 0.84$ & $80.03^{b}$ & 9.1 & $<0.6$ & $9.74 \mathrm{E}-05$ & 0.158 \\
\hline Bilby & U-3cn PS2 & $12 / 9 / 04$ & $62.6 \pm 6.9$ & $67.7 \pm 2.0^{b}$ & 9.5 & 3.4 & 1.48E-04 & 0.252 \\
\hline Bourbon & UE-7nS & $8 / 21 / 01$ & $<1.07$ & n.a. & 23.1 & 19.2 & $1.47 \mathrm{E}-07$ & 0.0006 \\
\hline Cambric & RNM-1 & $6 / 3 / 04$ & $<0.0034$ & $<1.0^{b}$ & 16.2 & 1.6 & 2.06E-07 & 0.0006 \\
\hline Cambric & RNM-2S & $10 / 11 / 99$ & $<0.0034$ & $0.0013 \pm 0.0007^{\mathrm{a}}$ & 12.1 & $<0.6$ & 2.12E-07 & n.d. \\
\hline Cambric & RNM-2S & $7 / 10 / 03$ & $<0.0034$ & n.a. & 12.2 & $<0.6$ & $6.16 \mathrm{E}-07$ & 0.0013 \\
\hline Cambric & UE-5n & 9/9/99 & 0.0047 & $0.0023 \pm 0.0019^{a}$ & 25.8 & 0.8 & $3.51 \mathrm{E}-09$ & n.d. \\
\hline Cambric & UE-5n & $2 / 12 / 04$ & 0.0072 & n.a. & 19.0 & 1.0 & 5.02E-07 & 0.0017 \\
\hline Camembert & U-19q PS1d & 10/21/98 & n.a. & $0.084 \pm 0.018^{a}$ & 4.1 & 2.5 & 5.54E-06 & 0.0041 \\
\hline Camembert & U-19q PS1d & $7 / 16 / 03$ & 0.013 & n.a. & 4.0 & 2.6 & 2.85E-06 & 0.0020 \\
\hline Cheshire & U-20n PS1ddh & $7 / 25 / 98$ & n.a. & $31.0 \pm 6.8^{a}$ & 5.9 & 1.5 & n.a. & n.a. \\
\hline Cheshire & U-20n PS1ddh & $9 / 21 / 98$ & $21.7 \pm 1.01$ & $20.0 \pm 0.4^{\mathrm{a}} ; 11.4^{\mathrm{b}}$ & 5.8 & 1.5 & n.a. & n.a. \\
\hline Cheshire & U-20n PS1ddh & 10/12/99 & $15.4 \pm 1.12$ & $22.3 \pm 4.4^{\mathrm{a}}$ & 3.5 & $<0.6$ & $1.82 \mathrm{E}-04$ & 0.114 \\
\hline Chancellor & U-19ad PS1A & $9 / 27 / 04$ & $46.0 \pm 0.15$ & n.a. & 19.4 & 13.1 & 5.59E-04 & 1.94 \\
\hline Dalhart & U-4u PS2a & 8/16/99 & $13.1 \pm 0.38$ & $16 \pm 0.6^{\mathrm{a}} ; 14.75^{\mathrm{b}}$ & 5.8 & $<0.6$ & 2.80E-05 & 0.029 \\
\hline Dalhart & U-4u PS2a & $10 / 9 / 03$ & $35.1 \pm 3.5$ & $34.8 \pm 1.8^{b}$ & 7.1 & $<0.6$ & 1.04E-04 & 0.132 \\
\hline Nash & UE-2ce & $8 / 22 / 01$ & $<0.0034$ & n.a. & 9.4 & 7.4 & $1.88 \mathrm{E}-05$ & 0.0315 \\
\hline Tybo/Benham & ER-20-5 \#1 & 7/9/98 & 0.582 & $0.27 \pm 0.05^{a}$ & 7.0 & $<0.6$ & 2.14E-04 & 0.268 \\
\hline Tybo/Benham & ER-20-5 \#1 & $11 / 30 / 04$ & 0.449 & $<1.0^{\mathrm{b}}$ & 5.4 & $<0.6$ & 1.99E-04 & 0.192 \\
\hline Tybo/Benham & ER-20-5 \#3 & 4/30/98 & $<1.07$ & $<0.03^{a}$ & 8.2 & $<0.6$ & n.a. & n.a. \\
\hline Tybo/Benham & ER-20-5 \#3 & $11 / 29 / 04$ & 0.019 & n.a. & 4.7 & $<0.6$ & 1.66E-06 & 0.0014 \\
\hline
\end{tabular}

n.a. $=$ not analyzed; $n . d .=$ not determined
${ }^{a}={ }^{99}$ Tc analyses performed by AMS (McAninch et al., 2000); ${ }^{b}={ }^{99} \mathrm{Tc}$ analyses performed by LSC (this study) 
Table 6.2 Results of ${ }^{99} \mathrm{Tc}$ analyses of Chancellor drillback core samples

\begin{tabular}{|c|c|c|c|c|c|c|c|c|}
\hline $\begin{array}{l}\text { Drill Line - Depth } \\
\text { (ft) }\end{array}$ & $\begin{array}{l}\text { Sample } \\
\text { Name }\end{array}$ & Material Type & $\begin{array}{c}\text { Sample } \\
\text { Mass } \\
\text { (g) }\end{array}$ & $\begin{array}{l}\text { Recovery of } \\
\text { spiked Re } \\
\text { (\%) }\end{array}$ & $\begin{array}{l}{ }^{99} \mathrm{Tc} \\
(\mathrm{ng} / \mathrm{g})\end{array}$ & $\begin{array}{c}{ }^{99} \mathrm{Tc} \\
\text { (atoms/g) }\end{array}$ & $\begin{array}{l}{ }^{99} \mathrm{Tc} \\
(\mathrm{pCi} / \mathrm{g})\end{array}$ & $\begin{array}{l}{ }^{99} \mathrm{Tc} \\
\text { water/ rock } \\
\text { ratio* }\end{array}$ \\
\hline \multirow{3}{*}{ PS1A-2232' } & Blank & & 0 & 101.4 & $<0.001$ & & $<0.025$ & \\
\hline & $\mathrm{CH} 01.1$ & rubble & 0.203 & 85.2 & 0.009 & $5.48 \times 10^{10}$ & 0.145 & 0.3013 \\
\hline & $\mathrm{CH} 01.2$ & rubble & 0.201 & 70.5 & 0.019 & $1.16 \times 10^{11}$ & 0.328 & 0.1423 \\
\hline \multirow[t]{4}{*}{ PS1A-2371' } & $\mathrm{CH} 03.1$ & glass & 0.101 & 77.2 & & & & \\
\hline & CH03.1 dup & glass & 0.102 & 80.9 & $0.729 \pm 0.031$ & $4.44 \times 10^{12}$ & $12.4 \pm 0.530$ & 0.0037 \\
\hline & $\mathrm{CH} 03.2$ & rubble & 0.407 & 48.2 & & & & \\
\hline & CH03.2 dup & rubble & 0.406 & 45.8 & $0.039 \pm 0.004$ & $2.37 \times 10^{11}$ & $0.660 \pm 0.076$ & 0.0697 \\
\hline \multirow[t]{3}{*}{ PS1AS-2181' } & $\mathrm{CH} 04.1$ & glass & 0.193 & 85.9 & 0.669 & $4.07 \times 10^{12}$ & 11.4 & 0.0041 \\
\hline & $\mathrm{CH} 04.2$ & rubble & 0.206 & 84.4 & & & & \\
\hline & CH04.2 dup & rubble & 0.234 & 92.6 & $0.061 \pm 0.003$ & $3.71 \times 10$ & $1.03 \pm 0.058$ & 0.0445 \\
\hline \multirow[t]{2}{*}{ PS1AS-2262' } & $\mathrm{CH} 06.1$ & glass & 0.201 & 83.1 & 0.597 & $3.63 \times 10^{12}$ & 10.1 & 0.0045 \\
\hline & $\mathrm{CH} 06.2$ & glass & 0.206 & 82.4 & 0.632 & $3.85 \times 10^{12}$ & 10.7 & 0.0043 \\
\hline \multirow[t]{2}{*}{ PS1AS-2313' } & $\mathrm{CH} 09.1$ & glass & 0.210 & 80.2 & 0.742 & $4.52 \times 10^{12}$ & 12.6 & 0.0037 \\
\hline & $\mathrm{CH} 09.2$ & glass & 0.199 & 77.0 & 0.695 & $4.23 \times 10^{12}$ & 11.8 & 0.0039 \\
\hline \multirow[t]{2}{*}{ PS1AS composite } & $\mathrm{CH} 12$ & glass & 0.200 & 85.7 & 001 & $002 \quad 1012$ & & \\
\hline & $\mathrm{CH} 12$ dup & glass & 0.199 & 83.0 & $0.645 \pm 0.017$ & $3.93 \times 10$ & $10.9 \pm 0.58$ & 0.0042 \\
\hline \multirow[t]{2}{*}{ PS1ASS-2240' } & $\mathrm{CH} 14$ & rubble & 0.199 & 92.0 & & & & \\
\hline & & rubble & 0.206 & 86.8 & $0.049 \pm 0.003$ & $2.98 \times 10^{11}$ & $0.837 \pm 0.058$ & 0.0554 \\
\hline PS1AS-2292' & $\mathrm{CH} 16$ & glass & 0.198 & 78.5 & 0.747 & $4.55 \times 10^{12}$ & 12.7 & 0.0036 \\
\hline
\end{tabular}

${ }^{*}{ }^{99} \mathrm{Tc}$ groundwater $\left(1.65 \times 10^{10}\right.$ atoms $\left./ \mathrm{g}\right) /{ }^{99} \mathrm{Tc}$ solid (atoms $\left./ \mathrm{g}\right)$ 
Zhao et al. (2008) calculated average ${ }^{99} \mathrm{Tc}$ concentrations in the melt glass $\left(4.2 \times 10^{12}\right.$ at/g), rubble $\left(2.2 \times 10^{11} \mathrm{at} / \mathrm{g}\right)$, and groundwater $\left(1.7 \times 10^{10} \mathrm{at} / \mathrm{g}\right) \mathrm{using}$ the statistical averages of measurements reported in Table 6.2 and Section 6.2.1. They assumed the total mass of the melt glass, rubble, and groundwater to be $1.43 \times 10^{11}, 1.52 \times 10^{12}$, and $1.80 \times 10^{11} \mathrm{~g}$, respectively, based on cavity volume, material density, and porosity calculations. Using these data, Zhao et al. (2008) estimated that approximately $65 \%$ of the ${ }^{99} \mathrm{Tc}$ is associated with the melt glass, and $35 \%$ is associated with the rubble. The groundwater fraction was $\sim 0.3 \%$. Note that the sample set used by Zhao et al. differs somewhat from that used for the gamma-emitting nuclides in Section 4.1, and the results are therefore not on an identical basis. Gamma spectroscopy data were acquired on bulk samples, whereas the ${ }^{99} \mathrm{Tc}$ measurements were performed on hand-selected separates.

Lastly, partitioning values for ${ }^{99} \mathrm{Tc}$ in the melt glass were also calculated using the fission chain yield data reported in England and Rider (1994). The method is identical to that shown in Table 4.5. The fission chain yield for ${ }^{99} \mathrm{Tc}$ varies over a relatively narrow range, from $4.8 \%$ for high-energy neutrons to $6.2 \%$ for thermal neutrons on ${ }^{239} \mathrm{Pu}$, and from $5.1 \%$ to $6.1 \%$ for the same reactions on ${ }^{235} \mathrm{U}$. This is because mass 99 occurs near one of the peaks of the double-humped mass yield distribution curve (Friedlander et al., 1981). Melt glass partitioning values calculated for ${ }^{99} \mathrm{Tc}$ using this approach vary from $47 \%$ to $63 \%$, with an average of $(52 \pm 6) \%$ (1 $\sigma$ standard deviation).

To recap, the ${ }^{99} \mathrm{Tc}$ melt glass partitioning values calculated during this study range from $45 \%$ based on the average Area 19 radionuclide inventory to $65 \%$ based on the material mass estimates from Zhao et al. (2008). The estimate based on fission chain yield data falls entirely within this range. In comparison, the IAEA (1998) estimated that $80 \%$ of the ${ }^{99} \mathrm{Tc}$ is present in the melt glass, and the remaining $20 \%$ is the rubble. The disparity between the IAEA estimate and the current work suggests the range in ${ }^{99} \mathrm{Tc}$ partitioning values likely encompasses a broader range than previously assumed.

\subsection{3 lodine-129 melt glass/rubble partitioning}

Total iodine concentrations and iodine-129 analytical results for test debris samples are reported in Table 6.3. Iodine-129 activities are quite low in all samples. Melt glass samples have activities ranging from $0.4 \times 10^{-3}$ to $2.3 \times 10^{-3} \mathrm{pCi} / \mathrm{g}$, with a mean value of $(1.17 \pm 0.64) \times 10^{-3} \mathrm{pCi} / \mathrm{g}$, based on the six analysis found in Table 6.3. The four rubble samples that were analyzed show a wider range in ${ }^{129} \mathrm{I}$ activities, but with a maximum value of only $0.24 \times 10^{-3} \mathrm{pCi} / \mathrm{g}$.

Total iodine concentrations were measured by ICP-MS on all samples that were prepared by the microwave digestion technique. The results are listed in the ${ }^{127} \mathrm{I}$ solid (ppb) column in Table 6.3. Concentrations range from $<1 \mathrm{ppb}$ to $>40 \mathrm{ppb}$, with no systematic difference between the melt glass and rubble samples. Independent concentration measurements were performed on four samples where the iodine was extracted by pyrohydrolysis. These results are found under the same column heading in Table 6.3 (data in parentheses). Three of the four samples analyzed by pyrohydrolysis had 
concentrations that were 22 to $34 \%$ higher than the microwave digestion values. These two sets of results are in reasonably good agreement considering the low iodine content of the samples. One of the pyrohydrolysis measurements was a factor of 10 lower than the microwave digestion result. In this case, it is inferred that the pyrohydrolysis measurement may be in error due to the small amount of sample used in the analysis.

Partitioning coefficients for ${ }^{129} \mathrm{I}$ were calculated using the three different approaches described in section 6.2.2 for the ${ }^{99} \mathrm{Tc}$ data. The average Area 19 inventory for ${ }^{129} \mathrm{I}$ is: $4.153 \times 10^{-1} \mathrm{Ci}^{129} \mathrm{I} / 36$ tests $=1.154 \times 10^{-2} \mathrm{Ci}$ per test (as of September 23, 1992). Decay correcting to the date of the Chancellor test does not affect this value due to the long half-life of ${ }^{129}$ I. Multiplying the average ${ }^{129}$ I activity measured in the melt glass by its total mass gives an estimate of the total ${ }^{129} \mathrm{I}$ activity in the glass: $\left(1.17 \times 10^{-3} \mathrm{pCi} / \mathrm{g}\right) \mathrm{x}$ $\left(1.43 \times 10^{11} \mathrm{~g}\right)=1.67 \times 10^{-4} \mathrm{Ci}$. Dividing this value into the average Area 19 inventory gives the fraction of the ${ }^{129}$ I inventory in the melt glass: $\left(1.67 \times 10^{-4}\right) /\left(1.154 \times 10^{-2}\right)=$ 0.015 , or only $1.5 \%$. The result suggests that nearly the entire ${ }^{129} \mathrm{I}$ inventory is present in the rubble and groundwater.

Zhao et al. (2008) used material mass estimates together with the measured values in Table 6.3 to calculate a very different inventory distribution. They estimated that $28 \%$, $24 \%$, and $48 \%$ of the ${ }^{129}$ I inventory was in the melt glass, rubble, and groundwater phases, respectively. The melt glass fraction determined by Zhao et al. (28\%) is considerably higher than the value obtained using the average Bowen inventory (1.5\%), but is lower than the IAEA (1998) prediction of $50 \%$.

Melt glass partitioning values that were calculated using the fission chain yield data from England and Rider (1994) are similar to those obtained from the Bowen et al. (2001) inventory, ranging from $0.6 \%$ to $3.9 \%$, with an average of $(1.8 \pm 1.3) \%(1 \sigma$ standard deviation).

The IAEA (1998) reported that $50 \%$ of the ${ }^{129}$ I inventory was contained in the melt glass, with $40 \%$ in the rubble, and $10 \%$ in the groundwater. Compared with IAEA estimates, partitioning calculations from Zhao et al. (2008) show that a larger fraction of the ${ }^{129} \mathrm{I}$ is present in groundwater (48\%) and a lower fraction is contained in the glass $(28 \%)$ and rubble (24\%). However, independent calculations of the melt glass fraction using the average Area 19 inventory from Bowen et al. (2001) and fission chain yield data from England and Rider (1994) imply much lower melt glass fractions of $<1 \%$ to $4 \%$.

The Zhao et al. (2008) partitioning estimate may be skewed to some extent by including sample $\mathrm{CH}-01$ in the average rubble inventory. Two of the four ${ }^{129} \mathrm{I}$ rubble analyses were made on $\mathrm{CH}-01$ (Table 6.3), but the ${ }^{129} \mathrm{I}$ concentrations in these samples are 100 to 1000 times lower than the other two rubble samples (CH-04.2 and $\mathrm{CH}-14.1)$. If $\mathrm{CH}-01$ is excluded from the rubble inventory and the calculation is repeated, the ${ }^{129} \mathrm{I}$ inventory distribution becomes $21 \%, 36 \%$, and $43 \%$ for the melt glass, rubble, and groundwater phases, respectively. 
Excluding $\mathrm{CH}-01$ from the average rubble inventory does not account for the difference between the Zhao et al. melt glass partitioning value and that obtained from the average Bowen inventory and the fission chain yield data. The available suite of analytical data may not adequately reflect the distribution of ${ }^{129} \mathrm{I}$ in the test cavity, particularly for the rubble. Analytical uncertainties may also contribute to the uncertainty in the partitioning estimates. The input parameters used to calculate melt glass partitioning from the Bowen inventory and fission chain yield data are also associated with relatively large uncertainties.

In general, it can be concluded that the ${ }^{129}$ I partitioning values reported by the IAEA are not applicable to the Chancellor test-cavity for either the melt glass or groundwater fractions. The IAEA melt glass value (50\%) is too high by a factor of 1.8 or more, and the groundwater value (10\%) is apparently 4 or 5 times too low. The IAEA rubble value $(40 \%)$ is in reasonable accord with the results from this study if sample CH-01 is excluded from the average rubble inventory.

\subsubsection{Water-rock ratios for ${ }^{99}$ TC and ${ }^{129}$ I}

Water-rock ratios for ${ }^{99} \mathrm{Tc}$ and ${ }^{129} \mathrm{I}$ provide a qualitative measure of the conversion of the radiologic source term into the hydrologic source term. Although the total volume of water that has interacted with the test debris is unknown, it is instructive to simply compare the rock-water ratios obtained by dividing the atom/gram concentrations in the groundwater by the atom/gram concentrations in the test debris samples. (The same ratios are obtained using activity data).

Water-rock ratios for ${ }^{99} \mathrm{Tc}$ vary from a high value of 0.30 (for $\mathrm{CH}-01$ rubble) to a low value of 0.0036 (melt glass CH16; see Table 6.2), which is less than a factor of 100 difference. The melt glass samples show a fairly narrow range in ratios between 0.0036 and 0.0045 . In other words, the ${ }^{99} \mathrm{Tc}$ concentration in the groundwater is only $\sim 0.4 \%$ of that in the melt glass on an equal mass basis. The rubble samples have higher water-rock ratios between 0.04 and 0.30 , such that the ${ }^{99} \mathrm{Tc}$ content of the water ranges from $4 \%$ to $30 \%$ of the rubble sample content.

In contrast to the ${ }^{99} \mathrm{Tc}$ data, the water-rock ratios for ${ }^{129} \mathrm{I}$ are greater than one for all but one glass sample (Table 6.3), indicating that the groundwater is enriched in ${ }^{129}$ I relative to the melt glass and rubble. The $\mathrm{CH}-03$ melt glass sample has the lowest ${ }^{129} \mathrm{I}$ water-rock ratio (0.86), while other melt glass samples have ratios between 1.5 and 4.4. Rubble samples have ${ }^{129}$ I concentrations that are lower than the melt glass, with water-rock ratios that range from 7.9 to $>10^{4}$. 
Table 6.3 Results of ${ }^{129}$ I analyses of Chancellor drillback core samples

\begin{tabular}{|c|c|c|c|c|c|c|c|c|}
\hline $\begin{array}{l}\text { Drill Line - Depth } \\
\text { (ft-bgs) }\end{array}$ & Sample & ${ }^{129} I /{ }^{127} I$ & $\begin{array}{c}{ }^{129} / /^{127} I \\
\text { uncertainty }\end{array}$ & $\begin{array}{l}{ }^{127} \text { I solid } \\
\text { (ppb) }\end{array}$ & $\begin{array}{c}\stackrel{127}{\mathrm{I}} \\
\text { (atoms/g) }\end{array}$ & $\begin{array}{c}{ }^{129} \mathrm{I} \\
\text { (atoms/g) }\end{array}$ & $\begin{array}{c}129 \mathrm{I} \\
(\mathrm{pCi} / \mathrm{g})\end{array}$ & $\begin{array}{l}129 \text { I } \\
\text { water / rock } \\
\text { ratio }\end{array}$ \\
\hline & Blank-1 & $1.89 \times 10^{-13}$ & $6.1 \%$ & & & & & \\
\hline & Blank-2 & $2.96 \times 10^{-13}$ & $2.8 \%$ & & & & & \\
\hline PS1A-2232' & $\mathrm{CH} 01.1$ & $3.07 \times 10^{-7}$ & $4.0 \%$ & 23.6 & $1.12 \times 10^{14}$ & $3.44 \times 10^{7}$ & $1.30 \times 10^{-6}$ & $1.49 \times 10^{3}$ \\
\hline PS1A-2232' & $\mathrm{CH} 01.2$ & $3.71 \times 10^{-8}$ & $0.3 \%$ & 26.0 & $1.23 \times 10^{14}$ & $4.58 \times 10^{6}$ & $1.73 \times 10^{-7}$ & $1.12 \times 10^{4}$ \\
\hline PS1A-2371' & $\mathrm{CH} 03.1$ & $8.78 \times 10^{-4}$ & $2.4 \%$ & $14.3(1.4)^{\mathrm{a}}$ & $6.78 \times 10^{13}$ & $5.96 \times 10^{10}$ & $2.25 \times 10^{-3}$ & 0.86 \\
\hline \multirow[t]{2}{*}{ PS1AS-2181' } & $\mathrm{CH} 04.1$ & $1.70 \times 10^{-4}$ & $2.0 \%$ & $40.3(51.9)^{\mathrm{a}}$ & $1.91 \times 10^{14}$ & $3.25 \times 10^{10}$ & $1.23 \times 10^{-3}$ & 1.58 \\
\hline & $\mathrm{CH} 04.2$ & $1.08 \times 10^{-4}$ & $2.0 \%$ & $12.6(18.4)^{\mathrm{a}}$ & $5.98 \times 10^{13}$ & $6.46 \times 10^{9}$ & $2.44 \times 10^{-4}$ & 7.94 \\
\hline \multirow[t]{2}{*}{ PS1AS-2262' } & $\mathrm{CH} 06.1$ & $1.32 \times 10^{-3}$ & $2.0 \%$ & $5.0(7.6)^{\mathrm{a}}$ & $2.37 \times 10^{13}$ & $3.13 \times 10^{10}$ & $1.18 \times 10^{-3}$ & 1.64 \\
\hline & $\mathrm{CH} 06.2$ & $7.20 \times 10^{-4}$ & $2.0 \%$ & 3.4 & $1.61 \times 10^{13}$ & $1.16 \times 10^{10}$ & $4.39 \times 10^{-4}$ & 4.42 \\
\hline PS1AS-2313' & $\mathrm{CH} 09$ & $3.89 \times 10^{-3}$ & $1.3 \%$ & 0.9 & $4.27 \times 10^{12}$ & $1.66 \times 10^{10}$ & $6.28 \times 10^{-4}$ & 3.09 \\
\hline PS1ASS-2240' & $\mathrm{CH} 14.1$ & $4.43 \times 10^{-5}$ & $2.0 \%$ & 16.7 & $7.92 \times 10^{13}$ & $3.51 \times 10^{9}$ & $1.33 \times 10^{-4}$ & 14.6 \\
\hline PS1ASS-2292' & $\mathrm{CH} 16.1$ & $2.45 \times 10^{-3}$ & $1.3 \%$ & 3.0 & $1.42 \times 10^{13}$ & $3.49 \times 10^{10}$ & $1.32 \times 10^{-3}$ & 1.47 \\
\hline
\end{tabular}

${ }^{a}$ Values listed in parentheses were from samples prepared by pyrohydrolysis instead of microwave digestion. 


\subsection{Summary of Partitioning Results}

Partitioning ratios for ${ }^{99} \mathrm{Tc}$ and ${ }^{129} \mathrm{I}$ were evaluated using the three different approaches outlined in Section 1.5. For ${ }^{99} \mathrm{Tc}$, the three methods gave a reasonably consistent set of results. The calculation based on the average NNSS Area 19 inventory from Bowen et al. (2001) indicated $44.5 \%$ of the ${ }^{99} \mathrm{Tc}$ was contained in the melt glass. Fission chain yield data from England and Rider (1994) showed a range for the melt glass fraction of $47 \%$ to $63 \%$, with an average of $(52.0 \pm 6.1) \%$. Calculations based on material mass estimates from Zhao et al. (2008) gave partitioning values of $65 \%, 35 \%$, and $0.3 \%$ for the melt glass, rubble, and groundwater, respectively. Overall, these results imply a range in the ${ }^{99} \mathrm{Tc}$ partitioning fractions of $45-65 \%$ for the melt glass and $35-55 \%$ for the rubble, with a groundwater fraction of $<1 \%$. In comparison, the IAEA (1998) partitioning values for ${ }^{99} \mathrm{Tc}$ are $80 \%$ in the glass and $20 \%$ in the rubble. The results of this study indicate a much broader range in values is likely.

The results obtained for ${ }^{129} \mathrm{I}$ partitioning were less consistent. The average Area 19 inventory gave a melt glass fraction of only $1.5 \%$, and the fission chain yield calculations gave a similarly low range of values for the melt glass of $0.6 \%$ to $3.9 \%$, with an average of $(1.8 \pm 1.3) \%$. In contrast, the Zhao et al. calculations gave partitioning values of $28 \%$, $24 \%$, and $48 \%$ for the melt glass, rubble, and groundwater, respectively. However, the average rubble concentration used in the Zhao et al. calculation included two analyses of sample $\mathrm{CH}-01$, which has an anomalously low ${ }^{129} \mathrm{I}$ concentration. Excluding this sample from the calculation gave partitioning values of $21 \%, 36 \%$, and $43 \%$ for the melt glass, rubble, and groundwater. The combined results indicate the melt glass fraction for ${ }^{129} \mathbf{I}$ has a possible range from $\sim 1 \%$ to $28 \%$. Scaling the rubble and groundwater fractions to the melt glass range (including the possibility of a $1 \%$ glass fraction) implies a potential range in the rubble fraction of $24-45 \%$ and a range in the groundwater fraction of 43-66\%. The IAEA (1998) partitioning values for ${ }^{129} \mathrm{I}$ are $50 \%, 40 \%$, and $10 \%$ in the melt glass, rubble, and groundwater, respectively. Compared to the results from this study, the melt glass partitioning estimate appears to be too high, and the groundwater estimate is too low.

Iodine-129 is somewhat unusual compared to other fission products in that a large fraction its source term is present in the groundwater. Water-rock ratios calculated on an equal mass basis (Table 6.3) show that the concentration of ${ }^{129}$ I per unit mass in the water is greater than that of the test debris in all but one sample. The ${ }^{129}$ I enrichment in the water is up to 4.4 times that of the melt glass, and a factor of $10^{4}$ greater than the lowestconcentration rubble sample. These observations suggest that the ${ }^{129} \mathrm{I}$ source term is readily mobilized in circulating groundwater. Identical water-rock ratio calculations were also performed for ${ }^{99} \mathrm{Tc}$ (Table 6.2). In this case, the dissolved fraction of the source term was $\sim 0.4 \%$ of the average melt glass ${ }^{99} \mathrm{Tc}$ concentration, $4 \%$ of the high concentration rubble samples, and $30 \%$ of the lowest-concentration rubble samples.

Hydrothermal circulation of groundwater within the Chancellor test cavity is known to have occurred; the water temperature within the cavity is presently $\sim 75^{\circ} \mathrm{C}$. Soluble 
species that come in contact with this fluid will likely go into solution. Hence, some of the inconsistency between the partitioning estimates for ${ }^{99} \mathrm{Tc}$ and ${ }^{129} \mathrm{I}$ made during this study and those reported by the IAEA (1998) may be related to the leaching and/or remobilization of these elements long after the initial post-detonation elemental distribution was established.

\subsection{Comments on Redox Conditions in the Cavity Fluid}

The solubility of ${ }^{99} \mathrm{Tc}$ in water is highly sensitive to redox conditions. Under oxidizing conditions, it occurs as the soluble pertechnetate ion $\left(\mathrm{Tc}^{7+} \mathrm{O}_{4}{ }^{-}\right)$whereas under moderately reducing conditions it forms the low solubility compounds $\mathrm{Tc}^{4+} \mathrm{O}(\mathrm{OH})_{2}$ or $\mathrm{Tc}^{4+} \mathrm{O}_{2} 2 \mathrm{H}_{2} \mathrm{O}$. Lieser and Bauscher (1987) performed a series of experiments to elucidate the nature of the $\mathrm{Tc}^{7+} / \mathrm{Tc}^{4+}$ redox boundary in an experimental sediment-groundwater system. By varying the redox potential (Eh) in the system, they observed a three order of magnitude variation in the ${ }^{99} \mathrm{Tc}$ sorption ratio at $\mathrm{Eh}=170 \pm 60 \mathrm{mV}$ and $\mathrm{pH}=7 \pm 0.5$.

Groundwater from the Chancellor test cavity has an Eh value of $73.2 \mathrm{mV}$ (Table 2.3), which is well below the $170 \mathrm{mV}$ redox boundary reported by Lieser and Bauscher. This implies that $\mathrm{Tc}^{4+}$ compounds should be stable. However, the groundwater $\mathrm{pH}$ is 9.4, which is outside the range of $\mathrm{pH}$ conditions for Lieser and Bauscher's experiments. Hence, the two sets of results cannot be directly compared.

The stability boundary between $\mathrm{Tc}^{7+} \mathrm{O}_{4}{ }^{-}$and $\mathrm{Tc}^{4+} \mathrm{O}(\mathrm{OH})_{2}$ has a negative slope on an Eh$\mathrm{pH}$ diagram (see Lieser and Bauscher, 1987) such that the Eh value at $\mathrm{pH}=9.4$ is $~ 200$ $\mathrm{mV}$ lower than the value measured at $\mathrm{pH}=7$. This would suggest the Eh value for Chancellor groundwater actually lies in the $\mathrm{Tc}^{7+} \mathrm{O}_{4}{ }^{-}$stability field. However, Lieser and Bauscher note that the low solubility of the reduced Tc species can result in supersaturation with respect to $\mathrm{Tc}^{4+}$ at Eh values well above the stability boundary.

An indirect line of evidence suggests that the redox conditions in the cavity fluid are in fact favorable for Tc reduction. Chapter 2 of this report included a brief discussion of laboratory experiments involving the addition of excess $\mathrm{Fe}^{3+}$ to Chancellor groundwater samples. The lack of $\mathrm{Fe}(\mathrm{OH})_{3}$ precipitation during these experiments suggests the water is sufficiently reducing to immediately convert $\mathrm{Fe}^{3+}$ to $\mathrm{Fe}^{2+}$. Fortunately, the Eh- $\mathrm{pH}$ stability relationship for the $\mathrm{Fe}^{3+} / \mathrm{Fe}^{2+}$ redox boundary has been studied in detail (e.g. Krauskopf, 1979), permitting the direct calculation of an Eh value for any $\mathrm{pH}$ condition. For the reduction of $\mathrm{Fe}(\mathrm{OH})_{3}$ to $\mathrm{Fe}^{2+}\left(\right.$ at $\left.\left[\mathrm{Fe}^{2+}\right]=10^{-7} \mathrm{M}\right)$, the Eh value is 0.151 $\mathrm{mV}$ at $\mathrm{pH}=7$, and $-0.285 \mathrm{mV}$ at $\mathrm{pH}=9.4$. Note that the Eh value for the $\mathrm{Fe}^{3+} / \mathrm{Fe}^{2+}$ stability boundary is less than that of the $\mathrm{Tc}^{7+} / \mathrm{Tc}^{4+}$ boundary at both $\mathrm{pH}$ values. Hence, if iron reduction is occurring in the groundwater, it is likely that technetium reduction may also occur.

The amount of ${ }^{99} \mathrm{Tc}$ that is present in Chancellor groundwater is relatively low compared to the solubility of the $\mathrm{TcO}_{4}^{-}$ion. The groundwater concentration is $2.7 \times 10^{-11} \mathrm{~mol} / \mathrm{L}$, but the solubility of ionic $\mathrm{TcO}_{4}{ }^{-}$salts in aqueous solution is on the order of $10^{-1} \mathrm{~mol} / \mathrm{L}$ 
(Rard, 1983). A significant fraction (35-55\%) of the technetium source term is present in the rubble phase, where it is assumed that chemical reactions with groundwater can freely occur along open surfaces. The relatively low concentration of dissolved ${ }^{99} \mathrm{Tc}$ in Chancellor groundwater suggests its mobility may be inhibited, which is consistent with redox conditions that are favorable for the reduction of technetium. 


\subsection{Conclusions}

Radionuclide concentrations were measured in samples collected from the U-19ad (Chancellor) post-shot borehole and the results were used to calculate partitioning values for the melt glass, rubble, and groundwater phases. Partitioning values were determined on the basis of (1) the average Area 19 inventory from Bowen et al. (2001); (2) melt glass, rubble, and groundwater mass estimates from Zhao et al. (2008); and (3) fission product mass yield data from England and Rider (1994), though each method could not be applied to every nuclide. The evaluation included the fission products ${ }^{99} \mathrm{Tc},{ }^{125} \mathrm{Sb},{ }^{129} \mathrm{I}$, ${ }^{137} \mathrm{Cs}$, and ${ }^{155} \mathrm{Eu}$, the activation products ${ }^{60} \mathrm{Co},{ }^{152} \mathrm{Eu}$, and ${ }^{154} \mathrm{Eu}$, and the actinides U, $\mathrm{Pu}$, and ${ }^{241} \mathrm{Am}$. For $\mathrm{U}$ and $\mathrm{Pu}$, the measured data for the test debris are classified, and partitioning values were calculated directly from the classified Chancellor test inventory found in Miller et al. (2002).

Partitioning values from this study are summarized in Table 7.1 together with data previously published by the IAEA (1998). The values are reported in percent, and the sum of the glass + rubble + groundwater fractions should equal $100 \%$. For some nuclides, a range in plausible values was obtained (see Table 7.1). In other instances, the results were plainly erroneous or physically impossible; in those cases, the results are not reported here. The first two columns of data show results from the average Area 19 inventory (Bowen et al., 2001) and fission mass yield calculations (England and Rider, 1994) for the melt glass only. The next three columns contain results from the material mass estimate method (Zhao et al., 2008) or from the Miller et al. (2002) inventory (for $\mathrm{U}$ and $\mathrm{Pu}$ ), and include values for the glass, rubble, and groundwater phases. The last three columns contain the IAEA (1998) partitioning data.

The partitioning values from this study are consistent with the IAEA results for many of the radionuclides that were investigated, including ${ }^{60} \mathrm{Co},{ }^{137} \mathrm{Cs},{ }^{152} \mathrm{Eu},{ }^{154} \mathrm{Eu},{ }^{155} \mathrm{Eu},{ }^{241} \mathrm{Am}$, and $\mathrm{Pu}$. This increases our confidence in the application of the IAEA data to UGTA transport models for these nuclides. The results for ${ }^{99} \mathrm{Tc},{ }^{125} \mathrm{Sb},{ }^{129} \mathrm{I}$, and $\mathrm{U}$ show more substantive differences with the IAEA data. These differences are likely due to a combination of two factors: (1) chemical volatility during plasma condensation, and (2) chemical mobility in groundwater.

The distribution of fission products is strongly influenced by the chemical properties of the short-lived precursor elements in each fission chain. Since each precursor element decays on a different time-scale, test cavities that are 'quenched' soon after the detonation will have a different fission product distribution than cavities that stand for a longer period of time. For fission chains that include volatile or semi-volatile elements, like those at mass 99, 125, and 129, the cooling history of the test cavity will have an important influence on the fission product distribution. For this reason alone, it is not surprising to find inconsistencies with the IAEA partitioning values for these nuclides. 
Table 7.1 Summary of partitioning data from the present study and IAEA (1998)

\begin{tabular}{|c|c|c|ccc|ccc|}
\hline Nuclide & $\begin{array}{c}\text { Average } \\
\text { Area 19 }\end{array}$ & $\begin{array}{c}\text { Fission } \\
\text { Yield }\end{array}$ & \multicolumn{3}{|c|}{ Material Mass Estimate } & \multicolumn{3}{|c|}{ IAEA (1998) } \\
glass, \% & glass, \% & glass, \% & rubble, \% & water, \% & glass, \% & rubble, \% & water, \% \\
\hline Co-60 & --- & --- & 91 & 9 & 0.01 & 90 & 10 & 0 \\
Tc-99 & 45 & $47-63$ & $45-65$ & $35-55$ & 0.3 & 80 & 20 & 0 \\
Sb-125 & --- & --- & 60 & 39 & 1 & 70 & 30 & 0 \\
I-129 & 1.5 & $1-4$ & $1-28$ & $24-45$ & $43-66$ & 50 & 40 & 10 \\
Cs-137 & 36 & $32-47$ & 40 & 60 & 0.07 & $25-40$ & $60-75$ & 0 \\
Eu-152 & --- & --- & 94 & 6 & 0.01 & 95 & 5 & 0 \\
Eu-154 & --- & --- & 95 & 5 & 0.01 & 95 & 5 & 0 \\
Eu-155 & --- & --- & 94 & 6 & 0.01 & 95 & 5 & 0 \\
Am-241 & --- & --- & 95 & 5 & --- & 98 & 2 & 0 \\
\hline & & & Miller et al. (2002) inventory & & IAEA (1998) \\
& & & glass, \% & rubble, \% & water, \% & glass, \% & rubble, \% & water, \% \\
\hline U & --- & --- & 73 & 27 & $<0.01$ & 90 & 10 & 0 \\
Pu & --- & -- & 96 & 4 & $<0.01$ & 98 & 2 & 0 \\
\hline
\end{tabular}

Uranium is also known to exhibit chemical fractionation during plasma condensation (Moody, 2003), though the chemical processes that cause this behavior remain poorly understood. Krikorian (1981) calculated the equilibrium partial pressures of oxide and hydroxide species that are stable in the $1000-2000^{\circ} \mathrm{K}$ range for a number of elements and found that uranium shows a higher volatility than any of the other actinides. These data qualitatively support the idea that uranium will tend to show some chemical separation from the highly refractory elements that condense with the melt glass.

Groundwater interaction with test debris in the lower portion of the Chancellor cavity has occurred at elevated temperatures for more than two decades since the test was fired. Under these circumstances, some remobilization of soluble species is expected to occur, and Tc, Sb, I, and U all form relatively soluble anions in solution. Although the solubility of Tc (and perhaps Sb) may be inhibited by the moderately reducing conditions within the cavity, the solubility of iodine will not be similarly impacted. Hence, iodine mobility in solution may largely account for the discrepancy between the IAEA partitioning results and those reported here.

In general, chemical volatility and groundwater remobilization processes can reasonably account for the differences between the IAEA partitioning data and the results from this study. It is recommended that the partitioning results from this study should be used in combination with the IAEA (1998) data to define the initial radionuclide distributions used in the UGTA transport models. This recommendation will result in a broader range of partitioning values for ${ }^{99} \mathrm{Tc},{ }^{129} \mathrm{I}$ and the uranium isotopes, and a small increase in the ${ }^{137} \mathrm{Cs}$ partitioning range. ${ }^{125} \mathrm{Sb}$ is generally not included in the UGTA models due to its short half-life. All other nuclides show consistent behavior between the two studies. 
Any future studies of this nature should focus on underground tests that are inferred to have very fast or very slow cooling histories. Acquiring data for these 'end-member' cases would help determine the full range in radionuclide partitioning behavior in the underground testing environment. 


\subsection{References}

Adeleye, S.A., Clay, P.G., and Oladipo, M.O.A. (1994) Sorption of cesium, strontium, and europium ions on clay minerals. Journal of Materials Science, 29: 954-958.

ASTM (2005) Standard guide for the determination of Technetium-99 in soil. The American Society for Testing and Materials (ASTM International), West Conshohocken, PA.

Bechtel-Nevada (2002) A hydrostratigraphic model and alternatives for the groundwater flow and contaminant transport model of Corrective Action Units 101 and 102: Central and Western Pahute Mesa, Nye County, Nevada. DOE/NV/11718-706, 383 p.

Bedford, R.G., and Jackson, D.D. (1965) Volatilities of the fission products and uranium oxides. Lawrence Livermore National Laboratory Report UCRL-12314.

Bergquist, B.A., Marchetti, A.A., Martinelli, R.E., McAninch, J.E., Nimz, G.J., Proctor, I.D., Southon, J.R., and Vogel, J.S. (2000) Technetium measurements by accelerator mass spectrometry at LLNL. Nuclear Instruments and Methods in Physics Research $B, 172$ : 328-333.

Bish, D.L., and Aronson, J.L. (1993) Paleogeothermal and paleohydrologic conditions in silicic tuff from Yucca Mountain, Nevada. Clays and Clay Minerals, 41: 148-161.

Blankennagel, R.K., and Weir, J.E., Jr. (1973) Geohydrology of the eastern part of Pahute Mesa, Nevada Test Site, Nye County, Nevada. U.S. Geological Survey Professional Paper 712-B, $35 \mathrm{p}$.

Borg, I.Y. (1975) Radioactivity trapped in melt produced by a nuclear explosion. Nuclear Technology, 26: 88-100.

Borg, I.Y., Stone, R., Levy, H.B., and Ramspott, L.D. (1976) Information pertinent to the migration of radionuclides in ground water at the Nevada Test Site. Part 1: review and analysis of existing information. Lawrence Livermore National Laboratory Report UCRL-52078 Pt. 1, 216 p.

Bowen, S.M., Finnegan, D.L., Thompson, J.L., Miller, C.M., Baca, P.L., Olivas, L.F., Geoffrion, C.G., Smith, D.K., Goishi, W., Esser, B.K., Meadows, J.W., Namboodiri, N., and Wild, J.F. (2001) Nevada Test Site Radionuclide Inventory, 1951-1992. Los Alamos National Laboratory Report LA-13859-MS, 28 p.

Brookins, D.G. (1986) Rhenium as an analog for fissiogenic technetium: Eh-pH diagram $\left(25^{\circ} \mathrm{C}, 1\right.$ bar) constraints. Applied Geochemistry, 1: 513-517. 
Brown, C.F., Geiszler, K.N., and Legore, V.L. (2005) Extraction and quantitative analysis of iodine in solid samples. Geochimica et Cosmochimica Acta, 69: A717, Suppl. 1.

Broxton, D.E., Warren, R.G., Byers, F.M., and Scott, R.B. (1989) Chemical and mineralogic trends within the Timber Mountain-Oasis Valley caldera complex, Nevada: Evidence for multiple cycles of chemical evolution in a long-lived silicic magma system. Jour. Geophys. Res., 94: 5961-5985.

Buddemeier, R.W., Finkel, R.C., Marsh, K.V., Ruggieri, M.R., Rego, J.H., and Silva, R.J. (1991) Hydrology and radionuclide migration at the Nevada Test Site. Radiochimica Acta, 52/53: 275-282.

Carle, S.F., Maxwell, R.M., and Pawloski, G.A. (2003) Impact of test heat on groundwater flow at Pahute Mesa, Nevada Test Site. Lawrence Livermore National Laboratory Report UCRL-ID-152599, 143 p.

Carlos, B.A., Chipera, S.J., Bish, D.L. (1995) Distribution and chemistry of fracturelining minerals at Yucca Mountain, Nevada. Los Alamos National Laboratory Report LA-12977-MS, 92 p.

Chen, C.C., and Hayes, K.F. (1999) X-ray absorption spectroscopy investigation of aqueous $\mathrm{Co}(\mathrm{II})$ and $\mathrm{Sr}(\mathrm{II})$ sorption at clay-water interfaces. Geochimica et Cosmochimica Acta, 63: 3205-3215.

Chipera, S.J., and Apps, J.A. (2001) Geochemical stability of natural zeolites. In: D.L. Bish and D.W. Ming (eds.), Natural Zeolites: Occurrence, Properties, and Applications. Reviews in Mineralogy and Geochemistry, v. 45, Mineralogical Society of America, Washington D.C., pp. 117-161.

Daniels, W.R. (1981) Laboratory and Field Studies Related to the Radionuclide Migration Project, October 1, 1979 - September 30, 1980. Los Alamos National Laboratory Report LA-8670-PR, 26 p.

Dixon, P., Curtis, D.B., Musgrave, J., Roensch, F., Roach, J., and Rokop, D. (1997) Analysis of naturally produced technetium and plutonium in geologic materials. Analytical Chemistry, 69: 1692-1699.

DOE/NV (2000) United States Nuclear Tests, July 1945 through September 1992. U.S. Department of Energy, Nevada Operations Office, Las Vegas. DOE/NV-209 (Rev. 15), December 2000.

Dyer, A., Pillinger, M., Harjula, R., and Amin, S. (2000) Sorption characteristics of radionuclides on synthetic birnessite-type layered manganese oxides. Journal of Materials Chemistry, 10: 1867-1874. 
Eichrom Technologies, Inc. (2002) Technetium-99 in water. Analytical Procedures, procedure \# TCW01, Rev. 1.6.

England, T.R., and Rider, B.F. (1994) Evaluation and compilation of fission product yields: 1993. Los Alamos National Laboratory, LA-UR-94-3106, October 1994.

Finkel, R.C., Caffee, M.W., Marsh, K.V., and Rego, J.H. (1992) Accelerator mass spectrometry measurements of ${ }^{129} \mathrm{I}$ in Cheshire site groundwater. In: K.V. Marsh (ed.), Hydrology and Radionuclide Migration Program 1988 Progress Report. Lawrence Livermore National Laboratory Report UCRL-53779-88, pp. 11-12.

Friedlander, G., Kennedy, J.W., Macias, E.S., and Miller, J.M. (1981) Nuclear and Radiochemistry, 3rd Edition. John Wiley \& Sons, New York, 684 p.

Germain, L.S., and Kahn, J.S. (1968) Phenomenology and containment of underground nuclear explosions. Lawrence Radiation Laboratory, UCRL-50482, 49 p.

Glasstone, S. and Dolan, P.J. (1977) The effects of nuclear weapons, 3rd edition. United States Department of Defense and Energy Research and Development Administration, U.S. Government Printing Office, Washington, D.C., 653 p.

Gunnarsson, M., Jakobsson, A.M., Ekberg, S., Albinsson, Y., and Ahlberg, E. (2000) Sorption studies of cobalt (II) on colloidal hematite using potentiometry and radioactive tracer technique. Journal of Colloid and Interface Science, 231: 326336.

Harvey, B.R., Williams, K.J., Lovett, M.B., and Ibbett, R.D. (1992) Determination of technetium-99 in environmental material with rhenium as a yield monitor. Journal of Radioanalytical and Nuclear Chemistry, 158: 417-436.

Holler, H., and Wirsching, U. (1980) Experiments on the formation of zeolites by hydrothermal alteration of volcanic glass. In: L.B. Sand and F.A. Mumpton (eds.), Natural Zeolites: Occurrence, Properties, and Use. Pergamon Press, Oxford, UK, pp. 329-350.

Hu, Q., and Moran, J.E. (2005) Simultaneous analyses and applications of multiple flurobenzoate and halide tracers in hydrologic studies. Hydrological Processes, 19: 2671-2687.

IAEA (1998) The Radiological Situation at the Atolls of Mururoa and Fangataufa, Technical Report, Volume 3: Inventory of Radionuclides Underground at the Atolls. International Atomic Energy Agency Report IAEA-MFTR-3, Vienna, Austria.

Kersting, A.B., D.W. Efurd, D.L. Finnegan, D.J. Rokop, D.K. Smith, and J.L. Thompson (1999) Migration of plutonium in groundwater at the Nevada Test Site. Nature, 397: $56-59$. 
Krauskopf, K.B. (1979) Introduction to Geochemistry, second edition. McGraw-Hill, New York, 617 p.

Krikorian, O.H. (1981) Predictive calculations of volatilites of metals and oxides in steam-containing environments. Lawrence Livermore National Laboratory, UCRL85553.

Krupka, K.M., and Serne, R.J. (2002) Geochemical factors affecting the behavior of antimony, cobalt, europium, technetium, and uranium in vadose sediments. Pacific Northwest National Laboratory Report PNNL-14126, 95 p.

Laczniak, R.J., Cole, J.C., Sawyer, D.A., and Trudeau, D.A. (1996) Summary of hydrogeologic controls on ground-water flow at the Nevada Test Site, Nye County, Nevada. U.S. Geological Survey Water-Resources Investigations Report 96-4109, 59 p.

Lieser, K.H. (1993) Technetium in the nuclear fuel cycle, in medicine, and in the environment. Radiochimica Acta, 63: 5-8.

Lieser, K.H., and Bauscher, C. (1987) Technetium in the hydrosphere and in the geosphere. 1. Chemistry of technetium and iron in natural waters and influence of the redox potential on the sorption of technetium. Radiochimica Acta, 42: 205-213.

Lieser, K.H., and Steinkopff, T. (1989) Chemistry of radioactive cesium in the hydrosphere and in the geosphere. Radiochimica Acta, 46: 39-47.

LLNL (2004) Analytical Measurements: Standard Operating Procedures, Underground Test Area Project. Chemical Biology and Nuclear Science Division, Lawrence Livermore National Laboratory, June 30, 2004.

Mas, J.L., Tagami, K., and Uchida, S. (2004) Method for the detection of Tc in seaweed samples coupling the use of Re as a chemical tracer and isotope dilution inductively coupled plasma mass spectrometry. Analytica Chimica Acta, 509: 83-88.

McAninch, J.E., Martinelli, R.E., and Smith, D.K. (2000) Measurements of technetium99 in Nevada Test Site well water samples. In: D.K. Smith and G.F. Eaton (eds.), Hydrologic Resources Management Program and Underground Test Area FY 1999 Progress Report. Lawrence Livermore National Laboratory Report UCRL-ID139226, pp. 35-44.

Miller, C.M., Bowen, S.M., Finnegan, D.L., Thompson, J.L., Baca, P.L., Olivas, L.F., Geoffrion, C., Smith, D.K., Goishi, W., Esser, B.K., Meadows, J.W., Namboodiri, N., and Wild, J.F. (2002) Total radionuclide inventory associated with underground nuclear tests conducted at the Nevada Test Site, 1951-1992 (U). Los Alamos National Laboratory Report LA-13989, Secret / Restricted Data, 966 p. 
Moody, K.J. (2003) Underground chemistry and the uncertainty of the yields of nuclear devices. Lawrence Livermore National Laboratory Report UCRL-TR-200852, Export Controlled Information / Official Use Only, 49 p.

Moran, J.E., Fehn, U., and Hanor, J.S. (1995) Determination of source ages and migration patterns of brines from the U.S. Gulf Coast basin using ${ }^{129}$ I. Geochimica et Cosmochimica Acta, 59: 5055-5069.

Ohnuki, T., and Kozai, N. (1994) Sorption characteristics of radioactive cesium and strontium on smectite. Radiochimica Acta, 66/67: 327-331.

Olsen, C.W. (1967) Time history of the cavity pressure and temperature following a nuclear detonation in alluvium. Journal of Geophysical Research, 72: 5037-5041.

Olsen, C.W. (1993) Site selection and containment evaluation for LLNL nuclear events. In: C.W. Olsen (ed.), Proceedings of the Seventh Symposium on Containment of Underground Nuclear Explosions - Volume 1, Sept. 13-17, 1993, Boeing Space Center East, Kent Washington, Conf-9309103-Vol. 1, pp. 85-119.

Pawloski, G.A. (1999) Development of phenomenological models of underground nuclear tests on Pahute Mesa, Nevada Test Site - BENHAM and TYBO. Lawrence Livermore National Laboratory Report UCRL-ID-136003, 46 p.

Pawloski, G.A., A.F.B. Tompson, and S.F. Carle (2001) Evaluation of the hydrologic source term from underground nuclear tests on Pahute Mesa at the Nevada Test Site: The Cheshire test. Lawrence Livermore National Laboratory Report UCRL-ID147023.

Pawloski, G.A., Rose, T.P., Meadows, J.W., Deshler, B.J., and Watrus, J. (2002) Categorization of underground nuclear tests on Pahute Mesa, Nevada Test Site, for use in radionuclide transport models. Lawrence Livermore National Laboratory Report UCRL-TR-208347, 235 p.

Rajec, P., Macášek, F., Féder, M., Misaelides, P., and Šamajová, E. (1998) Sorption of cesium and strontium on clinoptilolite- and mordenite-containing sedimentary rocks. Journal of Radioanalytical and Nuclear Chemistry, 229: 49-55.

Rard, J.A. (1983) Critical review of the chemistry and thermodynamics of Technetium and some of its inorganic compounds and aqueous species. Lawrence Livermore National Laboratory, UCRL-53440, 86 p.

Rego, J. (1979) Jonah Algorithms: C-2, The Ratio Option. Lawrence Livermore National Laboratory Report UCID-18033, 21 p. 
Reiner, S.R., Laczniak, R.J., DeMeo, G.A., Smith, J.L., Elliot, P.E., Nylund, W.E., and Fridrich, C.J. (2002) Ground-water discharge determined from measurements of evapotranspiration, other available hydrologic components, and shallow water-level changes, Oasis Valley, Nye County, Nevada. U.S. Geological Survey WaterResources Investigations Report 01-4239, 65 p.

Richter, R.C., Koirtyohann, S.R., and Jurisson, S.S. (1997) Determination of technetium99 in aqueous solutions by inductively coupled plasma mass spectrometry: Effects of chemical form and memory. Journal of Analytical Atomic Spectrometry, 12: $557-$ 562.

Rose, T.P., Smith, D.K., and Phinney, D.L. (2000) Secondary ion mass spectrometry measurements of volcanic tuffs containing radionuclides from underground nuclear tests. Radiochimica Acta, 88: 465-473.

Rose, T.P., Nelson, E.J., Allen, P.G., Ryerson, F.J., and Pawloski, G.A. (2003) The redox state of nuclear melt glass. In: Rose, T.P., Eaton, G.F., and Kersting, A.B. (eds.), Hydrologic Resources Management Program and Underground Test Area Project FY 2001-2002 Progress Report. Lawrence Livermore National Laboratory Report, UCRL-ID-154357, August 2003, pp. 41-59.

Rose, T.P., Eaton, G.F, Williams, R.W., Zhao, P., Hudson, G.B., Moran, J.E., Hu, Q., and Harris, L.J. (2004) FY 2003 Hot Well Data Summary. In: T.P. Rose, G.F. Eaton, and A.B. Kersting (eds.), Hydrologic Resources Management Program and Underground Test Area Project FY 2003 Progress Report. Lawrence Livermore National Laboratory Report UCRL-TR-206661, pp. 1-16.

Rose, T.P., Benedict, F.C., Thomas, J.M., Sicke, W.S., Hershey, R.L., Paces, J.B., Farnham, I.M., and Peterman, Z.E. (2006) Geochemical data analysis and interpretation of the Pahute Mesa-Oasis Valley groundwater flow system, Nye County, Nevada, August 2002. Lawrence Livermore National Laboratory report UCRL-TR-224559.

Sawyer, D.A., Fleck, R.J., Lanphere, M.A., Warren, R.G., Broxton, D.E., and Hudson, M.R. (1994) Episodic caldera volcanism in the Miocene southwestern Nevada volcanic field: revised stratigraphic framework, ${ }^{40} \mathrm{Ar} /{ }^{39} \mathrm{Ar}$ geochronology, and implications for magmatism and extension. Geological Society of America Bulletin, 106: 1304-1318.

Schroeder, N.C., Morgan, D., Rokop, D.J., and Fabryka-Martin, J. (1993) Migration of technetium-99 in the alluvial aquifer at the Nevada Test Site, Nevada. Radiochimica Acta, 60: 203-209.

Schwartz, L., Piwinskii, A., Ryerson, F., Tewes, H., and Beiriger, W. (1984) Glass produced by underground nuclear explosions. Journal of Non-Crystalline Solids, 67: 559-591. 
Sheppard, R.A., Gude, A.J., and Fitzpatrick, J.J. (1988) Distribution, characterization, and genesis of mordenite in Miocene silicic tuffs at Yucca Mountain, Nye County, Nevada. U.S. Geological Survey Bulletin 1777, 22 p.

Silva, R.J., Evans, R., Rego, J.H., and Buddemeier, R.W. (1988) Methods and results of ${ }^{99} \mathrm{Tc}$ analyses of Nevada Test Site groundwaters. Journal of Radioanalytical and Nuclear Chemistry, 124: 397-405.

Smith, D.K. (1995) Characterization of nuclear explosive melt glass. Radiochimica Acta, 69: $157-167$.

Smith, D.K., Nagle, R.J., and Kenneally, J.M. (1996) Transport of gaseous fission products adjacent to an underground nuclear test cavity. Radiochimica Acta, 73: 177-183.

Smith, D.K. (1998) A recent drilling program to investigate radionuclide migration at the Nevada Test Site. Jour. Radioanalytical Nuclear Chem., 235: 159-166.

Smith, D.K. (2002) Evaluation of the radiochemistry of near-field water samples at the Nevada Test Site applied to the definition of a hydrologic source term. Lawrence Livermore National Laboratory Report UCRL-ID-149049, 49 p.

Stoller-Navarro Joint Venture (2004) Underground Test Area Project NEARFIELD03rev1.mdb Groundwater Chemistry Database for Nearfield Wells at the Nevada Test Site, Rev. 1, May 2004.

Thompson, J.L. (1995) Laboratory and Field Studies Related to the Hydrologic Resources Management Program, October 1, 1994 - September 30, 1995. Los Alamos National Laboratory Report, LA-13064-PR, 27 p.

Thompson, J.L. (1996) Radionuclide distribution in a nuclear test cavity: the Baseball event. Radiochimica Acta, 72: 157-162.

Uchida, T., Isoyama, H., Yamada, K., Oguchi, K., Nakagawa, G., Sugie, H., and Iida, C. (1992) Determination of 12 elements in botanical samples with inductively coupled plasma atomic emission-spectroscopy after leaching with tetramethylammonium hydroxide and ethylenediaminetetraacetic acid. Analytica Chimica Acta, 256: 277 284.

U.S. Congress, Office of Technology Assessment (1989) The containment of underground nuclear explosions. U.S. Government Printing Office, Washington, D.C., OTA-ISC-414, 80 p. 
VanMiddlesworth, L., Handle, J., and Johns, P. (2000) Iodine-129 in thyroid glands: A sensitive biological marker of fission product exposure. Journal of Radioanalytical and Nuclear Chemistry, 243: 467-472.

Wharton, M.J., Atkins, B., Charnock, J.M., Livens, F.R., Pattrick, R.A.D., and Collison, D. (2000) An X-ray absorption spectroscopic study of the co-precipitation of Tc and Re with mackinawite (FeS). Applied Geochemistry, 15: 347-354.

Wolfsberg, A., Glascoe, L., Lu, G., Lichtner, P., McGraw, M., Cherry, T., and Roemer, G. (2002) Tybo/Benham: model analysis of groundwater flow and radionuclide migration from underground nuclear tests in southwestern Pahute Mesa, Nevada. Los Alamos National Laboratory Report, LA-13977, 490 p.

Yamada, H., Kiriyama, T., Onagawa, Y., Hisamori, I., Miyazaki, C., and Yonebayashi, K.K. (1999) Speciation of iodine in soils. Soil Science and Plant Nutrition, 45: 563568.

Zavarin, M., Roberts, S.K., Zhao, P., Williams, R.W., Rose, T.P., Rainer, A., and Pawloski, G.A. (2004a) High-Temperature Studies of Glass Dissolution Rates Close to Saturation. Lawrence Livermore National Laboratory Report UCRL-TR-204874, $42 \mathrm{p}$.

Zavarin, M., Roberts, S.K., Viani, B.E., Pawloski, G.A., and Rose, T.P. (2004b) Nuclear Melt Glass Dissolution and Secondary Mineral Precipitation at 40 to $200^{\circ} \mathrm{C}$. Lawrence Livermore National Laboratory Report UCRL-TR-204870, 46 p.

Zhao, P., Hu, Q., Rose, T.P., Nimz, G.J., and Zavarin, M. (2008) Distribution of ${ }^{99}$ Tc and ${ }^{129} \mathrm{I}$ in the vicinity of underground nuclear tests at the Nevada Test Site. Journal of Radioanalytical and Nuclear Chemistry, 276 (3): 755-761.

Zhou, C.Y., Wang, M.K., Koh, L.L., and Weeb, Y.C. (1996) Microwave digestion of biological samples with tetramethylammonium hydroxide and ethylenediaminetetraacetic acid for element determination. Talanta, 43: 1061-1068. 


\section{Appendix A.}

\section{Lithologic Descriptions of U-19ad PS1A Sidewall Core Samples}

CH01.1 (PS1A - $2232 \mathrm{ft})$

Grayish-green to dark greenish-brown banded melt glass, sometimes with thin bands of opaque rust-brown or black inclusions that are visible at 40x. The glass is non-vesicular, but contains common inclusions of white granular material up to $1 \mathrm{~mm}$ in size, comprising $\sim 5 \%$ of the material by volume.

CH01.2 (PS1A - $2232 \mathrm{ft})$

Pale to medium-gray banded rhyolite with $<5 \%$ colorless/white feldspar phenocrysts (to 1 $\mathrm{mm}), \sim 1 \%$ biotite that is sometimes chloritized $(<1 \mathrm{~mm})$, and $<1 \%$ Fe-oxides $(<0.5 \mathrm{~mm})$. The rock exhibits varying degrees of heating and partial melting. Weakly heated material shows a granular 'sugary' texture that darkens with more intense heating, finally grading into a mottled grayish-green glass that contains white, granular selvages of unmelted, but intensely altered rock.

CH02.1 (PS1A - $2361 \mathrm{ft})$

Pale brown to medium reddish-brown, transparent to translucent melt glass containing rare, flattened oval shaped vesicles to $\sim 1 \mathrm{~mm}$ in size. The glass contains up to $5 \%$ (by volume) irregular white inclusions, apparently unassimilated host rock, that are typically $<1 \mathrm{~mm}$ in size.

CH02.2 (PS1A - $2361 \mathrm{ft})$

Pale gray to reddish-brown rhyolite with a mottled texture due to varying degrees of thermal alteration; contains 3-5\% feldspar phenocrysts (to $2 \mathrm{~mm}$ in size), $1 \%$ biotite $(<1$ $\mathrm{mm}$ in size), and accessory Fe-oxides. The rock appears to become darker brown in color with increasing metamorphism, but turns glassy white and granular when completely fused.

CH03.1 (PS1A - $2371 \mathrm{ft})$

Pale to medium reddish-brown melt glass; semi-transparent, non-vesicular, with $\sim 3 \%$ small, irregular granular white inclusions to $0.3 \mathrm{~mm}$ in maximum dimension.

CH03.2 (PS1A - $2371 \mathrm{ft})$

Pale-gray rhyolite containing up to $\sim 10 \%$ colorless/white feldspar phenocrysts (to $2 \mathrm{~mm}$ ), $\sim 1 \%$ bronze-colored biotite (to $1 \mathrm{~mm}$ ), and $<1 \%$ Fe-oxides (to $0.2 \mathrm{~mm}$ ). Matrix is highly fractured, with a granular, quartzite-like texture. More intensely heated material is darker brown in color, and develops a glassy appearance, but is not totally fused. The contact between the brown glassy material and granulated rock is commonly quite sharp.

CH04.1 (PS1AS - $2181 \mathrm{ft})$

Reddish-brown, semi-transparent melt glass containing oval-shaped vesicles up to 2.5 $\mathrm{mm}$ in size, with a fairly uniform vesicle size distribution. Glass contains small $(<0.5$ 
$\mathrm{mm}$ ) inclusions of granular, white material (host rock?), 2-3\% by volume. No alteration minerals are present.

CH04.2 (PS1AS - $2181 \mathrm{ft})$

Pale gray to grayish-brown rhyolite, ranging in appearance from hard, silicified lava with small feldspar phenocrysts to fused glass. Glass is typically pale grayish-brown in color and ranges from non-vesicular to pumiceous in texture. Where vesicles are present, they are small $(<1 \mathrm{~mm})$, highly elongated, and occur in parallel orientation. Selected fragments show melting rims on the rhyolite, with a distinct glass-rock interface. In the partially melted samples, the non-fused rhyolite assumes a granular, glassy texture indicative of intense heating.

CH05 (PS1AS - $2252 \mathrm{ft}$ )

Opaque black, obsidian-like melt glass with deep reddish-brown internal reflections. The glass is nearly non-vesicular, though a few fragments show small (to $1 \mathrm{~mm}$ ), highly flattened pockets, some of which appear to be lined with white, secondary minerals. Granular, white inclusions of unmelted protolith comprise 1 to $2 \%$ of the sample, and are less than $1 \mathrm{~mm}$ in size.

CH06 (PS1AS - $2262 \mathrm{ft}$ )

Black, obsidian-like melt glass; dark reddish-brown in thin fragments. Glass is homogeneous, but contains rare sub-millimeter inclusions of white, granular material (possible relict grains of host rock that were not totally fused). The glass also contains elongated, oval-shaped vesicles to $5 \mathrm{~mm}$ in maximum dimension with a flattened aspect ratio ( 1:5), in sub-parallel orientation with the long axis. No alteration minerals are present on vesicle walls.

CH07 (PS1AS - $2280 \mathrm{ft}$ )

Black, obsidian-like melt glass, dark reddish-brown in thin fragments; very homogeneous with no discernable inclusions at 40x. Vesicles are rare, ranging from oval shaped (aspect ratio 1:2) to flattened (aspect ratio 1:5); $5 \mathrm{~mm}$ in maximum dimension, though most are $<2 \mathrm{~mm}$. No alteration minerals are present.

CH08 (PS1AS - $2299 \mathrm{ft}$ )

Sample is dominated by pale brown to gray-colored rhyolite containing sparse $(\sim 2 \%)$, euhedral, glassy phenocrysts of feldspar to $1 \mathrm{~mm}$ in size. Some of the rhyolite exhibits color banding, and in general the rock becomes a darker brown color with increasing thermal metamorphism. A few small black melt glass fragments are mixed in with the sample, but this material appears to have been entrained in the drilling mud, and is probably not from this depth interval.

CH09 (PS1AS - $2313 \mathrm{ft}$ )

Uniform, dark brown obsidian-like melt glass; semi-transparent, non-vesicular. Contains 3-5\% granular white inclusions (unassimilated host rock?) up to $1 \mathrm{~mm}$ in size, though most inclusions are $<0.5 \mathrm{~mm}$. 
CH10 (PS1AS - $2441 \mathrm{ft}$ )

Heterogeneous mixture of non-vesicular pale smoky gray to dark gray glass with abundant inclusions of white to orange-brown rhyolite fragments. The sample also contains white to pale brown aphyric rhyolite fragments. The sample location below the test cavity, the unusual gray color of the glass, and the near-absence of radioactivity suggests this sample is probably a natural volcanic glass.

CH11 (PS1AS - $2450 \mathrm{ft}$ )

Pale to medium gray glass occurring as distinct spherulitic 'pellets' and rounded masses with a 'cracked' onion-skin appearance. This texture is referred to as 'perlitic' in the literature (e.g. Fisher and Schmincke, 1984), and commonly develops in natural hydrated obsidian. As with sample $\mathrm{CH} 10$, this sample was collected below the base of the cavity, and the glass is inferred to be natural in origin. The small amount of radioactivity that was detected in this sample probably comes from a few tiny fragments of black melt glass that were observed to be admixed with the sample.

CH12 (PS1AS - composite)

This sample was collected from the bottom of the PS1AS borehole using a 'junk basket' tool, and consists almost entirely of coarse fragments of massive black obsidian-like melt glass. Most of the glass fragments are non-vesicular; some contain small white inclusions of fused, but non-assimilated host rock.

CH13 (PS1ASS - $2190 \mathrm{ft}$ )

Pale gray to medium grayish-brown rhyolite showing evidence of incipient thermal metamorphism, as indicated by its glassy, granular texture. Rock is highly fractured and contains $\sim 3 \%$ feldspar (as lath-like crystals to $1 \mathrm{~mm}$ ), $<1 \%$ biotite $(<1 \mathrm{~mm}$ in size), and $<1 \% \mathrm{Fe}$-oxide (to $0.2 \mathrm{~mm}$ ). Fracture surfaces are commonly coated with ochre-colored secondary Fe-oxides.

CH14.1 (PS1ASS - $2240 \mathrm{ft}$ )

Light gray to reddish-brown, translucent melt glass; non-vesicular, but with common inclusions of white granular material (host rock?) that are $\leq 1 \mathrm{~mm}$ in size. The glass also contains less-common opaque, rust-colored inclusions, $<1 \mathrm{~mm}$ in size and irregular in shape.

CH14.2 (PS1ASS - $2240 \mathrm{ft}$ )

Pale gray to pale reddish-brown rhyolite, ranging from moderately altered to fully melted, with a range in textures between. The melt glass is brown, non-vesicular, and irregularly distributed as bands and patches within the rock. The less altered material shows evidence of intense heating that imparted a 'sugary' quartzite-like texture to the rock. Feldspar phenocrysts (to $1 \mathrm{~mm}$ ) and Fe-oxides $(<1 \mathrm{~mm})$ comprise less than $5 \%$ of the rock. 
CH15.1 (PS1ASS - $2286 \mathrm{ft})$

Transparent, pale-green to opaque, greenish-brown melt glass showing distinct color banding, with infrequent sub-millimeter inclusions of granular white material (unmelted host rock?). The glass contains no vesicles.

CH15.2 (PS1ASS - $2286 \mathrm{ft}$ )

Pale gray to grayish-brown rhyolite, becoming a deeper reddish-brown and vesicular when fused. The less altered gray-colored rhyolite has a granular texture from incipient melting and contains $\sim 5 \%$ chalky-white feldspar grains (to $2 \mathrm{~mm}$ ), $\sim 1 \%$ bronze-colored biotite $(<1 \mathrm{~mm})$, and $<1 \%$ Fe-oxides $(<1 \mathrm{~mm})$. The fused, reddish-brown material contains numerous small vesicles, generally $<0.5 \mathrm{~mm}$ in size, with a fairly uniform size distribution and very weak elongation. The contact between the fused and unmelted rock is very distinct.

CH16.1 (PS1ASS - $2292 \mathrm{ft})$

Dark brown melt glass, weakly banded in places, with uncommon oval vesicles to $\sim 1 \mathrm{~mm}$ in maximum dimension. Selected vesicles appear to show the incipient development of very fine-grained secondary minerals, white in color. In addition, the glass contains sparse white-colored inclusions, $<1 \mathrm{~mm}$ in size, that are inferred to represent unmelted host rock.

CH16.2 (PS1ASS - $2292 \mathrm{ft}$ )

Pale gray to light brown, partially-fused rhyolite/glass mixture with a heterogeneous, mottled texture. Glassy material commonly contains rounded inclusions of intensely altered rhyolite, up to $3 \mathrm{~mm}$ in size. Pale gray glass contains small, irregular vesicles to $\sim 2 \mathrm{~mm}$ in size, some of which appear to be lined with fine-grained white minerals. Other parts of the material consist of non-vesicular, pale brown, semi-transparent glass with numerous tiny inclusions of unmelted material.

CH17 (PS1ASS - $2306 \mathrm{ft}$ )

Flow banded, highly vesicular melt glass with extremely elongated, highly flatted vesicles, forming interconnecting networks. The glass ranges from colorless to light reddish-brown to dark brown in color, and commonly grades from one color to the next over short (mm-scale) distances perpendicular to the direction of flow banding. Lightercolored glass contains more frequent inclusions of white, non-assimilated protolith material, up to $2 \mathrm{~mm}$ in size, but highly irregular in shape. In at least one sample, the pale-colored glass contains $0.1 \mathrm{~mm}$ euhedral reddish-brown hexagonal crystals (hematite?) that appear to have grown in the glass.

CH18 (PS1ASS - $2332 \mathrm{ft}$ )

Very heterogeneous mixture of vari-colored glass containing $~ 15 \%$ admixed rubble debris. Glass ranges from pale gray to orange-brown to dark brown in color, and varies from non-vesicular to highly porous. In places, irregular networks of interconnected vesicles form large open cavities in the glass, with individual pockets up to $\sim 5 \mathrm{~mm}$ in size that are separated from the next vesicle by very thin glass walls. Some of the vesicles show strong evidence for the development of small, white secondary minerals on the 
glass surfaces (see Chapter 3). Unmelted inclusions of rhyolite form irregular masses within the glass and range from glassy white to chalky gray in appearance. Larger rhyolite grains contain sparse, chalky white feldspar phenocrysts (to $2 \mathrm{~mm}$ ) and bronze colored biotite grains $(<1 \mathrm{~mm})$. 


\section{Appendix B}

\section{Analytical Methods for Uranium and Plutonium}

\section{Sample selection and dissolution}

The selection of samples for Pu and $\mathrm{U}$ analysis was based on the general criteria outlined in Section 1.3 of this report. The primary objectives were to (1) quantitatively evaluate the $\mathrm{Pu}$ and $\mathrm{U}$ distribution between melt glass and rubble samples; and (2) determine the spatial variations in concentrations and isotope ratios within the test cavity. The samples returned from the drillback exercise originally consisted of a mixture of melt glass, rubble and wet drilling mud. These samples were washed with Milli-Q water, followed by acetone washing, and then dried in an oven at $60^{\circ} \mathrm{C}$ overnight. Melt glass and rubble fragments were then manually separated with the aid of a microscope. After the samples were selected, they were ground into a fine powder using a mortar and pestle.

Powdered samples were weighed on an analytical balance and then spiked with standard solutions of ${ }^{244} \mathrm{Pu}$ and ${ }^{233} \mathrm{U}$ for tracking recovery yield. Sample sizes used for $\mathrm{U}$ and $\mathrm{Pu}$ analysis were typically $0.1 \mathrm{~g}$ for melt glass, and $0.2 \mathrm{~g}$ for rubble debris. An acid digestion method was used to dissolve the samples, and up to $1 \mathrm{~mL}$ of concentrated $\mathrm{HF}$ and $0.1 \mathrm{~mL}$ of concentrated $\mathrm{HClO}_{4}$ was added in order to assure the silicate material was completely dissolved. The samples were dried on a hotplate at a moderate temperature, re-dissolved in concentrated $\mathrm{HNO}_{3}$, and dried again.

\section{Reagents and Materials}

Ultra-high purity reagent acids and bases were purchased from Seastar Chemicals Inc. These included concentrated nitric $\left(\mathrm{HNO}_{3}\right)$, hydrochloric $(\mathrm{HCl})$, perchloric $\left(\mathrm{HClO}_{4}\right)$, and hydrofluoric (HF) acids, and ammonium hydroxide $\left(\mathrm{NH}_{4} \mathrm{OH}\right)$. Other chemicals used during sample preparation, including sodium nitrite $\left(\mathrm{NaNO}_{2}\right)$, hydriodic acid $(\mathrm{HI})$ and acetone $\left(\mathrm{CH}_{3} \mathrm{COCH}_{3}\right)$, were commercially available reagent-grade compounds. TEVA resin used in the $\mathrm{Pu}$ and $\mathrm{U}$ purification column work was obtained from Eichrom Technologies Inc. The anion exchange resin AG1×8 (100-200 $\mu \mathrm{m}$ mesh size) and Polyprep plastic columns were from Bio-Rad Laboratories. All solutions were prepared with ASTM Type II reagent-grade water from a Milli-Q® Ultrapure Water Purification System (Millipore). PFA Teflon vials with screw tops (14 mL capacity) were obtained from Savillex. Only new laboratory materials were used for each sample analysis to eliminate the possibility of cross contamination.

\section{Plutonium and uranium separation and purification}

The dried samples were dissolved in $5-10 \mathrm{~mL}$ of $8 \mathrm{M} \mathrm{HNO}_{3}$ containing $0.2 \mathrm{~mL}$ saturated $\mathrm{NaNO}_{2}$. Each sample was then run through a $2 \mathrm{~mL}$ AG1 $\times 8(100-200 \mu \mathrm{m}$ mesh) anion exchange resin column. $\mathrm{Pu}$ and $\mathrm{U}$ adsorb to the resin while most of other matrix constituents pass the column without retention. We used $2 \mathrm{~mL}$ of $8 \mathrm{M} \mathrm{HNO}_{3}$ at a time to rinse the Teflon vial and resin bed three times, or until all yellow color was washed off. 
At this point $\mathrm{Pu}$ and $\mathrm{U}$ were separated from the matrix constituents. We then eluted both adsorbed $\mathrm{Pu}$ and $\mathrm{U}$ from the resin column using $2 \mathrm{~mL} \times 2$ (two times) of $0.1 \mathrm{M} \mathrm{HCl}-0.005$ $\mathrm{M} \mathrm{HF}$, followed by $2 \mathrm{~mL} \times 3$ of freshly prepared mixture of $0.1 \mathrm{M} \mathrm{HCl}$ :concentrated $\mathrm{HI}$ (15:1 volume ratio). The elution was collected in the same Teflon vial. We took the elution to dryness on a moderate temperature hotplate. After all the added iodine had evaporated (when the solution color changed from brown to clear), we added a few drops of concentrated $\mathrm{HNO}_{3}$ and again brought the sample to dryness. Then, we added a few drops of concentrated $\mathrm{HCl}$ and dried the sample again in order to convert the sample from a nitrate into a chloride matrix. After drying, we dissolved the sample in 1-2 $\mathrm{mL}$ of $9 \mathrm{M}$ $\mathrm{HCl}$ plus $10 \mu \mathrm{L}$ of concentrated $\mathrm{HNO}_{3}$.

To separate uranium from plutonium, we used a $1 \mathrm{~mL}$ AG1×8 (100-200 mesh) anion exchange resin in a poly-prep plastic column. We pre-conditioned the resin column with $4 \mathrm{~mL}$ Milli-Q water followed with $6 \mathrm{~mL}$ of $9 \mathrm{M} \mathrm{HCl}$, and loaded the sample solution onto the conditioned column. Both $\mathrm{U}$ and $\mathrm{Pu}$ adsorb while most other constituents, including thorium, pass through. We rinsed the vial and resin bed with $1 \mathrm{~mL} \times 3$ of $9 \mathrm{M} \mathrm{HCl}$, and used a new Teflon vial to collect $\mathrm{Pu}$ fraction after eluting the $\mathrm{Pu}$ with $6 \mathrm{~mL}$ of freshly prepared $9 \mathrm{M} \mathrm{HCl}: \mathrm{HI}$ mixture $(15: 1)$. The $\mathrm{Pu}$ fraction was then dried on a hotplate.

After the plutonium separation was completed, the uranium fraction was eluted from the resin column with $7 \mathrm{~mL} 0.1 \mathrm{M} \mathrm{HCl}$. The original sample vial was used to catch this fraction. After drying the $\mathrm{U}$ fraction on a hotplate, we added a few drops of concentrated $\mathrm{HNO}_{3}$ and dried the sample again. We then dissolved the $\mathrm{U}$ sample in $1 \mathrm{~mL} 2 \% \mathrm{HNO}_{3}$ solution for ICP-MS analysis.

The separated $\mathrm{Pu}$ fraction still required further purification to remove the small fraction of uranium that typically co-elutes with the Pu. A $0.3 \mathrm{~mL}$ TEVA resin column was used for this purpose. We pre-conditioned the TEVA column with $1 \mathrm{~mL}$ Milli-Q water followed by $2 \mathrm{~mL}$ of $3 \mathrm{M} \mathrm{HNO}_{3}$, and dissolved the dried sample in $0.5-1 \mathrm{~mL}$ of $3 \mathrm{M}$ $\mathrm{HNO}_{3}$ plus $20 \mu \mathrm{L}$ saturated $\mathrm{NaNO}_{2}$ solution. The sample was warmed on a hotplate to convert $\mathrm{Pu}(\mathrm{VI})$ into $\mathrm{Pu}(\mathrm{IV})$, the latter of which is effectively adsorbed on the TEVA resin. We rinsed the vial and column with $0.5 \mathrm{~mL} \times 4$ of $3 \mathrm{M} \mathrm{HNO}_{3}$ to clean $\mathrm{Pu}$ from other impurities such as uranium, loaded the $\mathrm{Pu}$ sample on the column, and eluted the $\mathrm{Pu}$ using $0.5 \mathrm{~mL}$ of $0.1 \mathrm{M} \mathrm{HCl}$ followed by $3 \mathrm{~mL}$ of freshly prepared $0.1 \mathrm{M} \mathrm{HCl}: \mathrm{HI}(15: 1)$ mixture. The eluted $\mathrm{Pu}$ was mixed with $25 \mu \mathrm{L}$ of concentrated $\mathrm{HClO}_{4}$, dried on a hotplate, re-dissolved with a few drops of concentrated $\mathrm{HNO}_{3}$, and dried again. Finally, we dissolved the sample in $1 \mathrm{~mL}$ of $2 \% \mathrm{HNO}_{3}$ for ICP-MS analysis.

\section{ICP-MS analyses}

Quantitative analyses of plutonium, uranium and their isotopic ratios were performed by the method of isotope dilution using an inductively coupled plasma-mass spectrometry (ICP-MS). All analyses were performed at LLNL using a multi-collector magnetic sector ICP-MS (Micromass IsoProbe). For $U$ isotope ratio measurements, the signals at mass 233, 234, 235, 236 and 238 were monitored and their concentrations were determined using the spiked concentration of the ${ }^{233} \mathrm{U}$ tracer with its recovery yield. The estimated

${ }^{233} \mathrm{U}$ recoveries for the test debris samples were between $25-75 \%$ with an average of $60 \%$. 
For $\mathrm{Pu}$ isotope ratio measurements, the signals at mass 239, 240, 241, 242 and 244 were monitored, and their concentrations were determined using the spiked concentration of the ${ }^{244} \mathrm{Pu}$ tracer with its recovery yields. The estimated ${ }^{244} \mathrm{Pu}$ recoveries were between $30-85 \%$ with an average of $70 \%$.

The precision and accuracy of the ${ }^{238} \mathrm{U} /{ }^{235} \mathrm{U}$ ratio analyses is $0.2 \%$ at the $99 \%$ confidence interval. Uranium concentrations are not a limiting factor in these analyses (i.e. concentrations are always high enough to make determinations at the reported level of precision and accuracy). For samples containing greater than $10 \times 10^{-12} \mathrm{~g}(10 \mathrm{pg})$ of plutonium, the precision and accuracy on the ${ }^{240} \mathrm{Pu} /{ }^{239} \mathrm{Pu}$ ratio is $<1 \%$ at the $99 \%$ confidence interval. The precision in plutonium measurements decreases at concentrations $<10 \mathrm{pg}$. 


\section{Appendix C}

\section{Analytical Methods for Technetium and lodine}

\section{Analysis of Technetium-99}

During the testing program, drillback samples were not routinely analyzed for ${ }^{99} \mathrm{Tc}$ or ${ }^{129} \mathrm{I}$ because some fraction of the technetium and iodine is lost as volatile chemical species during acid digestion. For the present study, new analytical methodologies were adopted from the literature, as described in the following section, and the possible loss of material during sample preparation was tracked using non-volatile tracers. Although this introduces some uncertainty into the final reported values, this approach is sufficient for determining the relative partitioning of ${ }^{99} \mathrm{Tc}$ or ${ }^{129} \mathrm{I}$ in the melt glass and rubble samples.

Technetium-99 was analyzed in both groundwater and solid samples using a modified isotope dilution ICP-MS method. For groundwater samples, we used TEVA resin columns to enrich and separate the ${ }^{99} \mathrm{Tc}$ from other chemical species that may interfere with the mass 99 measurement (such as ${ }^{99} \mathrm{Ru}$ and ${ }^{98} \mathrm{Mo}{ }^{1} \mathrm{H}$ ). The amount of sample that is processed depends on the ${ }^{99} \mathrm{Tc}$ concentration; up to 2 liters of water may be needed for samples with very low ${ }^{99} \mathrm{Tc}$ concentrations. For solid samples (melt glass and rubble), powdered sample material is mixed with a flux consisting of sodium peroxide $\left(\mathrm{Na}_{2} \mathrm{O}_{2}\right)$ and low carbonate sodium hydroxide $(\mathrm{NaOH})$ and is fused under highly oxidizing conditions. The fused sample is then dissolved in weak acid and the ${ }^{99} \mathrm{Tc}$ is separated on a TEVA resin column. This fusion method is very effective in converting the glass or rock to a soluble form without significant volatile loss of ${ }^{99} \mathrm{Tc}$. In both methods, the samples are spiked with a rhenium (Re) standard solution that acts as a tracer to monitor the chemical yield recovery of ${ }^{99} \mathrm{Tc}$ during sample processing.

Rhenium is a suitable analog for technetium because of strong similarities in the chemical behavior of both elements (Brookins, 1986; Harvey et al., 1992; Wharton et al., 2000). The crystal chemical behavior of Tc and Re in solids is almost identical, and Eh-pH diagrams show that nearly identical stability fields are occupied by the aqueous species of both elements (e.g. $\mathrm{TcO}_{4}{ }^{-}$and $\mathrm{ReO}_{4}{ }^{-}$). The main difference between $\mathrm{Re}$ and $\mathrm{Tc}$ is in their respective oxidation potentials; the reduction of $\mathrm{Re}$ is more difficult than that of $\mathrm{Tc}$ (Richter et al., 1997; Mas et al., 2004).

\section{Technetium-99 analysis of groundwater samples}

To analyze groundwater with low ${ }^{99} \mathrm{Tc}$ concentrations, a 1 to 2 liter sample was weighed and then spiked with a rhenium tracer solution $(\sim 0.5-1 \mu \mathrm{g}$ Re total). We then added 10 $\mathrm{mL}$ of $30 \%$ hydrogen peroxide per liter of water and heated the sample at sub-boiling temperatures on a hotplate for 1 hour to oxidize all Tc to a dissolved $\mathrm{Tc}(\mathrm{VII})$ form, and to decompose any organic matter and excess hydrogen peroxide (Eichrom Technologies, 2002). After the sample had cooled to room temperature, sediments were removed by either filtration $(0.2 \mu \mathrm{m}$ filter) or centrifugation (at 4,000 rpm for $10 \mathrm{~min}$ ). 
Using a Bio-Rad poly-prep column, we prepared a $0.8 \mathrm{~mL}$ TEVA resin bed and preconditioned the resin column with $5 \mathrm{~mL}$ of $0.1 \mathrm{M}$ nitric acid. We ran the sample through the column and then washed the column with $30-50 \mathrm{~mL}$ of $0.01 \mathrm{M} \mathrm{HNO}_{3}$. This process effectively separates the Tc and Re from other potential ICP-MS mass interferences (Mo and $\mathrm{Ru}$ ) that may have been present in the sample. The Tc and Re were then eluted from the TEVA column using $5 \mathrm{~mL}$ of $12 \mathrm{M} \mathrm{HNO}_{3}$, and the effluent was collected in a $6 \mathrm{~mL}$ pre-weighed Teflon beaker. The sample was heated until it was nearly dry on a hotplate, maintaining a temperature of less than $90^{\circ} \mathrm{C}$ at all times to avoid the loss of $\mathrm{Tc}$ and $\operatorname{Re}$ due to volatilization. Once the sample had cooled, we weighed and recorded the mass of the sample and beaker, and then added $3 \mathrm{~mL}$ of $2 \% \mathrm{HNO}_{3}$ containing $5 \mathrm{ppb}$ of ICP-MS internal reference standards (Sc-45, In-115, and Bi-209). The final sample weight was then recorded before performing the ICP-MS analysis. For groundwater samples that contain higher concentrations of ${ }^{99} \mathrm{Tc}(>1 \mathrm{pCi} / \mathrm{L})$, the above concentration and purification procedure is not necessary. The groundwater sample can be directly analyzed after acidified with $2 \% \mathrm{HNO}_{3}$ containing $5 \mathrm{ppb}$ of internal standards. In this case, a separate Mo and $\mathrm{Ru}$ reference standard is also analyzed to obtain a mass bias correction for potential mass interferences.

Technetium-99 is a weak $\beta$-emitting radioisotope $\left(\beta_{\max }=293 \mathrm{KeV}\right)$, and can also be measured by the liquid scintillation counting (LSC) method. During this study, we performed ${ }^{99} \mathrm{Tc}$ analyses of groundwater samples using the LSC method to provide an independent comparison with the ICP-MS results. Technetium-99 was separated from water samples using a TEVA resin column, as described above. After pre-concentrating the pertechnetate ion $\left(\mathrm{TcO}_{4}{ }^{-}\right)$, the ${ }^{99} \mathrm{Tc}$-bearing resin was directly transferred into liquid scintillation cocktail for counting. Technetium-99 is analyzed within a counting window between 26 to $290 \mathrm{KeV}$. The sample can be analyzed with or without a Tc-99 standard spike to determine chemical recovery. We added the same amount of TEVA resin to a series of ${ }^{99} \mathrm{Tc}$ standard solutions to construct a matrix-specific calibration curve, from which the activities of ${ }^{99} \mathrm{Tc}$ in the samples were calculated. The detection limit for the LSC method is $1 \mathrm{pCi} / \mathrm{L}(37 \mathrm{mBq} / \mathrm{L})$.

\section{Technetium-99 analysis of melt glass and rubble samples}

For the analysis of ${ }^{99} \mathrm{Tc}$ in solid test debris samples, we developed a modified analytical procedure based on methods described in Dixon et al. (1997) and ASTM (2005). The samples were ground to a fine powder using a ball mill and between 0.1 and 1 gram of sample material was then weighed in a pre-cleaned $20 \mathrm{~mL}$ zirconium $(\mathrm{Zr})$ crucible. The sample was spiked with a rhenium tracer solution ( 10 ng Re total) and dried under a heat lamp. Low-carbonate $\mathrm{NaOH}$ and $\mathrm{Na}_{2} \mathrm{O}_{2}$ were then added to the sample in an amount that was equivalent to 2 and 6 times the sample weight, respectively. These flux chemicals were mixed with the sample in the $\mathrm{Zr}$ crucible using a wooden stick to ensure sample was in good contact with the flux, and the mixture was fused in a muffle furnace at $700{ }^{\circ} \mathrm{C}$ for 25-30 minutes. The sample was removed from the furnace and allowed to cool to room temperature. We added 5 to $10 \mathrm{~mL}$ of either Milli-Q water or $1 \mathrm{M} \mathrm{HNO}_{3}$ to dissolve the fusion cake; the fusion cakes dissolve slowly in the water, and the addition of 
1-2 $\mathrm{mL}$ of $1 \mathrm{M} \mathrm{HNO}_{3}$ at a time accelerates the dissolution process. The dissolved fusion cake and its hydroxide precipitates were quantitatively transferred into a $50 \mathrm{~mL}$ centrifuge tube; the total sample volume was kept at no more than $30 \mathrm{~mL}$, if possible.

Using concentrated nitric acid, we adjusted the sample solution $\mathrm{pH}$ to between 1 and 2 . Once the solution was acidified, we centrifuged it at 4,000 rpm for 10 minutes to separate any precipitate from the liquid, transferred the liquid into a new clean centrifuge tube, and washed the precipitates with $5 \mathrm{~mL}$ of Milli-Q water three times; the solution was centrifuge again and all the supernatants were combined for purification. A TEVA resin column was used to separate $\mathrm{Tc}$ and $\mathrm{Re}$ from the solution matrix and to purify $\mathrm{Tc}$ and $\operatorname{Re}$ for ICP-MS analyses.

After sample fusion, the $\mathrm{Zr}$ crucible can be cleaned by repeating the chemical flux fusion process without sample material, followed by overnight leaching in $12 \mathrm{M} \mathrm{HNO}_{3}$. In some cases, the fusion cakes showed a green color indicating that some transition metals such as $\mathrm{Ni}, \mathrm{Co}$, and even $\mathrm{Zr}$ were dissolved from the crucible during high-temperature fusion; this was confirmed during the ICP-MS analyses. However, both Tc and Re exhibited very low background so that the partial surface dissolution of the crucible during the fusion process did not cause a serious background problem in our analyses. This was verified in the blank treatment with only fluxing chemicals in a crucible that underwent the same treatment as the solid samples.

\section{ICP-MS analysis of ${ }^{99} \mathrm{TC}$}

During ${ }^{99} \mathrm{Tc}$ analyses on the ICP-MS, the major mass interferences are those arising from ruthenium $\left({ }^{99} \mathrm{Ru}\right.$, natural abundance $\left.12.6 \%\right)$ and molybdenum $\left({ }^{98} \mathrm{Mo}{ }^{1} \mathrm{H}, 24 \%\right.$ and ${ }^{100} \mathrm{Mo}$, $9.6 \%$ ) isotopes present in the analyzed solution. In addition, the rhenium (Re) that serves as a chemical yield tracer has a possible isobaric interference from tungsten (W) hydrides that form with $\mathrm{W}$ isotopes at masses 185 and 187 . We used a $10 \mathrm{ppb}$ solution of $\mathrm{Mo}, \mathrm{Ru}$, and $\mathrm{W}$ to evaluate these interferences by monitoring masses $92,95,96$ and 98 (Mo), 100, 101 and $102(\mathrm{Ru})$, and 182 and $184(\mathrm{~W})$. The instrumental mass bias was determined with a linear correction algorithm with respect to the atomic mass. Typical mass-bias factors throughout this study were about 3\% per mass unit at mass ranges of 92 to 98 (obtained from $10 \mathrm{ppb}$ standard Mo solution) and $0.4 \%$ per mass unit at a higher mass ranges of 182 to 184 (from $10 \mathrm{ppb}$ of $\mathrm{W}$ solution). The mass bias value and the natural abundance information were used to correct the ${ }^{99} \mathrm{Tc}$ results for mass interferences. The $10 \mathrm{ppb} \mathrm{Ru}$ solution was used to verify the mass correction and instrumental performance; the difference between the measured and expected signal at mass 99 (from $\mathrm{Ru}$ ), as determined by monitoring mass 101 , was consistently about $\pm 5 \%$. Hydride formation, for ${ }^{98} \mathrm{Mo}{ }^{1} \mathrm{H},{ }^{184} \mathrm{~W}^{1} \mathrm{H}$, and ${ }^{186} \mathrm{~W}^{1} \mathrm{H}$, under the instrumental condition was not significant, at the level of $<10^{-5} \mathrm{ppb}$ of Mo or W.

The NIST ${ }^{99}$ Tc standard SRM4288 was used to prepare the standard reference curves for the ICP-MS analyses. A sample of Irish Sea Water from the International Atomic Energy Agency (IAEA-381) was used an independent calibration standard. The reported ${ }^{99} \mathrm{Tc}$ 
activity in this standard is $5.86 \pm 0.30 \mathrm{pCi} / \mathrm{L}(217 \pm 11 \mathrm{mBq} / \mathrm{L})$. Our procedure yielded a ${ }^{99} \mathrm{Tc}$ activity of $5.41 \mathrm{pCi} / \mathrm{L}$ for IAEA-381, which is close to the reported value.

\section{Analysis of lodine-129}

In order to determine the ${ }^{129} \mathrm{I}$ concentration in groundwater and test debris samples, it is necessary to measure both the total iodine concentration with an ICP-MS and the ${ }^{129} \mathrm{I} /{ }^{127} \mathrm{I}$ isotope ratio using accelerator mass spectrometry (AMS). For groundwater, the sample is first analyzed for total iodine using the ICP-MS. The water is then processed to prepare a silver iodide (AgI) target for ${ }^{129} \mathrm{I} /{ }^{127} \mathrm{I}$ analysis. For solid samples, we used a microwave digestion technique with 5\% tetra-methyl ammonium hydroxide (TMAH) to extract iodine from solid. An aliquot of the resultant sample solution is used to measure total iodine with an ICP-MS, and another aliquot is used to prepare the AgI target for ${ }^{129} \mathrm{I} /{ }^{127} \mathrm{I}$ analysis. The NIST Standard Reference Material SRM4949C was used as a calibration standard.

\section{lodine analysis of groundwater samples}

The acidic matrix that is normally used for elemental analyses on the ICP-MS is poorly suited for iodine concentration measurements. The iodine measurements will show a significant memory effect because iodine species are more retentive under acidic conditions. NNSS groundwater samples, including those from U-19ad PS1A, are normally in the slightly alkaline $\mathrm{pH}$ range and can be directly analyzed on the ICP-MS after spiking the sample with a 5 ppb internal reference standard (rhodium, Rh). Recently we have used a solution of CFA-C (Spectrasol, Warwick, New York), a proprietary tertiary amine alkaline solution that can be used to reduce the memory effect. The CFA$\mathrm{C}$ is a surfactant that coats the glassware and helps to prevent the build-up of iodine in the ICP-MS inlet system. The CFA-C is diluted in Milli-Q water to create a $1 \%$ working solution as the ICP-MS matrix (Brown et al., 2005).

In addition to measuring the total iodine concentration on the ICP-MS, the concentration of dissolved iodide $\left(\mathrm{I}^{-}\right)$in groundwater was determined by ion chromatography (IC) analysis (e.g. Hu and Moran, 2005). We used a Dionex IC system equipped with an electrochemical detector that uses a silver working electrode and $\mathrm{Ag} / \mathrm{AgCl}$ reference electrode. Iodide separation was achieved in a ion column using $50 \mathrm{~m} M$ nitric acid eluent under an isocratic flow of $1.5 \mathrm{~mL} / \mathrm{min}$. The iodide detection limit by this method is less than $1 \mathrm{ppb}$.

\section{lodine analysis of melt glass and rubble samples}

A microwave oven digestion method was used to extract iodine from test debris samples for total iodine and isotope ratio analyses. We weighed 0.5 to $1 \mathrm{~g}$ of sample powder in a pre-weighed Teflon digestion vessel, and added $4 \mathrm{~mL}$ of $5 \%$ tetra-methyl ammonium hydroxide (TMAH) solution. TMAH has previously been used to extract iodine from a variety of sample matrices (Uchida et al., 1992; Zhou et al., 1996; Yamada et al., 1999). The Teflon vessel containing the sample was placed into a digestion vessel, capped with 
a sensor head and pressure rupture disc, and placed in a microwave oven. After connecting the sensor cables to a port in the microwave oven cavity, the power level and time for each digestion stage were programmed into a computer controller. The oven power was slowly ramped up to a maximum value of $800 \mathrm{~W}$ over the duration of 15 minutes. The maximum temperature and pressure conditions were $90^{\circ} \mathrm{C}$ and $180 \mathrm{psi}$, respectively. When the power reached $800 \mathrm{~W}$, the sample was digested for an additional 10 minutes. After the digestion step was completed and the sample vessels had cooled, 6 $\mathrm{mL}$ of $1 \%$ CFA-C solution were added to the sample, and the sample was transferred to a $15 \mathrm{~mL}$ polypropylene centrifuge tube. The sample was centrifuged at 4,000 rpm for 10 20 minutes to separate the solid and liquid phases. The supernatant was then transferred into a clean test tube using a transfer pipette, and the resultant solution was ready for total iodine analysis on the ICP-MS.

The total iodine concentration was also measured using a pyrohydrolysis technique where the sample was heated to $1100^{\circ} \mathrm{C}$ under a $100 \mathrm{~mL} \mathrm{~min}^{-1}$ flow of wet oxygen to extract iodine from the test debris. The technique used was adapted from that described by Schnetger and Muramatsu (1996). Oxygen gas is passed through water at $60^{\circ} \mathrm{C}$, and is then introduced to a quartz tube inside a tube furnace at $1100^{\circ} \mathrm{C}$. Between 0.1 and $1 \mathrm{~g}$ of powdered sample and an equivalent mass of $\mathrm{V}_{2} \mathrm{O}_{5}$ were weighed into a ceramic boat and placed inside the quartz tube. The outflow was bubbled through a solution containing $1 \%$ TMAH, $0.5 \mathrm{mM} \mathrm{NaHSO}_{3}$, and 1\% CFA-C, which traps the iodine that is volatilized from the test debris during combustion. The trap solution was passed through a $200 \mathrm{~nm}$ PallGelman Acrodisc filter, and the filtrate was analyzed for its total iodine concentration on the ICP-MS. The results were used to verify the measurements made using the microwave digestion technique discussed above.

\section{Preparation of lodine-129 targets for the AMS}

In order to prepare silver iodide (AgI) targets for ${ }^{129} \mathrm{I}$ analysis on the AMS, the total concentration of iodine in the sample must be known (from ICP-MS analysis), and the ${ }^{129} \mathrm{I} /{ }^{127} \mathrm{I}$ ratio must be estimated to within a few orders of magnitude. These two pieces of information are important in determining the sample size and the quantity of iodine carrier to be used during target preparation. Samples with high ${ }^{129} I /{ }^{127} I$ ratios, such as those found in nuclear test cavities, must be diluted with a stable ${ }^{127}$ I carrier that has low ${ }^{129} \mathrm{I}$ in so that the ${ }^{129} \mathrm{I} /{ }^{127} \mathrm{I}$ ratios of the targets are within the working range of the AMS. Although the AMS can produce isotope ratio data over a four order of magnitude range (ratios from $\sim 10^{-14}$ to $10^{-10}$ ), near-field groundwater samples may have ${ }^{129} \mathrm{I} /{ }^{127} \mathrm{I}$ ratios as high as $10^{-2}$, requiring a large dilution factor.

The ${ }^{129} \mathrm{I} /{ }^{127} \mathrm{I}$ ratios of the Chancellor melt glass and rubble samples were unknown, but it was assumed that the ratios in the melt glass would be at least as high as the groundwater ratio. The following equation was used to estimate the amount of sample extract, prepared by microwave digestion, needed for ${ }^{129}$ I target preparation: 


$$
m_{s}=\frac{m_{c} \times C_{c} \times r_{t}}{C_{s} \times r_{s}} \times 1000
$$

where $m_{\mathrm{s}}, C_{\mathrm{s}}$ and $r_{\mathrm{s}}$ are the mass, iodine concentration, and estimated ${ }^{129} \mathrm{I} /{ }^{127} \mathrm{I}$ ratio of the sample extract, respectively; $m_{\mathrm{c}}$ and $C_{\mathrm{c}}$ are the mass and iodine concentration of the carrier; and $r_{t}$ is the ${ }^{129} \mathrm{I} /{ }^{127} \mathrm{I}$ ratio of the target (assumed to be $\sim 5 \times 10^{-12}$ ). For all of the test debris samples, the final mass of AgI target was approximately equal to the mass of the carrier since the test debris sample extract was diluted by orders of magnitude. In practice, the total mass of the target needs to be only a few milligrams of AgI.

The detailed step-by-step procedure used to prepare samples for ${ }^{129} \mathrm{I} /{ }^{127} \mathrm{I}$ analysis is found in Standard Operating Procedures written in support of the UGTA Project (LLNL, 2004). In brief, the sample + carrier solution is placed in a separatory funnel, and oxidized iodine species such as iodate $\left(\mathrm{IO}_{3}{ }^{-}\right)$are reduced to iodide $\left(\mathrm{I}^{-}\right)$by adding hydroxylamine hydrochloride in $\mathrm{pH} 8$ ammonium hydroxide solution. $5 \mathrm{~mL}$ of carbon tetrachloride $\left(\mathrm{CCl}_{4}\right)$ is added to the separatory funnel, followed by $0.4 \mathrm{~mL}$ of concentrated nitric acid, decreasing the $\mathrm{pH}$ to $\sim 2$. Hydrogen peroxide $\left(\mathrm{H}_{2} \mathrm{O}_{2}\right)$ is then added to convert iodide (and any dissolved organic iodine) into molecular iodine $\left(\mathrm{I}_{2}\right)$. Shaking the funnel causes the iodine to be extracted into the immiscible $\mathrm{CCl}_{4}$ phase, which turns purple in color. The $\mathrm{CCl}_{4}+\mathrm{I}_{2}$ are then physically separated from the aqueous acid phase. A solution of sodium bisulphate $\left(\mathrm{NaHSO}_{3}\right)$ and sulfuric acid $\left(\mathrm{H}_{2} \mathrm{SO}_{4}\right)$ is added to the $\mathrm{CCl}_{4}+\mathrm{I}_{2}$ to convert iodine back to iodide, which is then back-extracted into the aqueous phase. Lastly, silver nitrate solution is added into the aqueous phase to precipitate $\mathrm{I}^{-}$as silver iodide (AgI), which is used as the ${ }^{129} \mathrm{I}$ target for ${ }^{129} \mathrm{I} /{ }^{127} \mathrm{I}$ ratio analysis on the AMS. 